\title{
Scientific and Technical Serials Holdings Optimization in an Inefficient Market: A LSU Serials Redesign Project Exercise
}

\section{Stephen J. Bensman and Stanley J. Wilder}

In this paper, we analyze the structure of the library market for s ientific and technical (ST) serials. The analysis takes the form of an exercise aimed at a theoretical reconstruction of the ST serials holdings of LSU Libraries after almost a decade of massive cancellations and a policy of adding no new subscriptions. This exercise was done in conjunction with the Louisiana State University (LSU) Serials Redesign Project (SRP), and it utilized an experimental computer program called the Serials Evaluator. Much of the paper is devoted to a discussion of the set definitions, measures, and algorithms necessary in the design of a computer program to appraise ST serials.

LSU faculty ratings were utilized as the main measure of ST value, and we investigated the nature as well as the strengths and weaknesses of faculty ratings. Chemistry played the role of the test discipline, and other ST fields were investigated to determine whether the processes affecting chemistry are also active in them. We develop the hypothesis that human knowledge functions on the same probability structure as biological nature and society. We show that this probability structure results in the highly skewed, stable distributions that characterize the social stratification system of science and technology as well as of the serials system based upon it.

Science and technology are seen in this paper as dominated by stable elites, who tend to center around traditionally prestigious institutions and publish theirwork in U.S. association journals. Consequently, U.S. association serials have higher ST value, and they play a dominant role not only in internal library use but also in interlibrary loan. Due to theirhigher ST value, U.S. association jourmals can be sold to libraries in greater numbers at cheaper prices than the journals of commercial publishers, and this causes the ST serials market to bifurcate, with ST value tending to concentrate on the U.S. association serials and costs on the commercial ones.

As a result of the highly skewed, stable nature of the ST serials system, the

Stephen J. Bensman (notsjb@unixl.sncc.lsu.edu) is Special Projects Librarian and STANLey J. WILDER (swilder@lsu.edu) is Assistant Dean for Technical and Financial Services, LSU Libraries, Louisiana State University in Baton Rouge. The authors of the this paper would like to thank Charles A. Hamaker, Assistant Dean for Collection Development, LSU Libraries, Tina E. Chrzastowski, Chemistry Librarian, University of Illinois at Urbana-Champaign, and the National Research Council for supplying the data on which much of their research was based. Manuscript received November 12, 1997; accepted for publication January 31, 1998. 
ST serials holdings of LSU Libraries were found to have suffered little damage, despite almost a decade of massive cancellations and no new subscriptions in the face of an exponentially growing serials population. To bring the serials holdings at LSU Libraries up to optimal level in 33 ST disciplines, it was estimated that only 118 new subscriptions costing $\$ 81,882$ were needed, and of these much of the perceived value derived from 53 titles that cost $\$ 39,948$. Moreover, it was still possible to cancel subscriptions to another 342 titles that cost $\$ 222,409$ without materially affecting the perceived value of LSU Libraries' serials holdings in the 33 disciplines. We see no solution to the present crisis of the ST serials system in its present form, through technology, cooperative collection development, or consortia, and we state that librarians will have to change the nature of this system by utilizing the new technology's capability of delivering information rapidly to move from subscriptions to a free market in ST information through document delivery.

In this paper, we describe an exploration of the structure of the library market for scientific and technical (ST) serials that was done in conjunction with the Louisiana State University (LSU) Serials Redesign Project (SRP). It is a continuation of Bensman (1996). The purpose of the exploration was to analyze the options open to academic libraries for resolving the serials crisis currently occurring. The exploration was done as a mock exercise in reconstructing the ST journal holdings of LSU Libraries after almost a decade of massive cancellations and a policy of adding no new subscriptions. An experimental computer program called the Serials Evaluator was designed and utilized in the reconstruction of these holdings.

This paper is divided into five main sections. The first section is historical, locating the roots of the current crisis in the nature of ST growth and price inflation and showing that these factors compelled academic libraries to begin the transition from ownership to access in their handling of ST serials. The section describes how the crisis forced LSU Libraries into massive serials cancellations and increased reliance on interlibrary loan borrowings, finally culminating in the birth of the SRP-a conscious attempt to integrate the concepts of ownership and access.

The next section is theoretical. The nature of set definitions and probability distributions in library and information science together with their statistical ramifications are analyzed. The system of probability distributions that biologists have developed to model patterns in nature is set forth, and we show how the key distribution of this system - the negative binomial distribution (NBD)-has penetrated the information and social sciences because it models the stochastic processes underlying the highly skewed distributions typically found in these disciplines. Particular attention is given here to the controversy over the applicability of the NBD to external monographic circulation.

Using chemistry as an example, we then illustrate with the aid of the National Research Council (NRC) database how the highly stratified social system of science and technology resulting from these stochastic processes is dominated by stable elite groups. We next demonstrate with chemistry data that the ST journal system is a reflection of this social structure, proving by citation analysis that the superiority of U.S. association journals derives from the elite group publishing in them. We conclude the theoretical section by describing how the ST journal system functions in much the same way as the social stratification system of science and technology, concentrating on the stability at the top of the citation distribution and the zero citation class.

Following the theoretical section are two practical sections in which we demonstrate the implementation of theory in an analysis of the LSU Libraries serials holdings in science and technology. The vehicle for this is a discussion of the set definitions and measures necessary for the design and operation of an experimental computer program called the Serials 
Evaluator. We begin by showing how the Library of Congress (LC) classification schedules were utilized to construct statistically valid subject sets. We then describe the way in which LSU faculty ratings of journals were quantified into an ST value measure called faculty score and our method for validating this score with citation-based measures as well as both external and internal library use.

Data from the University of Illinois at Urbana-Champaign (UIUC) Chemistry Library are employed to measure the effect of the operating algorithms of the Serials Evaluator in terms of cost-per-use. We then show that virtually all ST fields manifest the same phenomenon previously found in chemistry, i.e., a bifurcated pattern with ST value concentrating in the journals of the U.S. associations and costs in the titles of commercial publishers. We conclude by demonstrating how this fact was utilized to design a leveraged restructuring of LSU Libraries' ST serials holdings.

The last section is an economic one, and it delineates the contradiction between social and economic logic that leads to the paradox of an inefficient market in which libraries have to pay more money for the less important ST information. Analyzing the options available to librarians, we conclude that librarians will be compelled to continue the transition from ownership to access by moving from subscriptions to the free market of document delivery.

Such is the overall structure of the paper. However, a caveat must be issued before it is read. We present what can be called "a stick figure view" of the ST elite. This elite is much more complex than the depiction given here, where we analyze only the academic social stratification system of U.S. science and technology. Even here the picture may be oversimplified. The ST elite is not located entirely at the academic institutions repeatedly mentioned in this paper. These institutions are utilized as exemplars of the ST elite, which spreads out over other institutions in the manner typical of bibliometric distributions. Then there is the question of the role of research establishments in government and industry. Moreover, the presentation of the elite in this paper may be distorted from the international perspective. There is ample anecdotal evidence that the superiority of U.S. association journals may not be so much a function of the superiority of U.S. science and technology as of a globalization of world science and technology through the U.S. associations.

As a result of doing the research for this paper, we have formed the opinion that library and information science might be poised to rise from a social to a natural science. This is because library and information science appears to have a coherent probability structure, strong relationships, and stable phenomena, resulting in a high degree of predictability.

However, before library and information science can make this transition, two major problems have to be solved. The first is the crucial problem of set definition. The persistent failure to define proper sets obscured for years the strong correlation of citations with library use. Now this same problem appears to be complicating the uncovering of the true probability structure of human knowledge. Sets in library and information science are inherently ambiguous due to the way disciplines overlap and share the same literature. For example, during the course of the research, there were constant problems with biochemistry journals. The logic of the chemistry journal set used in this paper and its predecessor was defined by a survey of the Department of Chemistry without the participation of the Department of Biochemistry. This resulted in the biochemistry journals being more highly cited than warranted by their importance to the faculty of the Department of Chemistry alone-a characteristic particularly of the Journal of Biochemistry, which had a citation rate much higher than that of the most highly faculty-rated title, the Journal of the American Chemical Society. Consequently, sometimes the biochemistry journals fell out of the statistical models as outliers, and sometimes they remained in the models, distorting the parameters. This problem was crudely handled by 
running the models both with and without the outliers, but a far better solution would probably have been the application of fuzzy set theory.

The other major problem that has to be solved is the construction of better measures of ST value. These better measures must exhibit two primary characteristics. First, they have to reflect accurately the way the human mind perceives such value. From this perspective, major deficiencies were discovered in the impact factor citation measure published by the Institute for Scientific Information (ISI), even though ISI citations performed much better as predictors of library use than LSU faculty ratings, which not only suffered major perceptual failures but were politically difficult and expensive to obtain. Unlike total citations, ISI impact factor failed to correlate well with either faculty ratings or library use due to its controlling for size. The only way impact factor could be used statistically was to construct from it crude ordinal variables for nonparametric models.

The second necessary attribute of value measures is that they must accurately capture the stochastic processes underlying the production, utilization, and evaluation of information. On this attribute the traditional way of measuring the peer opinion of the scholarly quality of U.S. research-doctorate program faculty suffered a total failure. When tested, the peer ratings of the scholarly quality of chemistry research-doctorate program faculty resulted in a probability distribution that not only gave a false picture of the structure of these ratings but also of the stochastic processes by which this structure arose.

\section{The Crisis and the Birth oF the Serials Redesign Project}

The Crisis and the Transition from OWNERSHIP TO ACCESS

\section{Scientific Growth and Price Inflation}

The current serials crisis engulfing academic libraries is rooted in the very nature of scientific growth. Price (1986, 4-29) brilliantly described this nature a generation ago. According to Price, the normal mode of scientific growth is exponential, and in this respect it agrees with the common natural law of growth governing the number of human beings in a country, the number of fruit flies growing in a bottle, or the number of miles of railroad built in the early Industrial Revolution. However, the law of scientific growth is marked by two remarkable features. First, the exponential law of scientific growth holds true with high accuracy for long time periods extending for centuries. Second, scientific growth is surprisingly rapid, outstripping that of the size of the population and nonscientific institutions.

It is in the latter feature that the roots of the current serials crisis should be sought. In Price's view, all exponential growth curves must ultimately hit an upper limit and flatten into logistic curves, and such a flattening process is marked by violent fluctuations of the curve and prolonged periods of crisis. With telling prescience, Price (p. 28) predicted for science just such a period of crisis marked by "rapidly increasing concern over those problems of manpower, literature, and expenditure that demand solution by reorganization."

As part of his analysis of scientific growth, Price (1986, 5-8; 1975, 164-73) dealt with the problem of scientific journals. He stated that the exponential increase in the number of scientific periodicals has proceeded with an extraordinary regularity seldom seen in any human-made or natural statistic ever since the earliest surviving such journal, Philosophical Transactions of the Royal Society of London, was first published in 1665. Price estimated that starting from 1750 , when there were 10 scientific periodicals, the number of such periodicals has increased by a power of 10 every half century, which has lead to a doubling every 15 years. Taking a longer view, he calculated that this corresponded to a factor of 1,000 in a century and a half and of $1,000,000$ since the mid-seventeenth century. Price compared the growth of scientific journals to that of a colony of rabbits breeding among themselves and reproducing ever so often.

Price might have overestimated the growth in the number of scientific jour- 
nals, because he did not exclude discontinued serials (Line and Roberts 1976, 128). Nevertheless, his estimates take on a frightening reality as soon as one considers the constantly expanding coverage of the standard reference source on serials, Ulrich's International Periodicals Directory. Whereas the 20th edition of Ulrich's for 1981 (vii) together with its companion volume Irregular Serials \& Annuals (6th ed. 1980-81) listed some 96,000 titles, the 34th edition of Ulrich's for 1996 (vol. 1, vii) contained information on nearly 165,000 titles including irregulars and annuals-a gain of $71.9 \%$. As a base of comparison, it should be noted that the first edition of this publication (Ulrich 1932, ix) covered 6,000 titles.

By itself, the exponential growth in the number of scientific serials would have been a difficult enough problem for academic libraries to handle. However, the problem has been immensely compounded by an extraordinary inflation in serials prices. An idea of the extent of this inflation and the role of scientific serials in it can be gained from analyzing the data published annually in the U.S. Periodical Price Index (USPPI) (Carpenter and Alexander 1996). Excluding Russian translation journals, the average price of a U.S. periodical rose $154.8 \%$ from $\$ 65.00$ in 1986 to $\$ 165.61 \mathrm{in} 1996$. This rate of inflation exceeded both the general inflation rate as measured by the U.S. Consumer Price Index (CPI) and that in the cost of higher education as measured by Higher Education Price Index (HEPI).

Thus, from 1986 to 1995 the USPPI rose $129.9 \%$, while the CPI increased $39.0 \%$; whereas from 1986 to 1994 the USPPI gained $108.3 \%$, the HEPI went up $41.2 \%$. The most expensive subject category in the 1996 USPPI is Chemistry and Physics. Its inflation rate by far outstripped that of the overall USPPI, and the average price of chemistry and physics periodicals rose $228.4 \%$ from $\$ 264.05$ in 1986 to $\$ 867.00$ in 1996 . The rapid increase in chemistry and physics serials prices greatly affected the overall structure of U.S. periodical prices, and this was evident in an exploding Gap Factor, which was calculated by dividing the aver- age price of the highest priced subject category by the average price of the lowest priced subject category after discarding Russian translations and children's periodicals as constant outliers. In both 1987 and 1996 Chemistry and Physics was the highest cost subject category, but the Gap Factor surged from 11.49 in 1987 to 22.02 in 1996. The ultimate result of this process is evident from the fact that, with again the exclusion of Russian translations and children's periodicals, while chemistry and physics serials comprised only $4.7 \%$ the titles of the periodical sample used to construct the 1996 USPPI, these serials accounted for $23.9 \%$ of the total cost of this sample.

\section{IMPACT ON ASSOCIATION OF}

RESEAHCH LibRARIES

Under the twin pressures of exponential growth and rampant price inflation, academic libraries have begun to undergo fundamental changes. This emerges from the statistics published by the Association of Research Libraries (ARL) for 1994-95 (pp. 7-16) on its 119 members, which constitute the largest research libraries in North America. Of these 119 ARL members, 108 are university libraries. The ARL statistics reveal that inflationary pressures forced research libraries to cut down on the number of their paid serials subscriptions through cancellations even in the face of the exponentially growing number of serials. Thus, while the median serial unit price paid by ARL libraries rose $137.9 \%$ from $\$ 88.81$ in 1986 to $\$ 211.29$ in 1995, during the same period the median number of ARL paid subscriptions dropped $7.8 \%$ from 16,198 to 14,942 .

This drop, however, did not relieve the budgetary pressures on ARL libraries, and their median serials expenditure increased $106.5 \%$ from $\$ 1,517,724$ in 1986 to $\$ 3,133,885$ in 1995 . To maintain their serials collections even at reduced levels, it appears from the ARL statistics that research libraries were compelled to utilize monograph funds. This is shown by the fact that while the median monograph unit price paid by ARL libraries increased $58.0 \%$ from $\$ 28.65$ in 1986 to $\$ 45.27$ in 
1995-less than half the median serials price increase-the median number of monographs purchased by ARL libraries fell $22.6 \%$ from 33,210 in 1986 to 25,719 in 1995 (nearly triple the drop in serials subscriptions). Moreover, the median amount spent by ARL libraries for monographs increased $21.9 \%$ from $\$ 1,120,645$ in 1986 to $\$ 1,365,575$ in 1995 -approximately one-fifth the percentage increase in median ARL serials expenditures during the same period. The sharp reduction in the purchasing power of academic libraries took place in conjunction with a continued growth in their patron base, with the median number of teaching faculty served by ARL libraries rising $17.4 \%$ and the median number of students increasing 8.4\% during the period 1986-95.

All these factors combined to force a change of emphasis among academic libraries from ownership to access as the cost of access became more affordable compared to the cost of ownership-a trend assisted by improvements in electronic communications and the establishment of networks, consortia, etc. This continuous shift from ownership to access was marked by the annual average increase of $9.3 \%$ in the median number of interlibrary borrowings by ARL members during the period 1986-95, which grew $104.3 \%$ from 7,049 in 1986 to 14,403 in 1995.

\section{IMPACT ON THE LIBRARIES OF LSU}

The serials crisis hit the libraries at LSU harder than other members of the ARL. These libraries are organized into three administratively separate units: (1) LSU Libraries, encompassing the main Middleton Library, Hill Memorial Library for special collections, and a number of branch libraries; (2) the Law Library; and (3) the Veterinary Medicine Library. Louisiana has always ranked near the bottom on all economic and social indices, and from around the mid-1980s onward the state's fiscal problems were compounded by the decline of petroleum as a source of revenue. LSU was wracked by a series of budgetary emergencies that severely affected its libraries.

The impact of these emergencies is evident in the ARL Statistics for fiscal years
1985-86 and 1994-95, which reports on all three LSU library administrative units. Of crucial importance was the freezing of the materials budgets for these libraries. In fiscal year 1985-86 these materials budgets were $\$ 3,385,282$, and in fiscal year $1994-95$ they were $\$ 3,094,789$ - a decline of $8.6 \%$. Not surprisingly, there began wave after wave of serials cancellations. Internal LSU Libraries documents show that 2,207 titles were canceled from 1986 to 1994 and that the serials canceled in the period 1987-94 cost $\$ 618,883.54$. These cancellations were accompanied by a policy of no new subscriptions. For its part, in 1993 LSU Law Library canceled approximately 2,000 of its 4,000 current serials. The consequences of these actions are manifested in the ARL Statistics. Whereas in 1985-86 the libraries of LSU are listed as having 17,970 current serials, the ARL data for 1994-95 show these libraries as subscribing to only 11,853 serials - a reduction of $34.0 \%$ or 4.4 times more than median reduction in the number of such serials for all ARL libraries in the same period.

However, even these drastic reductions in the number of subscriptions did not provide budgetary relief, and current serials expenditures of the libraries on the LSU campus rose $29.8 \%$ from $\$ 1,897,212$ in $1985-86$ to $\$ 2,462,368$ in $1994-95$. The increase was 3.6 times less than the median increase in current serials expenditures for all ARL libraries, but it was not enough to save monograph purchases, given the conditions of frozen materials budgets. While median monograph expenditures of all ARL libraries rose $21.9 \%$, such expenditures at the libraries of LSU dropped $50.3 \%$ from $\$ 1,244,466$ in $1985-86$ to $\$ 617,998$ in $1994-95$. Due to inflation, the drop in the number of monographs acquired was even greater, falling $62.9 \%$ from 29,811 in $1985-86$ to 11,048 in 1994-95.

As a result of such pressures, the libraries on the LSU campus rapidly transferred from ownership of materials to access to them. Interlibrary borrowing increased $138.3 \%$ from 4,802 in 1985-86 to 11,441 in $1994-95$. However, the rapid escalation in interlibrary borrowing 
might not have been due only to reductions in serials and monographic acquisitions; it might also have been affected by a major improvement in the academic level of the libraries' patron base. While from the fall of 1986 to the fall of 1994 the number of faculty remained virtually constant, the number of full-time-equivalent graduate students rose $27.5 \%$ from 3,177 to 4,052 , even though the overall number of full-time-equivalent students was sharply decreased $22.2 \%$ from 26,180 to 20,379 by the raising of entrance requirements.

It was under such crisis conditions that LSU Libraries decided to launch its Serials Redesign Project (SRP).

\section{BIRTH OF THE SERIALS \\ Redesign Project}

Provision of Access

The Serials Redesign Project (SRP) can be described as an endeavor to integrate the two concepts of access and ownership. The first step in this integration related to access and was taken in 1993, when LSU Libraries introduced the UnCover document delivery system. UnCover was developed starting in 1988 by the Colorado Alliance of Research Libraries through its CARL Systems, Inc., which in 1993 formed The UnCover Company in joint partnership with B.H. Blackwell, the British subscription agency. The UnCover database contains approximately 17,000 journals primarily in the English language. Of these journals, an estimated $51 \%$ are in science, medicine, and technology; $40 \%$ in the social sciences; and $9 \%$ in the arts and humanities.

Among other services, UnCover provides subscribers with free online access and searching; delivery of full-text articles by fax within 24 hours for $\$ 8.50$ plus copyright fee and applicable fax surcharge; and a current awareness alerting service covering the table of contents of up to 50 titles. For libraries, UnCover has a special service called the Customized Gateway designed to assist in serials collection development. Its features include support for unmediated -i.e., without the mediation of the library-article ordering, holdings match, and patron validation.
LSU Libraries took advantage of this service to provide faculty, research staff, and graduate students with direct access to serials that had been either canceled or never on subscription. Serials available at LSU were blocked from the system. LSU Libraries covered the expense of obtaining these articles except for those costing more than $\$ 26.50$ or those from researchers making heavy demands on the system.

There are definitely problems with UnCover, including unclear fax copies of articles; difficulty in using the system; lack of foreign titles in the database; and publishers forbidding the transmission of articles from their journals. However, these problems appear to be more than offset by the cost effectiveness of the system. In a study covering a six-month period of UnCover use, Hamaker (1996), Assistant Dean for Collection Development at LSU Libraries, found that LSU Libraries spent $\$ 12,278$, including $\$ 5,740$ in copyright fees, to obtain 1,006 articles from 480 journals whose subscriptions would have cost $\$ 207,000$. It was facts such as these that caused Hamaker to call for the integration of the concept of remote access into local collection development policies.

\section{ADJUSTMENT OF OWNERSHIP}

With respect to ownership, by the early 1990 s there was a growing realization within LSU Libraries that major changes had to be made in the method of dealing with the serials crisis. The old method had consisted primarily in distributing lists of serials holdings to the faculty in order to identify titles for cancellation. This method was perceived to have two basic faults. First, it was a negative exercise in the emotional sense, causing major discontent among the faculty. Second, the distribution of prepared lists of serials had led faculty to make poorly considered decisions and to identify readily as important titles that were not necessarily high in priority. Thus, in the 1992 cancellation project, the faculty reviewed over a million dollars in serials but identified less than $\$ 60,000$ worth of titles that could be canceled (Hamaker 1994, 37). Combined with the perceived faults of the old 
method, a restructuring of serials holdings of LSU Libraries became regarded as necessary both to bring them into conformance with the current needs of the university, because no new subscriptions had been instituted since 1986, and to take advantage of the opportunities offered by the UnCover document delivery system.

\section{The Faculty Survey}

The above considerations gave birth to the concept of surveying the faculty not by having them mark prepared lists of serials for cancellation purposes alone, but by having them list on blank questionnaires in priority order the journals they considered important for research and teaching. This survey was to be conducted after faculty were instructed in the use of UnCover and after they were informed that the cancellations would provide resources for new subscriptions. The faculty was to designate on the questionnaires whether the journals had to be on the LSU campus or whether remote access to them via document delivery would be sufficient.

The concept was tested in 1993 with pilot projects with the Department of Chemistry and the Department of Geography \& Anthropology. The results were promising. Whereas in the 1989 serials review project the chemistry faculty had ranked 410 titles as important to research and teaching, in the 1993 project it did so only for 287 titles. Moreover, in 1993, 35 titles on subscription in the Chemistry Library were omitted from the high priority list, in comparison with 1989 when 20 of these same titles were ranked as "essential." The outcome of the pilot project with Geography \& Anthropology was similar. In 1989, faculty in this department ranked 1,808 titles as important to teaching and research, but in 1993 gave such status only to 535 . In 1994, the LSU Faculty Senate Library Committee approved the concept, and the SRP was born. The project was intended to be carried out in three stages: (1) science and technology, (2) social sciences, and (3) humanities.

Phase one of the SRP began in the autumn of 1994 and lasted through 1995. To initiate the survey, library subject liaisons met with the faculty of the LSU academic units involved in science and technology. At these meetings, the liaisons explained the budgetary situation of LSU Libraries and the need to restructure the serials collection. The liaisons also gave a demonstration of the capabilities of UnCover.

Following the presentation, survey forms along with a cover letter were distributed to the faculty. Faculty were asked to list in descending rank order of priority up to a maximum of 45 titles important to them for teaching and research. In listing these titles, the faculty were instructed to disregard whether LSU Libraries had them on subscription or not. Each title also had to be designated as either DD (Document Delivery) or S (Subscription). In the first case, access to it could be satisfied by a service such as UnCover; in the second, it had to be on subscription at LSU Libraries.

The faculty were instructed that the ones marked for subscription should be "titles used on a daily or weekly basis or that are published in a format that requires direct access (i.e. illustrations that do not photocopy well)." Henceforth in this paper the titles so selected by the faculty will be called the "desired universe" of serials. Upon the return of the survey forms, the titles on them were bibliographically identified, classed with $\mathrm{Li}-$ brary of Congress (LC) call numbers, and given their prices as of 1995 . Table 1 lists the LSU academic units surveyed in the first phase of the SRP together with their faculty response rates.

Overall the response rate was $392 \mathrm{fac}-$ ulty members of 728 , or $53.8 \%$. However, if the branch research stations of the College of Agriculture are excluded as isolated for the most part from the LSU campus, the response rate becomes 384 of 662 or $58.0 \%$. For a comparison, the faculty response rate in the 1993 survey of U.S. research-doctorate programs carried out by the National Research Council (NRC) was $51.0 \%$ (Goldberger, Maher, and Flattau 1995, 134). An additional indicator of the validity of the SRP survey was that a Spearman correlation coefficient of 0.56 was found between the 
percentages of faculty response and the 1993 NRC peer ratings of the scholarly quality of the faculty for the academic units where such comparisons could be made. This is evidence that the faculty tending to respond to the SRP survey were those more actively engaged in research recognized at the national level.

We will examine the validity of faculty ratings of serials and the options such ratings opened in serials collection development for LSU Libraries by the first phase of the SRP. Henceforth in this paper, this first phase will be referred to as just the SRP.

\section{The Serial Evaluator and the Structure of the Scientific and Technical (ST) Journal System}

Origin of THE SERIALS Evaluator

As the SRP was being launched, a special project was undertaken within LSU Libraries to analyze the structure of the library market for ST serials. Faculty survey data obtained in the 1993 pilot project with the Department of Chemistry was used to determine whether cancellations could be made without seriously damaging the ST serials holdings at LSU Libraries. The results of the study have been published (Bensman 1996), and the main conclusion was that scientific value as measured by faculty ratings and total citations played no role in the pricing of scientific serials. Not only is this the case, the study also revealed that the library market for ST serials appeared to be severely bifurcated, with scientific value concentrating on the titles of the U.S. associations and costs concentrating on the serials of the commercial--largely foreign-publishers.

Because of this fact, major cancellations could be implemented without seriously affecting the ST value of the LSU Libraries' serials holdings. Moreover, during the course of the study, it became obvious that a computer program could be developed to take advantage of this situation. This software, ultimately called the Serials Evaluator, was created with the assistance of a programmer in the university's Administrative Information Systems. How- ever, before one can understand how the Evaluator works, one must have an understanding of three principles that affect the structure of the ST journal system: (1) set definition, (2) skewed distributions, and (3) the social bases of ST value.

\section{Set Definition and Its Statistical CONSEQUENCES}

Need for Set Definition

Any database in library and information science contains a witches' brew of variables. This is a result of the complex actions of social groups differing in size, subject interest, level of understanding and agreement, time framework, as well as purpose and intention. Due to these reasons, before library and information science data are analyzed, they should be broken down into well-defined sets. Otherwise, complex interactions among the variables will negate statistical relationships and lead to mistaken conclusions.

The usual way of sorting library and information science data into sets is to define the sets by subject matter. This is particularly important in serials analysis, where prices, citation rates, etc., differ vastly from subject group to subject group. For example, if one decides to cancel subscriptions by price alone, one runs the risk of canceling good science journals while leaving bad social science and humanities journals outside the range of analysis. However, set definition in library and information science is complicated by the interaction of processes that are best described by two eponymic bibliometric laws.

\section{Bibliometric Laws That AfFect Set \\ DEFINITION IN LIBRARY AND INFORMATION SCIENCE}

The first of these is "Bradford's law of scattering" formulated by Bradford while he served as chief librarian from 1925 to 1938 at the National Science Library in South Kensington, England. In the formulation of his law, Bradford (1953, 148-59) started from the principle that "every scientific subject is related, more or less remotely, to every other scientific subject" and that therefore "the articles of 
TABLE 1

ACademic Units Surveyed During the First Phase of the Serials Redesign Project and Faculty Response Rates

\begin{tabular}{|c|c|c|c|}
\hline Academic Units & $\begin{array}{c}\text { No. of } \\
\text { Faculty } \\
\text { Responding }\end{array}$ & $\begin{array}{c}\text { Total } \\
\text { Faculty } \\
\text { in Unit }\end{array}$ & $\begin{array}{r}\text { Response } \\
\text { Rate (\%) }\end{array}$ \\
\hline \multicolumn{4}{|l|}{ College of Agriculture } \\
\hline Agricultural Economics \& Agribusiness & 13 & 13 & 100.0 \\
\hline Agronomy & 15 & 20 & 75.0 \\
\hline Animal Science & 8 & 16 & 50.0 \\
\hline Dairy Science & 4 & 8 & 50.0 \\
\hline Entomology & 13 & 18 & 72.2 \\
\hline Experimental Statistics & 5 & 12 & 41.7 \\
\hline Food Science & 3 & 6 & 50.0 \\
\hline Forestry, Wildlife, \& Fisheries & 29 & 33 & 87.9 \\
\hline Horticulture & 0 & 8 & 0.0 \\
\hline Human Ecology & 18 & 26 & 69.2 \\
\hline Plant Pathology \& Crop Physiology & 14 & 17 & 82.4 \\
\hline Poultry Science & 4 & 5 & 80.0 \\
\hline Vocational Education & 5 & 10 & 50.0 \\
\hline Branch Research Stations ${ }^{1}$ & 8 & 66 & 12.1 \\
\hline \multicolumn{4}{|l|}{ College of Arts \& Sciences } \\
\hline Geography \& Anthropology & 27 & 27 & 100.0 \\
\hline Mathematics & 22 & 44 & 50.0 \\
\hline \multicolumn{4}{|l|}{ College of Basic Sciences } \\
\hline Biochemistry & 8 & 10 & 80.0 \\
\hline Chemistry & 23 & 40 & 57.5 \\
\hline Computer Science & 4 & 15 & 26.7 \\
\hline Geology \& Geophysics & 10 & 20 & 50.0 \\
\hline Microbiology & 5 & 13 & 38.5 \\
\hline Physics \& Astronomy & 25 & 39 & 64.1 \\
\hline Plant Biology & 6 & 12 & 50.0 \\
\hline Zoology \& Physiology & 12 & 22 & 54.5 \\
\hline
\end{tabular}

(Continued on next page)

an interest to a specialist must occur not only in the periodicals specialising on his subject, but also, from time to time, in other periodicals." He applied this principle in an analysis of two specific subjects, applied geophysics and lubrication, and the results of this studyled him to state his famous law on the scattering of articles on a given subject among scientific journals in the following manner (p. 154): 
TABLE I (cont.)

ACademic Units Surveyed During the First Phase of the Serials Redesign Project and Faculty Response Rates

\begin{tabular}{lccc}
\hline \hline & No. of & Total & \\
Faculty & Faculty & Response \\
in Unit & Responding & $\%$ Ratemic Units & \\
\hline
\end{tabular}

College of Education

Kinesiology

\section{College of Engineering}

Biological \& Agricultural Engineering

Chemical Engineering

Civil \& Environmental Engineering

Electrical \& Computer Engineering

Industrial \& Manufacturing Systems Engineering

Mechanical Engineering

Petroleum Engineering

\section{3}

22

\section{Office of Research \& Economic Development}

\begin{abstract}
Advanced Microstructures \& Devices ${ }^{2}$
Coastal, Energy, \& Environmental

Resources $^{3}$

\section{TOTALS}

${ }^{1}$ LSU has 18 branch agricultural research stations spread out across the state of Louisiana. Five of these branch stations have respectively research specialties in the following areas: citrus, pecans, rice, sugar, and sweet potatos. 2 The Center for Advanced Microstructures \& Devices is a purely research institute centered around a high-energy particle accelerator. It specializes in the following areas: (1) fabrication of extremely small electronic and mechanical devices, using X-ray lithography; (2) spectroscopic investigations of atoms, molecules, solids, and surfaces; and inalytical applications for determining the structure and elemental composition of materials.

${ }^{3}$ The Center for Coastal, Energy, \& Enviromental Resources consists of a melange of departments, centers, and institutes. Among these are the following: Basin Research Institute, Center for Energy Studies, Coastal Ecology Institute, Coastal Fisheries Institute, Coastal Studies Institute, Department of Oceanography \& Coastal Sciences, Institute for Environmental Studies, Mining \& Mineral Resources Research Institute, Nuclear Science Center, and Wetland Biogeochemistry Institute. However, only 3 of these units-the Department of Oceanography \& Coastal Sciences, Institute for Environmental Studies, and Nuclear Science Center-have curricula attached to them and give courses for credit.

$\ldots$ if scientific journals are arranged in order of decreasing productivity of articles on a given subject, they may be divided into a nucleus of periodicals more particularly devoted to the subject and several groups or zones containing the same number of articles as the nucleus, when the numbers of periodicals in the nucleus and succeeding zones will be as $1: n: n^{2}$...

Bensman (1982, 286-87) further ana- lyzed Bradford's data to reveal (1) that in the applied geophysics set, $9.2 \%$ of journals accounted for $51.7 \%$ of the articles on that subject with the other $48.3 \%$ of these articles spread out over journals of other disciplines, and (2) that in the lubrication set, the same $9.2 \%$ of the journals accounted for $40.8 \%$ of the articles on this subject with the remaining $59.2 \%$ spread out over the journals of other disciplines.

The second bibliometric law that 
complicates set definition in library and information science is "Garfield's law of concentration." This law was formulated by Garfield, founder of the Institute of Scientific Information (ISI), which publishes the Science Citation Index (SCI), Social Sciences Citation Index (SSCI), and Arts \& Humanities Citation Index $(A \& H C I)$. Along with its citation indexes, ISI produces two annual publications, the SCI Journal Citation Reports (SCI JCR) and the SSCI Journal Citation Reports (SSCI JCR), which give various citation measures for the serials covered by their respective indexes. A series of exploratory studies was conducted at ISI with a prototype of the SCI JCR containing citation data from one quarter of 1969, and these studies revealed that a multidisciplinary mix of 152 journals accounted for $50 \%$ of the citations processed for the $S C I$ in 1969.

This finding caused Garfield to formulate his law of concentration, which he derived from Bradford's law of scattering by transposing the latter law from the level of a single discipline to that of science as a whole. Garfield devised a physical analogy to Bradford's law, one based upon a comet. In this analogy, the nucleus of the comet represents the core journals of a discipline's literature with the debris and gas molecules of the tail representing the additional journals that sometimes publish material relevant to the discipline. With this analogy in mind, Garfield described his law of concentration and its practical implications in the following manner $(1979,160)$ :

[The bibliographic law of concentration] goes an important step beyond the Bradford law by stating that the tail of the literature of any one discipline consists, in large part, of the cores of the literature of all other disciplines, and that all the disciplines combined produce a multidisciplinary literature core for all of science that consists of no more than 1,000 journals. In fact, this multidisciplinary core might be as small as 500 journals. Though larger collections certainly can be justified in many cases, the single function of providing reasonably cost-effective coverage of the literature most used by research scientists requires no more than 500 to 1,000 journals.

The findings of the study with the 1969 SCI JCR data were replicated with an analysis of 1974 SCI JCR data (Garfield 1979, 21-23, 158-61).

\section{REFLECTION OF THE BiBLIOMETRIC LAWS}

IN LibRARY USE

Both Bradford's and Garfield's laws are operative in the arrangement and use of library materials. Librarians have long known about the inadequacies of classification schemes. For example, Kelley (1937, 66-99) listed no less than 13 factors limiting the usefulness of any classification scheme for books. Among these factors, the most interesting were the following: the changing order of knowledge, which makes impossible the static perfection of any classification system; the inadequacy of any single linear representation of subject matter for expressing the variety of its relationships; the nature of systematic classification, which separates parts from the whole, and that sometimes results in forced and useless subdivisions; the tendency of students or specialists to organize subject matter around their own special and immediate interests; the content make-up of books, which interferes with the satisfactory application to books of any system of classification; and the general impracticality of reclassifying old books on any wide scale as new expansions and reconstructions of the classification system appear. Checking three simple concepts-beaver, buffalo, and cormorant-against the Library of Congress (LC) and Dewey Decimal classification schemes, Kelley found that only from $2.2 \%$ to $5.9 \%$ of the total material in a library on those subjects were found under their specific class number.

In a pioneer study, Fussler (1949) checked the citations made by chemists and physicists against the LC classification system. To obtain the citations for his study, he constructed subject cores of journals for the two disciplines by using the two key journals in each discipline-Journal of the American Chemical Society and Physical Review - and then 
selected the other journals for the cores from among those most cited by these key journals and located in the same LC class group-QD (Chemistry) and QC (Physics). For 1939, Fussler found that only $30.5 \%$ of titles cited by chemists were in QD, although $71.2 \%$ of the citations went to these journals, and that only $20.2 \%$ of the journals cited by physicists were classed in QC, although 63.1\% of the citations were to these journals.

The rest of the titles and citations were spread out over other LC classes. Thus, $12.2 \%$ of the titles cited by chemists in 1939 were in QC, but these citations comprised only $6.5 \%$ of the chemists' total citations, whereas $10.4 \%$ of the titles cited by physicists in that year were in QD, although these citations were only $3.1 \%$ of the physicists' citations.

Fussler's findings with respect to chemistry were replicated by Hurd (1992), who compared the articles published by the chemistry faculty of the University of Illinois at Chicago against the broad subject categories of the 27th edition of Ulrich's International Periodicals Directory. Hurd found that only $59.3 \%$ of these articles were published in journals classed by Ulrich's in chemistry and that only $47.4 \%$ of the references made in these articles were to journals classed in that same category.

An interesting approach to the relationship of the LC class groups to university departments was taken by McGrath, Simon, and Bullard (1979) at the University of Southwestern Louisiana (USL). They started out by utilizing the LC schedules to classify courses given at USL in 43 academic departments that granted bachelor's degrees, using a method developed by McGrath and Durand (1969). Of these 43 departments, 19 offered graduate degrees. With both books and students classified in the same manner, McGrath, Simon, and Bullard then used circulation data for academic years 1974-75 and 1975-76 to test whether and by how much student majors in the 43 subject areas were "ethnocentric"-i.e., used books in their own subject areas -and whether and by how much books in the 43 subject areas were "support- ive"-i.e., used by students majoring in other subject areas.

Concerning the former characteristic, undergraduate music majors were the most ethnocentric, borrowing books from their own subject area $71.7 \%$ of the time, while undergraduate vocational education majors were the least ethnocentric, checking out no books in their subject area. The undergraduate ethnocentricity median was represented by French majors at $17.9 \%$. Graduate students exhibited higher ethnocentricity, where again music majors were highest at $87.4 \%$, while management majors were the lowest at $2.2 \%$. The graduate ethnocentricity median was the $45.7 \%$ of computer science majors.

In terms of supportiveness of other programs at the undergraduate level, vocational education books were the highest, with $100.0 \%$ of them being checked out by nonmajors, and nursing books were the lowest, with only $24.7 \%$ being charged out to nonmajors. Applied arts books were at the undergraduate median of $81.6 \%$. Supportiveness was lower at the graduate level. Management was highest at $98.5 \%$, while computer science was lowest at $13.1 \%$. The graduate supportiveness median was $55.2 \%$, as seen in biology. These subject use patterns were fairly stable over the two-year period.

The techniques and concepts of McGrath, Simon, and Bullard (1979) were utilized by Metz (1983) in his study of external monographic circulation at Virginia Polytechnic Institute and State University (VPI). Metz obtained the main data for his study from a computer program run against the library database on May $24-25,1982$. The result was a snapshot of the books in circulation at that particular point in time. He also related academic departments to LC class groups, and he tested monographic use by the VPI faculty for ethnocentricity and supportiveness. Concerning ethnocentricity, the range ran from a high of $68.4 \%$ for the mathematics faculty to a low of $7.8 \%$ for the geography faculty. The median ethnocentricity of 14 subject groups was $38.9 \%$, between the sociology faculty at $37.1 \%$ and the foreign language faculty at 
$40.7 \%$. On a broad basis, the checkout rates were the following: for the humanities faculty- $78.8 \%$ in the humanities, $12.0 \%$ in the social sciences, and $9.1 \%$ in science and technology; for the social sciences faculty-24.4\% in the humanities, $64.1 \%$ in the social sciences, and $11.5 \%$ in science and technology; and for the science and technology faculty- $8.9 \%$ in the humanities, $6.7 \%$ in the social sciences, and $84.3 \%$ in science and technology (Metz 1983, 66-69). As for faculty supportiveness, psychology materials were most supportive with a $96 \%$ supportiveness ranking, and classics materials were the least supportive with a $2 \%$ supportiveness ranking. The median supportiveness was $51 \%$, as seen in library science. Of great import was Metz' finding $(1983,81)$ that knowledge of an undergraduate's major was significantly less predictive of the library materials the undergraduate would borrow than knowing the departmental affiliation of a faculty or graduate student.

Metz and Litchfield (1988) conducted another study of VPI library use in which they gathered monthly circulation data for each month from January through May 1987, and compared these data with the 1982 data. They found that the subject distribution of circulation patterns was remarkably stable over time for an institution not undergoing dramatic curricular change or extensive changes in the direction of library acquisitions.

\section{Statistical Consequences of Set}

DEFINITION IN LIBRARY AND INFORMATION SCIENCE

Set definition by subject in library and information science entails two major statistical consequences. The first of these consequences relates to the concept of a statistical set and the interaction between subject fields as described by Bradford's and Garfield's laws. In his classic statistics textbook, Hays (1994, 973-74) places the concept of a set at the basis of all modern mathematics and probability, giving the following definition of a set: "Any well-defined collection of objects is a set" (bold in original). He then goes on to point out that the qualification "well- defined" means that "it must be possible, at least in principle, to specify the set so that one can decide whether any given object does or does not belong" (italics in original). To make things more complicated, Hays goes on to point out that the word "object" denotes not only an object in the usual sense but also a "phenomenon," "happening," or "logical possibility." For example, the fact that there are no females in the set of U.S. presidents might not mean that there are none in the set but simply that one has not yet "happened."

Due to the interaction of Bradford's and Garfield's laws, it is extremely difficult, if not impossible, to follow Hays' rules for set definition. The principle behind these laws is that subjects intermix, and the problem of subject intermixing is compounded, when one uses a library classification system to define subject sets, by the flaws inherent in such a system as described by Kelley (1937). Due to these factors, defining sets by subject in library and information science brings one face to face with the statistical problem of "outliers."

As defined by Barnett and Lewis $(1984,4)$, an outlier in a set of data is " $a n$ observation (or subset of observations) which appears to be inconsistent with the remainder of that set of data" (italics in original). As such, the appearance of outliers depends upon the logic underlying the definition of the set. In their literature review of outliers, Beckman and Cook (1983) describe outliers as a "subjective, post-data concept," and they divide them into two types: (1) "discordant observations"- any observations that appear discordant or discrepant to the investigator, and (2) "contaminants"-any observations that are not a realization from the target population. Given the operation of Bradford's and Garfield's laws, contaminants or observations foreign to the population under investigation are a common problem in library and information science, and it is often impossible to exclude them on a logical basis. When contaminants appear at the extreme end of a distribution, they can cause major difficulties in attempts to represent the 
population by grossly distorting the parameter estimates in some model of the population. Often the only alternative open to an investigator in library and information science is to do the test with and without the contaminants to determine their effects.

The other major statistical consequence brought forward by subject set definition in library and information science relates to the differing levels of consensus in the various fields of human knowledge. This problem was most succinctly defined by Kuhn (1970) in his famous book, The Structure of Scientific Revolutions. In this book Kuhn advanced two closely interrelated concepts: scientific community and paradigm. Scientific community was described by him as follows (1970, 177):

A scientific community consists ... of the practitioners of a scientific specialty. To an extent unparalleled in most other fields, they have undergone similar educations and professional initiations; in the process they have absorbed the same technical literature and drawn many of the same lessons from it. Usually the boundaries of that standard literature mark the limits of a scientific subject matter, and each community ordinarily has a subject matter of its own.

Kuhn defined his concept of a paradigm in the following way $(1970,175)$ :

... the term 'paradigm' is used in two different senses. On the one hand, it stands for the entire constellation of beliefs, values, techniques, and so on shared by members of a given community. On the other, it denotes one sort of element in that constellation, the concrete puzzle-solutions [which], employed as models or examples, can replace explicit rules as a basis for the solution of the remaining puzzles of normal science.

Kuhn distinguished between disciplines having a paradigm and those in a preparadigmatic phase. A preparadigmatic school has no generally accepted theory and is split into several competing schools. For example, he considered it an open question whether the social sciences had yet acquired any paradigms at all and noted, "History suggests that the road to a firm research consensus is extraordinarily arduous" $(1970,15)$.

The two statistical consequences of subject set definition-contaminants and differing levels of consensus--have important implications for the analysis of the skewed distributions that dominate library and information science. Attention will now be turned to this analysis.

\section{SKeWEd Distributions}

Absence of the Normal Distribution in LibraRY AND INFORMaTion SCIENCE

It is with great trepidation that mere practitioners of statistics undertake a discussion of probability distributions. This is a world where statisticians conduct dogfights in the mathematical stratosphere, and a ground observer in the trenches has extreme difficulty in deriving conclusions about the course of the combat from the formulaic contrails in the skies overhead. Yet it is a necessary exercise. Standard parametric statistical operations such as correlation and regression assume the so-called normal distribution, which is virtually absent in library and information science. In this respect, library and information science is like many areas of human knowledge, particularly in the biological and social sciences. The relatively infrequent occurrence of the normal distribution was noted by Geary (1947, $240-41$ ), who attributed the use of it in statistics largely to its mathematical characteristics as well as its applicability predominantly in astronomy and games of chance-areas suitable for the mathematical model. However, as a result of its rarity, Geary advised that the following warning be printed in bold type in all statistics textbooks to make amends to future generations of students: "Normality is a myth; there never was, and never will be, a normal distribution."

Given this clash between statistical theory and much of reality, one must have some concept of the probability distribution underlying the data, so that it can be transformed mathematically into at least an approximation of the normal distribution in order to obtain correct results 
from standard statistical operations. As if this is not complicated enough, many sets of data in library and information science are what is known technically as "truncated on the left." This means that a group of observations-the so-called "zero class"-should have been included in them but were not counted because they either did not happen or were excluded by the system of measurement. The zero class can be the source of enormous difficulties.

Bibliometric Laws, Stochastic Processes, and the Biological Model: The Negative Binomial Distribution

Library and information science has been marked by a number of empirical, eponymous laws describing the skewed distributions inherent within it. Not only are there "Bradford's law of scattering" and "Garfield's law of concentration" described above, but there are also "Lotka's law of scientific productivity"-later modified by Price (1986, 38-44, 222-23) - on the distribution of authorship over scientists; "Zipf's law of word frequency" on the occurrence of words in a text; and "Trueswell's 80/20 rule" on library circulation. A major trend in library and information science literature has been to treat these laws as particular manifestations of more general statistical distributions and develop stochastic models to represent them (Oluić-Vuković 1997).

In a series of papers worthy of being termed an intellectual tour de force, Bookstein (1990a; 1990b; 1995; 1997) compares these "informetric" laws to similar laws in the biological and social sciences, such as those of John Christopher Willis on the distribution of species and Vilfredo Pareto on the distribution of income. According to Bookstein, all these laws are similar in that they describe the distribution of the yield in a population of discrete entities over a time-like variable. He defines "yield" as a quantity such as income or journal citations that is possible to cumulate. In his view, the underlying similarity of these laws has been obscured by their differing subject content as well as their different ways of describing the distribution of yields. Bookstein then subjected Bradford's law, the Leimkuhler variant of Bradford's law, Lotka's law, Zipf's law, and Pareto's law to rigorous mathematical analysis, and came to the conclusion that all these distributions were "variants of a single distribution." Bookstein further found this distribution to be extremely robust and resilient to ambiguity in that it was not sensitive to time period or to the way the data are counted or conceptualized. Bookstein finished by locating this single informetric distribution in the family of compound Poisson distributions.

A workable candidate for the single informetric distribution posited by Bookstein appears to be the negative binomial distribution (NBD). Although Bookstein did not endorse the distribution, he did indicate that the NBD has been successfully applied to many problems in the information sciences (Bookstein 1997, 8). An interesting feature of the NBD its malleability, i.e., its capability of being shaped into other probability distributions by the adjustment of its parameters. In the biological sciences, the NBD is usually presented in conjunction with the binomial and Poisson distributions (Elliot 1977, 14-66; Williams 1964, 15-16; Bliss 1953, 176-77). Here it serves to model concentration in contrast to the binomial (which models uniformity) and the Poisson (which models randomness). The generating function of the binomial is $(p+q)^{k}$, where $p$ and $q$ are chances of two alternative happenings in $\mathrm{k}$ number of repetitions. Its defining characteristic is that the variance is less than the mean. The NBD is the mathematical counterpart of the binomial, and therefore the probability series of the NBD is given by the expansion of $(q-p)^{-k}$

The defining characteristic of the NBD is that the variance is greater than the mean, and it has two parameters, the arithmetic mean and the exponent $k$. However, unlike in the binomial, $\mathrm{k}$ does not measure number of repetitions but degree of concentration. As $k$ approaches infinity, the NBD converges to the Poisson, whose defining characteristic is that the variance equals the mean. On the 
other side, as $\mathrm{k}$ approaches 0 , the NBD converges into the logarithmic series, which models superconcentration. The geometric distribution is a particular case of the NBD with $k=1$ (Cooper and Weekes 1983, 137; Haight 1978, 158). However, perhaps the most useful feature of the NBD is that it can be converted into the normal distribution for standard parametric statistical operations by a series of logarithmic transformations whose form depends upon the size of the exponent $k$ and whether the data contains zero counts (Elliot 1977, 30-36). In the study utilizing survey data gathered by the 1993 pilot project with the LSU Department of Chemistry, it was found that all the quantitative variables-faculty ratings, total citations, impact factor, source items, journal age, library holdings, and price - satisfied the basic NBD criterion of overdispersion, i.e., the variances significantly exceeded the means (Bensman 1996, 154-56).

The NBD satisfies one of the major conditions posited by Bookstein (1990a, 369) for his single informetric distribution given its robustness, i.e., that it be the consequence of a wide variety of underlying models. In a review of the chance mechanisms causing the NBD, Boswell and Patil (1970) described no less than 12 stochastic models that lead to the full NBD plus two more leading to its zero-truncated form. This multitude of causal processes is probably behind its apparent ubiquity. However, of all these models, two have proven to be the most influential: the compound gamma-Poisson model and the Polya-Eggenberger model derived from the Polya urn scheme.

The first can perhaps be simply presented in the following way. A Poisson distribution arises from counts of random occurrences happening over time or space at a given rate in a population, and a compound Poisson distribution arises when there is a mixed population of different elements, each having different rates of occurrence distributed according to some function. If the function is the gamma function, the model is called gamma-Poisson. In contrast, the
Polya-Eggenberger model is derived by drawing balls of two different colors from an urn. As the balls are drawn, they are not only replaced, but new balls of the same color are added. In this way, numerous drawings of balls of one color greatly increases the probability of that color being drawn.

The conceptual interest of the negative binomial distribution for library and information science lies in the conundrum posed by Feller (1943) about apparent contagion and true contagion with respect to these two models. As Feller pointed out, the Poisson distribution describes mutually independent occurrences that have no influence on each other. Due to this feature, the compound Poisson distribution arises as a result of the inhomogeneity of the population. With the Polya-Eggenberger urn model, the occurrence of an event increases the likelihood of its happening again. Describing the first model as apparent contagion and the second as true contagion, Feller pointed out that because both models lead to the same result, it is impossible to know which process is taking place if the data conforms to the NBD.

Penetration of the NBD into the

INFORMATION AND SOCIAL SCIENCES

It is in the Polya-Eggenberger form that the NBD passed into library and information science as well as other social sciences as the model of "social contagion," "cumulative advantage," or the "successbreeds-success" phenomenon (Rapoport and Horvath 1961; Coleman 1961, 288-380; Price 1976; Tague 1981). This process was given its most elegant formulation by Merton (1968) in his concept of the Matthew Effect, whereby rewards were allocated among scientists according to the biblical dictum of St. Matthew (13:12): "For unto every one that hath shall be given, and he shall have abundance: but from him that hath not shall be taken away even that which he hath."

Price (1976) described the Polya urn NBD as modeling the "double-edged" Matthew Effect, because in it success is rewarded by increased chance of further success and failure is punished by 
increased chance of further failure. $\mathrm{He}$ contrasted it to the beta function, which he found to model the "single-edged" Matthew Effect with an urn scheme where success increases the chance of success, but failure has no subsequent effect in changing the probabilities.

In a series of articles devoted to the foundations of information science, Brookes (1980a; 1980b; 1980c; 1981) utilized a discography of phonograph recordings devoted wholly to the works of one composer and issued in the period 1972-76 to demonstrate frequency-rank statistics in contrast to frequencydistribution statistics. To illustrate the former, he applied the mathematics of Bradford's law to segregate composers into groups ranked in descending order of number of recordings on which their works appeared and then measured the Matthew Effect of the degree to which composers with the most recordings "robbed" those composers with the least. Brookes then exemplified frequency-distribution statistics by fitting the NBD to the discographic data, and stated that although the NBD explained the underlying probability mechanism of the recording industry, its application entailed the loss of important empirical information.

Incongruously, Brooks based the NBD on the gamma-Poisson version, which models qualitative inhomogeneity, after demonstrating cumulative advantage. Brookes then proceeded to argue that information quantities should be measured logarithmically to place them in proper perspective. As noted above, the NBD is converted into the normal distribution for parametric statistical operations by logarithmic transformations.

Regardless, given Feller's conundrum, if one finds the negative binomial, one still does not know, for example: whether the LSU chemistry faculty ranked one journal higher than another due to its inherent quality, or due to collegial influences; whether some of the journals selected by the LSU chemistry faculty were cited more than others due to their inherent quality, or because they had been cited heavily before; or whether some of these same journals were priced higher due to inherent propensity of publishers to price differently, or due to the ability of some publishers to raise prices continually, thus reducing the ability of other publishers to do likewise.

The negative binomial distribution models all these possibilities, and all these possibilities are not only conceptually plausible but can be conceived of as interacting with each other. Thus, with the NBD, statistics and conception merge in a particularly elegant fashion.

An interesting facet of the NBD is that it appears to link the production, dissemination, and use of human knowledge with other life processes. The NBD is widely used in the biological sciences, where it has been found to be the most useful mathematical model for contagious distributions (Elliott 1977, 23, 51). From this viewpoint it is also interesting to note that Williams $(1964,295)$ described the logarithmic series, into which the NBD converges as $k$ approaches zero, as the biological equivalent of "nothing succeeds like success."

The work of Cohen $(1971,1980,1981)$ in primatology forms a bridge from the biological to the social and information sciences. He formulated his basic premise with the classic understatement that "Who sleeps with whom interests primates of several species" (Cohen 1971, 3). Using a zero-truncated gammaPoisson version, Cohen found the NBD to be the equilibrium frequency distribution of size predicted by stochastic models for the dynamics of freely forming primate social groups. According to Cohen, not only is the NBD descriptive of the way monkeys distribute themselves into troops in the tree tops for sleeping and breeding purposes as well as of how children gather into play groups in nursery school, but it also describes the way scientists distributed themselves over the laboratories at Rockefeller University, the National Cancer Institute, and the British National Institute for Medical Research. Cohen found publication rate to be linearly related to the size of the laboratories at a rate of about 1.1 publications for each additional scientist. 
Cohen's findings bring into perspective those of Rapoport and Horvath (1961), Coleman (1964, 326-32), and Ehrenberg (1959). In their study Rapoport and Horvath discovered that the distribution of popularity among junior high school students fitted the NBD. This finding was replicated with data from seven 26-member cottages of girls by Coleman, who called the NBD the "contagious Poisson." Because of Feller's conundrum, neither Rapoport and Horvath nor Coleman could definitively state whether the skewed distribution of popularity was due to the inherent qualities of those chosen as popular or to some process of social contagion whereby the students and the girls influenced each other's decisions. For his part, Ehrenberg introduced the compound NBD into marketing as the model for consumer buying, with purchases following the Poisson distribution in time and the purchasing rates of different consumers being proportional to the chisquare or gamma distributions.

However, these are relatively simple situations. When Kochen, Crickman, and Blaivas (1982) and Blaivas et al. (1982) attempted to apply the NBD to the ratings by scholars of other scholars in seven academic disciplines, they ran into severe problems of set definition and levels of consensus within the disciplines. Despite these difficulties, they found that a law of cumulative advantage provided the best theoretical approximation of peer ratings but was fully effective only in welldefined disciplines with high levels of consensus. Their work shows the need for proper set definition to control for contaminants as well the effect of Kuhnian paradigms.

Pioneering work in the application of the NBD in library and information science has been done at the University of Western Ontario. Here, at the School of Library \& Information Science, Tague and Farradane (1978) found that the NBD modeled the processes of document retrieval, and Tague (1981) utilized single- and multiple-urn models to demonstrate that the NBD arises as a result of the success-breeds-success phenomenon. However, the most interesting work on the NBD was done by Ravichandra Rao, who obtained his doctorate at Western Ontario. In a further development of Lotka's work, Ravichandra Rao (1980) demonstrated that the NBD describes the pattern of the productivity of scientists under the success-breeds-success condition in a wide variety of social circumstances.

At approximately the same time, the sociologist Allison (1980, 170-73) also found the NBD to describe scientific productivity. However, Allison was aware of Feller's conundrum through the work of Coleman (1964), pointing out that the NBD could have arisen as a result of either the qualitative inhomogeneity of the scientists or a cumulative advantage process. Huber (1998) found that the gamma-Poisson NBD model of inhomogeneity fit the distribution of patents across a population of inventors, but he rejected cumulative advantage, because there was no evidence of increasing productivity with experience-grounds one of his referees found questionable.

In an extremely interesting paper, Ravichandra Rao (1990) confronted the problem of proper set definition in fitting the NBD to informetric data. He analyzed the distribution of 4,130 articles over 744 journals in economics. When he attempted to fit the negative binomial to the data on a global basis without any set definitions, he found that the NBD did not describe the distribution. Hypothesizing that he was dealing not with one but several NBD populations, he then conducted two experiments. First, he defined the journals that provided the most articles as contaminants originating from a different NBD set and eliminated them by truncating the distribution on the right. Chi-square tests showed that the NBD fit this truncated distribution very well. Second, he classified the journals under 15 subject rubrics such as "Methods," "History of Economic Thought," "Organization of Production," etc., thereby controlling for contaminants by defining the data into more homogeneous sets. When this had been done, the NBD fit 12 of the 15 subject groups, demonstrating the importance of proper set definition. 
The Controversy over THE NBD AND

Monographic Circulation

Ravichandra Rao (1982; 1988) dedicated his doctoral dissertation at Western Ontario to testing probability distributions against data from the automated circulation systems of six large Canadian academic libraries. These data sets covered circulation periods lasting from 1 academic year for the University of Guelph up to 11 academic years for the University of Saskatchewan. Ravichandra Rao tested no less than 17 probability distributions against 203 document frequency distributions and 200 user frequency distributions for different types of user populations. In both cases he found the NBD to be the best probability distribution for both theoretical and practical reasons. The full NBD fit 92 (45.3\%) of the 203 document distributions tested at the 0.01 level, and the truncated NBD fit $102(51.0 \%)$ of the 200 user distributions tested at the 0.01 level. In line with the work of Tague and his own work on scientific productivity, Ravichandra Rao located the causal process of the NBD in the success-breedssuccess phenomenon.

Most interestingly, Ravichandra Rao found that in the majority of cases the NBD did not fit the document distributions from undergraduate populations. Undergraduates may be considered a preparadigmatic population in the Kuhnian sense. Therefore, this finding of Ravichandra Rao corroborates the conclusion of Kochen, Crickman, and Blaivas (1982) that a certain level of knowledge and consensus is necessary for the NBD to form. It also corroborates Metz (1983, 81) that knowledge of an undergraduate's major was significantly less predictive of the library materials the undergraduate would borrow than knowing the departmental affiliation of a faculty or graduate student borrower.

However, the application of the negative binomial to library circulation data is chiefly associated with the name of Burrell at the Department of Mathematics Statistical Laboratory of the University of Manchester. Burrell developed his model in a series of papers over the years (Burrell 1980, 1982; Burrell and Cane 1982;
Burrell 1985, 1986, 1987, 1988). His motivation was the appearance in Great Britain in 1976 of the Atkinson Report, in which the principle was set forth that the assessment of future university library building requirements should be based on the concept of the "self-renewing" library, i.e., a library that is limited in size in which after a certain point material should be removed in proportion to the rate of acquisition. Burrell's aim was the development of a simple stochastic model that librarians could use to decide whether to purchase multiple copies or relegate stock, and he concentrated on monographic circulation at various university libraries in the Britain and the United States.

Burrell decided upon the gammaPoisson NBD, finding that it approximated Trueswell's 80/20 rule in certain cases (Burrell and Cane 1982, 460). Although he was aware of Feller's conundrum through the work of his collaborator Cane (Burrell and Cane 1982, 450), he deliberately chose to emphasize the processes of inhomogeneity in contrast to Ravichandra Rao, who based his work on the principle of contagion. As Burrell's model emerged in the mid-1980s, it consisted of three basic tenets. First, the borrowing of individual monographs is a Poisson process with a rate that varies from item to item. Second, the different borrowing rates of the individual monographs is described by a desirability distribution, which is the gamma function. And third, the aging of the desirability occurs exponentially at the same rate for all monographs, which results in fairly stable distributions over time, with a permanent and growing zero class, because certain monographs have zero desirability to begin with (Burrell 1985, 1986, 1987). It is interesting to note that in his analysis of monographs Burrell mathematically modeled on the basis of one side of Feller's conundrum, inhomogeneity, what Bensman (1985b, 24-26) deduced at about the same time in his study of journals as a logical consequence of the operation of the double-edged Matthew Effect, itself a reflection of the other side of Feller's conundrum, contagion, i.e., 
stable distributions of library usage over time with a large zero class.

Burrell developed his model largely on global library circulation data, without subject set definitions. However, in an interesting application of the NBD to public library circulation, Brownsey and Burrell (1986) constructed a model consisting of a mixture of three NBDs to account for the three gross subject classes of British public libraries-adult fiction, adult nonfiction, and junior. The result was a much improved fit to the data. This result was confirmed by Kinnucan and Wolfram (1990), and it corroborates the conclusion of Kochen, Crickman, and Blaivas (1982) as well as of Ravichandra Rao (1990) on the need for proper set definitions when dealing with information concerning human knowledge. After this, Burrell (1988, 303) wrote, " . . when we speak of a collection we do not necessarily mean the entire holdings of the library but rather some well-defined set of items within the library, e.g., all books acquisitioned in a particular year in a particular subject class."

The development by Burrell of his model was accompanied by a number of major controversies. The first of these involved his concept of a permanent zero class. For Burrell $(1982,2-3)$ the zero class as it appeared in circulation statistics was a highly complex phenomenon because it contained not only items that had zero desirability but also those that could not appear in these statistics because they were lost, stolen, placed on reserve, etc. Therefore, in his opinion, the zero class could not be treated as an item of hard data as the other circulation frequencies. To deal with it, he initially used a technique called "with added zeros," which basically involves first estimating the parameters of the distribution truncated by the omission of the zero class and then estimating the size of the zero class by assigning an artificial probability to it (Johnson and Kotz 1969, 205-7).

When Burrell presented his model calculated in this fashion to a session of the Royal Statistical Society, it drew fire from Chatfield, a professor of marketing and collaborator of Ehrenberg, who had introduced the NBD into marketing. Chatfield criticized the concept of zero desirability, noting that it had been found impossible to distinguish between "never-buyers" and buyers with a low mean rate of purchase who just had not purchased during the time period under review (Burrell and Cane 1982, 467). He recommended calculating the parameters on the full distribution with an estimated zero class.

Chatfield's criticism was repeated in a study of public library circulation by Bagust (1983), who described Burrell's concepts of desirability and zero class as "gratuitous assumptions" (p. 25). Accusing Burrell of "data-fitting," Bagust declared that (p. 25) “ . . . if a book is exposed to the client population no one can be certain that one day it will not be borrowed, i.e., it has a non-zero-probability of circulation." He then proceeded to fit the NBD to the full distribution of a public library, declaring (p. 32) that "the absence of a 'zero class' in the Negative Binomial model ensures that every acquisition kept on open access shelving will eventually circulate (if not eaten by bookworms first!)." Burrell (1984) responded with a harsh attack on both Bagust's reasoning and mathematics. Burrell (1985) then proceeded to develop his aging concept, the logic of which inevitably leads to a certain proportion of the collection never circulating (p. 103).

A second controversy arising from the development by Burrell of his model related to the other end of the distribution. It, too, began during the discussion of the model at the Royal Statistical Society with an observation by Chatfield that the NBD tended to overestimate the number of monographs at the high-circulation end of the distribution. Chatfield found this overestimation natural, because there is an upper limit to the number of times a book can go out in a year (Burrell and Cane 1982, 467). However, the matter took a serious turn when the tendency of the NBD to overestimate the number of high-circulation monographs caused Gelman and Sichel (1987) to question the validity of applying the Poisson process to 
library monographic circulation. An understanding of the nature of the controversy can be found in the following passage (Coleman 1964, 291):

The appropriateness of the Poisson process for social phenomena lies not in its empirical fit to social data. It lies instead in the assumptions on which the distribution is based. In the first place, it deals with numbers of events. Therefore, continuousvariable measurements, which are extremely rare in social science, are unnecessary. Second, the Poisson process occurs continuously over time, rather than at discrete "trials" like the binomial distribution. Thus, for naturally occurring events, in contrast to controlled experiments, something akin to the Poisson process is often appropriate.

Based on this difference, Gelman and Sichel (1987) believed that external monographic circulation more closely resembled the binomial process of discrete trials for two reasons: the books could not be continuously borrowed, because they were out for extended periods; and there was a finite bound to the number of circulations in a given time period. Therefore, in place of the gamma-Poisson NBD, they proposed for external monographic circulation the beta-binomial distribution (BBD), which is a compound binomial distribution with the beta function as the mixing function. Testing both the BBD and the NBD against the external monographic circulation of two university libraries, Gelman and Sichel found that the BBD provided a much better fit to the high-circulation end of the distribution.

Haight $(1978,158)$ describes the BBD as the discrete time analog of the gamma-Poisson NBD in that it models qualitative inhomogeneity for short time periods so that only a success or failure can be recorded. Interestingly enough, the mixing beta function is the very function that Price (1976) demonstrated as modeling the single-edged Matthew Effect. Moreover, the NBD arises as a limit of the BBD (Boswell and Patil 1970, 8-9). In library terms, as Gelman and Sichel (1987) describe it, the binomial process turns into a Poisson process as the loan period short- ens and the time the item is available for further use lengthens. Therefore, they suggested that binomial mixture models be applied to low-frequency use such as book lending and that Poisson mixture models be applied to high-frequency use such as journal or in-library use.

The controversies surrounding Burrell's development of his NBD model with aging on the basis of external monographic circulation came to a head with a study done by Tague and Ajiferuke (1987) at the Western Ontario School of Library and Information Science. They utilized University of Saskatchewan monographic circulation data for the academic years 1967-68 through 1977-78, which were organized into Collection I and Collection II. Collection I consisted of all those monographs that had circulated in the initial year 1967-68, and it traced their circulation history through the subsequent 10 academic years. It contained a zero class. Collection II contained monographic circulation data for the 11 academic years from 1967-68 through 1977-78. It was different from the first in that it provided information not on one set of monographs over time but on the 11 differing sets of the monographs that had circulated in each of the 11 academic years. Collection II did not have a zero class.

Tague and Ajiferuke applied the NBD to both of these collections. With respect to Collection I, they used two different ways to estimate the parameters of the NBD. The first way was to estimate the parameters by the method of moments in combination with another method that incorporated Burrell's aging factor (a proportion crudely obtained by dividing the circulation mean of the initial year into the circulation mean of the following year). This way comprised a technique for testing the predictiveness of Burrell's model. The second way was to use the method of moments to estimate both parameters for each year of circulation. As for Collection II, Tague and Ajiferuke employed a technique for estimating the parameters of the zero-truncated NBD, whose own inventor (Brass 1958, 59) described as suitable for exploratory work or to provide first-stage values for iterative 
maximum likelihood solutions. Tague and Ajiferuke then employed chi-square goodness-of-fit tests on the various circulation distributions, and in all cases the NBD was rejected as the appropriate model.

At this point it is necessary to pause to describe the general features of Collection I of the Saskatchewan circulation data and the results of Tague and Ajiferuke's tests upon it in order to bring into focus precisely what is at stake in these controversies. Collection I contained circulation data on 68,590 monographs, and in the first year, 1968-69, the zero class comprised 51,992 or $75.8 \%$ of the monographs in the set. Over the years, the zero class rapidly expanded until in the last year, 1977-78, it contained 63,251 or $92.2 \%$. For the complete ten-year period, the mean of the zero class was $86.2 \%$ of the monographs in the set. Such a phenomenon is not unusual in library use. For example, in his seminal article on library use, Trueswell (1969) showed that 50\% to $60 \%$ of library holdings satisfied $99 \%$ of circulation requirements.

During the 1970s Kent et al. found that $39.9 \%$ of the monographs acquired in 1969 by the Hillman Library at the University of Pittsburgh never circulated in the period from 1969 to 1975 and that in 6 branch science and technical libraries the zero class for journals ranged from a low of $63.1 \%$ in the Physics Library to a high of $93.2 \%$ in the Engineering Library. These zero classes can consume a considerable amount of resources, and the researchers found that the subscription costs of the zero class ranged from $47.9 \%$ of the Physics Library's serials budget to $86.5 \%$ of the Computer Science Library's serials budget (Kent et al. 1978, 61-62, 104-10; Kent et al. 1979, 9-104, 209-68; Flynn 1979). However, the Pittsburgh figures for serials might be overstated due to poor methodology. Whereas at Pittsburgh the Chemistry Library's serials zero class was estimated at $85.5 \%$ of the serials collection and its cost at $64.8 \%$ of the serials budget, a more careful study with a better sample by Chrzastowski (1991) at the University of Illinois at Urbana-Champaign (UIUC) Chemistry Library found the size of the zero class to be only $9 \%$ and its cost to be merely $3 \%$.

In comparison to the zero class, the high-circulation class of the Saskatchewan data-defined here as 5 uses per year or more-was extremely small and shrank rapidly. In 1968-69, the top monograph circulated in the range of 17 to 19 times, but by 1977-78 the highest number of circulations for any monograph had fallen to 6 . The size of the high-circulation class shrank parellel to the fall of the upper limit. In 1968-69 the high-circulation class contained 2,011 ( $2.9 \%)$ of the monographs in Collection I, and by 1977-78 it had diminished to $39(0.06 \%)$. Over the ten-year period the mean of the high-circulation class was $1.0 \%$ of the monographic set.

Tague and Ajiferuke's test of Burrell's NBD model with aging found that it underpredicted the zero class 8 of the 10 years and overpredicted it 2 of the 10 years. The absolute error rate for the zero class ranged from $141(0.22 \%)$ of the predicted frequency to $5,671(10.4 \%)$ of the predicted frequency, averaging out to $3.1 \%$ for the 10 years. However, viewed from the perspective of the entire set of 68,590 monographs, the picture drastically changes. The highest absolute error of 5,671 was then $8.3 \%$, and the average absolute error rate was 1,747 monographs (2.6\%). Burrell's model was much less accurate with respect to the high-circulation class, and this is not surprising, given the much smaller size of this class. His model consistently underpredicted the high-circulation class 10 of the 10 years, and its error rate ranged from $10.1 \%$ to $228.6 \%$, tending to grow larger as the high-circulation class became smaller. The average error rate in predicting the high-circulation class was $92.7 \%$. However, once again, viewing the error rate from the perspective of the entire set of 68,590 monographs radically alters the picture. The highest underprediction was 605 (merely $0.9 \%$ ), and the average underprediction of 177.4 (only $0.3 \%$ ) of the total set.

The standard NBD without aging performed much better in Tague and Ajiferuke's tests, and this is understand- 
able, because the parameters were estimated for each year without the element of predictiveness in Burrell's model. With respect to the zero class, the standard NBD's expected frequencies were consistently below the observed frequencies in all of the years. These differences ranged from $62(0.1 \%)$ to $1,258(2.3 \%)$, resulting in an average underestimation of $0.8 \%$. Needless to say, the perspective from the entire set of 68,590 monographs leads to a much different assessment. From this viewpoint, the largest underprediction of 1,258 was only $1.8 \%$, and the average underprediction error of 458.4 equaled only $0.7 \%$ of the entire set.

The performance of the standard NBD on the high-circulation class resembled that of Burrell's model, being much more erratic here, but its error rate was much smaller. Out of the 10 years, the expected frequencies were under the observed frequencies for 6 years, over for 3 , and exactly correct for 1 . The absolute error rate of the standard NBD on the high-circulation class ranged from $0.0 \%$ to $16.9 \%$, averaging out to $8.8 \%$. This error rate drops considerably when the entire set of 68,590 monographs is taken into account. In these terms, the highest absolute error of 268 equaled $0.4 \%$ of the set, whereas the average absolute error of 65.5 amounted to only $0.1 \%$ of the set. If the authors of this paper could bet the ponies or play the stock market with such odds, they would not be writing this paper! Moreover, without going into the highly technical question of the choice of estimators, it should be pointed out that Tague and Ajiferuke were running their tests on a global database without any division into well-defined subject sets, a procedure that Brownsey and Burrell (1986) as well as Ravichandra Rao (1990) have shown would have very possibly led to far better fits to the NBD.

The studies of Gelman and Sichel as well as of Tague and Ajiferuke provoked an outburst of exasperation from Burrell. Pointing to the general predictive success of his model in the tests by Tague and Ajiferuke, he concentrated his fire on them and wrote $(1990,166)$ :
Any theoretical model can only be regarded as an approximation to reality, to the extent that any differences between the model and the reality will inevitably be revealed by, e.g., a $X^{2}$ [chi-square] goodness-of-fit test given a sufficiently large sample, and our sample sizes here are very large. On the other hand, it is not really our aim to seek out an "optimal" model but rather one that catches the essential features of the data and provides useful information for management purposes.

Burrell concluded with the declaration (p. 167):

For all its deficiencies and theoretical drawbacks, the gamma-Poisson model can give the library manager useful guidance in decision making. It may not be the correct model or even the best, but in general terms it works!

Nevertheless, he went on to incorporate loan periods in his library book circulation model (Burrell and Fenton 1994).

The last word in this controversy will be given to several library school students in Belgium, which has become a center of informetrics due to the efforts of Egghe and Rousseau. As part of "bibliometric field work" for a course taught by Rousseau at the University of Antwerp, Leemans et al. (1992), collected book circulation data from several Flemish public libraries and fitted the NBD to it. They also sent one data set to Sichel to be fitted to the BBD. Although the BBD better fit the data, the students decided in favor of the NBD, pointing out that two attitudes are possible in the study of circulation data. The first is that of a statistician trying to fit the data as precisely as possible. In that case the NBD will often not be good enough, and more complicated models with more and more parameters will be necessary. The second attitude is to admit that there is more variation than simple statistics can explain and admit some discrepancies at the high end of the distribution. In this case simple statistics such as the NBD yield excellent trend curves, which are all the practicing librarian really needs. At the conclusion of their paper the students recommended that 
the NBD be taught in introductory library management courses.

It appears from the above literature survey that the NBD is a workable general probability distribution for library and information science. Therefore, if one finds a highly and positively skewed distribution in such work, one may operate under the assumption that one is dealing with the NBD or-if not precisely the NBD - a probability distribution closely related to it and modeling the same, often interacting processes of qualitative inhomogeneity and cumulative advantage. External monographic circulation might well be a special case, and even here the NBD works reasonably well. Gelman and Sichel themselves recommend mixed Poisson distributions for journal and in-library use. Therefore, for most purposes, practitioners can limit themselves to the simple index of dispersion test (Elliott 1977, 40-44), and, if the variance is found to be significantly greater than the means-and it almost invariably is, indicating a contagious distribution-one only has to carry out the proper logarithmic transformations and proceed to other questions.

Much of the work described above was done by statisticians trying to solve the problem mathematically without either proper set definitions or without reference to the sociological factors in human knowledge. Library use is strongly affected by these sociological factors, which comprise not only the Kuhnian concept of the "paradigm" but also the social bases of ST value. The case for the NBD is strengthened by the fact that the social bases of ST value are measured by such variables as peer ratings and citation rates, which are not subject to the periodicity limits of external library monographic circulation. It is to the problem of the social bases of ST value that attention is now directed.

\section{The Social Bases of Scientific and TEChNical (ST) VALUE}

Social Stratification and Libraky Use In two papers Bensman $(1982 ; 1985 \mathrm{~b})$ analyzed the social bases of bibliometric laws and library use particularly as they related to scholarly journals. During this analysis he demonstrated that the concentration of use on a relatively small proportion of a library's serials holdings was a function of a series of sociobibliometric laws based on the principle of cumulative advantage or, more specifically, the double-edged Matthew Effect. Bensman argued that these laws were operative not only in library use but also in the social stratification of scholarship, and he developed the hypothesis that the concentration of journal use in academic libraries was partially a reflection of the process of formation of scholarly elites. Bensman found peer ratings and citations to be virtually equivalent measures of scientific value, and he theorized that a logical result of the double-edged Matthew Effect should be distributions stable over time with large zero or random classes. In his opinion, citations represented a measure of the formation of scholarly elites, the highly stratified and relatively stable social system of scholarship, as well as of those journals that research scholars regard as important.

A unique opportunity to investigate this hypothesis further occurred when, through the mediation of the university's Dean of Graduate School and subsequent Provost, LSU Libraries became a test site for the database developed by the $\mathrm{Na}$ tional Research Council (NRC) during its 1993 survey of U.S. research- doctorate programs (Goldberger, Maher, and Flattau 1995). Because a major study of the structure of the library market for scientific journals in chemistry had just been completed, with data collected in the SRP pilot project at the LSU Department of Chemistry, it was decided to utilize the NRC database to investigate the interrelationship of the scientific social stratification system with the scientific journal system in this field. The NRC database is a massive one, containing not only the 1993 peer ratings of academic departments but also data developed by the Institute for Scientific Information (ISI) on the publication and citation rates of departments in the sciences, engineering, and the social sciences. An extremely 
valuable feature of the NRC database is that it contains statistical measures developed not only for the 1993 survey of U.S. research-doctorate programs but also for the three major such surveys immediately preceding it, making it possible to investigate stratification patterns over time.

\section{History of Research-Doctorate Program}

RATINGS IN THE UNITED STATES

The traditional method of evaluating university graduate programs is peer rating. This method was pioneered in the early 20th century by the noted psychologist Cattell $(1906 ; 1910)$, who statistically constructed a list of the 1,000 most-eminent American scientists through a survey of the leading representatives of 12 scientific disciplines. He first ranked universities and then academic departments by the number of these eminent scientists at them. This shift of focus from university to academic department or discipline became a standard feature in all later evaluations of graduate education.

Cattell's work was further developed by Hughes (1925), who while president of Miami University in Ohio conducted a study of U.S. graduate schools in 1924 as an aid in hiring new faculty and in advising students where to obtain advanced degrees. Hughes had Miami University faculty members in 20 disciplines draw up a list of major doctorate institutions, select 40 to 60 professors in each field throughout the U.S. to serve as raters, and on the basis of the responses construct a statistical ranking of the institutions offering the doctorate in the 20 disciplines. The 1924 rating represented an evolution from Cattell's work in two major respects: (1) it directly evaluated universities in each discipline instead of indirectly rating them by first ranking the persons working in the various fields and then locating the most eminent at specific institutions; and (2) it extended the process of academic evaluation from primarily the sciences to also the humanities and social sciences.

Hughes (1934) led a second study of U.S. graduate schools, this time for the Committee on Graduate Education of the American Council on Education. In this study graduate programs were not ranked but merely classified as "adequate" or "distinguished." The next peer rating was conducted in 1957 by Keniston (1959, $115-50$ ) as part of a comprehensive analysis of the University of Pennsylvania Graduate School. However, because of its special purpose, the study was limited to only 25 universities deemed similar to Pennsylvania.

The evaluation of U.S. graduate programs conducted by Cartter (1966) under the auspices of American Council on Education in 1964 represented a milestone in that its methodology for obtaining and presenting peer ratings of the quality of university faculty was adopted by all future such studies. In the questionnaire, raters were asked to judge "the quality of the graduatefaculty" (underlining in original), taking into consideration only their "scholarly competence and achievements," and to assign grades from 1 to 6 to the programs. In addition, the raters were given the option of not evaluating the programs by marking their questionnaire "Insufficient information" in the appropriate box. The grades were then assigned the following numerical weights: Distinguished-5; Strong-4; Good-3; Adequate-2; Marginal-1; Not sufficient to provide acceptable doctoral training- 0 . These numerical weights were averaged to obtain a score for each program.

This methodology for obtaining and presenting peer ratings of the scholarly quality of university faculty was essentially replicated by the second American Council on Education evaluation of graduate education done in 1969 by Roose and Andersen (1970); the 1981 Assessment of U.S. research-doctorate programs done under the auspices of the American Council of Learned Societies, American Council on Education, National Research Council, and Social Science Research Council (Jones, Lindzey, and Coggeshall 1982); and the 1993 evaluation of U.S. research-doctorate programs sponsored by the National Research Council (NRC) (Goldberger, Maher, and Flattau 1995). The latter two studies represented an advance over the preceding ones in that not only were the peer ratings of the research-doctorate programs given 
in them but also other measures of these programs, including publication and citation measures derived from ISI data for disciplines in the sciences, engineering, and the social sciences.

A notable feature of these peer ratings is the remarkable stability they exhibit at the top over time both at the institutional and the program level. In their book on elite U.S. research universities and their challengers Graham and Diamond (1997) identify 16 preeminent institutions that dominated American research prior to World War II: California at Berkeley, Cal Tech, Chicago, Columbia, Cornell, Harvard, Illinois at Urbana-Champaign (UIUC), Johns Hopkins, Michigan, Minnesota, MIT, Pennsylvania, Princeton, Stanford, Wisconsin at Madison, and Yale. The work of Graham and Diamond is not based on peer ratings, and, even though their central argument is that the traditional elite was successfully challenged after 1945 by rising new research universities, their statistical measures of research performance-institutionally based and controlled for institutional category and size-manifest the continued dominance of the old elite. Graham and Diamond point to the Matthew Effect as a causal process in this.

The traditional elite institutions identified by Graham and Diamond have always scored high in peer ratings no matter how these ratings are constructed or aggregated. For example, 14 of these 16 institutions appeared among the top 15 universities in Cattell's $(1906,739)$ first such ranking based on peer ratings of individual scientists. Moreover, when Webster and Skinner (1996, 26-27) ranked 104 universities with 15 or more programs evaluated by the 1993 NRC study according to the mean peer rating of the scholarly quality of all their programs, the traditional 16 were all among the top 23 institutions. As a further test of the relative stability of the academic stratification system, the NRC database was used to rank universities by aggregating the 1993 scholarly quality peer ratings of all their evaluated programs into one total score, and 14 of the traditional elite universities came in the top 19 out of 274 institutions.
Only Cal Tech and MIT were not in the top 19 due to their narrower subject focus and the resulting smaller number of rated programs.

The stability of the overall institutional ratings is a function of the underlying stability of the program ratings. This question was analyzed in the recent NRC evaluation of U.S. research-doctorate programs (Goldberger, Maher, and Flattau 1995, 42-43). In this study the relative ranking of programs rated in both 1981 and 1993 were compared. These programs were distributed over quality quarters ranked in descending order by the mean peer rating of the scholarly quality of the faculty. It was found that those programs in the top quarter in 1981 tended to remain there in 1993 (399 of 468 ) and those in the bottom quarter in 1981 also tended to stay there in 1993 (363 of 487). The top was most stable in the social sciences $(89 \%$ of the 1981 top quarter programs remained there in 1993) and lowest in the arts and humanities $(80 \%$ of the 1981 top quarter programs stayed there in 1993). Programs rated for the first time in 1993 generally fell into the bottom half of the quality groupings.

\section{The Social Stratification System of ChemisTRY}

A historical analysis done for this paper revealed that stability over time is certainly a hallmark of the peer ratings in chemistry. Of the top 15 programs in the 1924 ratings, 11-California at Berkeley, Cal Tech, Chicago, Columbia, Cornell, Harvard, MIT, Stanford, UIUC, Wisconsin at Madison, and Yale-remained consistently in the top 15 by peer ratings of scholarly quality in 1964, 1969, 1981, and 1993. Of these 11 programs, eight-Chicago, Columbia, Cornell, Harvard, MIT, UIUC, Wisconsin at Madison, and Yale-were listed among the 9 top U.S. chemistry departments by Cattell ( 1910 , 685 ) in the first ranking of such departments. Moreover, the 4 chemistry programs in the top 15 of 1924 not remaining there still ranked in the top 35 of the 168 chemistry programs rated in 1993.

However, the stability of the chemistry 
peer ratings is not limited to the top but manifests itself throughout the entire ranking. The NRC database contains the peer ratings of the scholarly quality of program faculty from 1964 through 1993, although the ones for 1964 are not the actual ratings but an ordinal ranking system constructed from the ratings. A correlation matrix was constructed from these four ratings, and the correlations ran from a low of 0.78 between 1964 and 1981 to a high of 0.93 between 1981 and 1993. In general, the closer the rating years were together, the higher the correlation, showing a slow change over time.

A major advance of the 1993 NRC evaluation of U.S. research-doctorate programs over the preceding ones was that the ISI provided the numbers of citations to the publications of the faculty of the rated programs in the sciences, engineering, and social sciences. These citation data are contained in the database developed by the NRC as part of the 1993 evaluation. It was decided to use these ISI data for two citation measures of the chemistry programs: (1) total number of citations to faculty publications in the period 1988-92, and (2) total number of citations to faculty publications in the period 1981-84. The purpose of these measures was threefold: (1) to verify the relationship of citations to the peer ratings of faculty scholarly quality, (2) to test the stability of citation patterns to academic departments over time, and (3) to quantify the dominance of the elite departments over the others.

Correlation analysis was utilized to verify the relationship of total citations to peer ratings and to test for the stability of citation patterns over time. With respect to the first relationship, it was once again revealed that peer ratings and total citations are virtually equivalent measures of scientific value, because the correlation between the 1993 peer ratings of the scholarly quality of the chemistry program faculty and the number of citations to their publications in 1988-92 was 0.91. Concerning the second relationship, it was found that citation patterns resemble peer ratings in that they also are highly stable over time. The correlation between the to- tal citations to chemistry program faculty publications in 1981-84 and 1988-92 was 0.93. As a further sign of the stability of both peer ratings and citation patterns the correlation between the 1993 peer ratings of the scholarly quality of chemistry program faculty and total citations to their publications in 1981-84 was 0.89 .

The dominance of the elite chemistry research-doctorate programs over the others is evident in the fact that the top 42 of 168 programs (25\%) accounted for $63.6 \%$ of the total citations to the publications of the rated program faculty in 1988-92, leaving the other 126 programs (75\%) to share the remaining $36.4 \%$ of the citations. This dominance becomes more striking when one realizes there was a zero class of 35 chemistry programs that awarded doctorates in 1986-92 but were not evaluated by the 1993 NRC study (Goldberger, Maher, and Flattau 1995, 20 ). These 35 programs accounted for $17.2 \%$ of the chemistry programs awarding doctorates in chemistry in 1986-92 but only for $3.0 \%$ of the doctorates in chemistry given during this period.

As part of the correlation analysis, tests were made to estimate the probability distributions underlying the data in order to make the proper mathematical transformations. For both sets of citation data, the variance was considerably greater than the mean, which indicated the NBD with its probabilistic mechanisms of qualitative inhomogeneity and cumulative advantage. However, the variance was substantially less than the mean in all four sets of peer ratings, and this suggested the positive binomial, which in large samples such as these approximates the normal distribution (Snedecor and Cochran 1989, 117-19). The positive binomial models a uniform distribution, and in its presence one estimates the probability of success by dividing the mean of the distribution by the maximum count possible in any given sample (Grieg-Smith 1983, 57-58; Elliot 1977, 17).

Excluding the special case of the 1964 peer ratings, whose actual scores are not in the NRC database, the maximum count or score a chemistry program could have was 5 , and the means of the peer ratings 
were 2.69 for 1969 , yielding 0.54 probability of success, and 2.60 for both 1981 and 1993 , giving a 0.52 probability of success. A 50/50 chance of success does not jibe with the fact that the same 11 chemistry programs appeared in the top 15 programs by peer ratings in all the years even in the face of an ever increasing number of programs being rated-99 in 1969, 134 in 1981, and 168 in 1993. It suggests that the peer rating method designed in 1964 is seriously flawed.

The main problem with the peer rating methodology designed in 1964 is that it is only a grading of the scholarly quality of a program by persons purporting to be familiar with its faculty. Those not familiar with the program faculty are allowed to exclude themselves from the grading process by marking "Insufficient information." As such, it is not a measure of the impact or the influence of the faculty. The designers of the 1981 and 1993 surveys of research-doctorate programs were aware of this problem, and they created measures to capture the latter effect. In 1981, a familiarity index was created in which raters were asked to describe their knowledge of the program in the following terms that were given the accompanying numerical weights: Considerable familiarity-2; Some familiarity-1; Little or no familiarity- 0 . The familiarity index was constructed by taking the mean of the numerical weights of the responses. In 1993, a visibility index was constructed by calculating the percentage of the raters who did not mark their questionnaires "Insufficient information" or "Little or no familiarity."

It was decided to use the NRC database to build the familiarity index into the 1981 chemistry peer ratings and the visibility index into the 1993 chemistry ratings. For 1981, the method was simply to multiply the peer rating score of scholarly quality by the familiarity index, and for 1993 the visibility index was first divided by 10 , the reciprocal of this quotient was taken by dividing it into 1 , and then the resulting reciprocal was divided into the peer rating of scholarly quality. These multiplicative methods were deliberately chosen, because science, like many other biological and social processes, is a multi- plicative process with data frequently requiring logarithmic transformations to conform to the additive and linear requirements of standard parametric statistics. The multiplicative nature of science was succinctly summarized by Zuckerman $(1977,60)$ in her book on Nobelists in a passage illustrative of the stochastic processes involved in the NBD:

Advantage can accumulate in two ways: by addition or by multiplication. In the additive model, people who begin their careers with certain ascribed advantages continue to benefit, to receive resources and rewards on grounds that are 'functionally irrelevant'-that is, irrespective of their occupational role performance. In the second model, people judged on functionally relevant criteria as the most likely to make effective use of resources are also the most likely to receive them. Recipients are advantaged in the sense of being more able to begin with, of getting more of what is needed to perform their roles, and of consequently achieving more. The resulting gap in attainment between the advantaged and the others is far greater than under the conditions of the additive model, in which the ability to use resources for further achievements is randomly distributed among recipients and nonrecipients.

When the familiarity index was structured into the 1981 chemistry peer ratings of scholarly quality and the visibility index was built into the 1993 ratings, the peer rating distributions resembled the total citation distributions as the variances became greater than the means. This suggested the operation of the qualitative inhomogeneity and cumulative advantage of the negative binomial. However, despite the differences in the underlying probabilistic mechanisms, the correlation of the traditional 1981 peer rating measure with the one augmented by the familiarity index was 0.99 , while that of the traditional 1993 peer rating with the one augmented by the visibility index was 0.94 , showing that the peer rating methodology established in $1964 \mathrm{had}$ captured the overall ranking structure of the scientific stratification system, if not its skewness. 
SOCIAL STRATIFICATION AND THE

ST JOURNAL SYSTEM

With the basic features of the social stratification system in chemistry sketched out, it is now possible to use the findings of the 1993 SRP pilot project (Bensman 1996) to demonstrate how this social stratification system integrates with the scientific journal system in chemistry. Two of the major findings of this pilot project were the following. First, there was high correlation-0.72--between the LSU chemistry faculty ratings of journals and the total ISI citations to these journals. This high correlation was even more striking given the fact the LSU chemistry faculty was not a large sample randomly selected but a small, local group of 25 professors, and it strongly suggests that the LSU chemistry faculty were responding to an extremely powerful variable.

Second, the library market for chemistry journals is bifurcated, with costs concentrating in commercial, largely foreign journals, and scientific value (as measured by LSU faculty ratings and total ISI citations) concentrating in journals of U.S. associations. The data collected by the NRC show that there was a high correlation between peer ratings of the quality of the program faculty with total ISI citations to their publications and that the citations concentrated on the publications of faculty mainly at the traditional elite research institutions. It seems reasonable to deduce that the journals of U.S. associations are highly cited because the scientific elite (located largely at the traditional elite research institutions) is publishing in them. Therefore it appears that the LSU chemistry faculty - as any other freely forming band of primates-was responding to the imperatives of their social stratification system in rating journals.

The ST journal system is thus in many respects an external manifestation of the underlying social stratification system of science and technology. As such, the ST journal system displays many of the same characteristics as its underlying social stratification system. Strong evidence for this was discovered in the tests done to check the validity and stability of the faculty scores constructed for journals from the survey data gathered in the SRP. Such evidence will be presented below. For the time being, we will restrict ourselves to analyzing two major phenomena of the ST journal system: (1) the stability of citation patterns at the upper end of the distribution, and (2) "uncitedness," better defined as the zero citation class.

Similar to the academic social system, the scholarly journal system is remarkably stable at the top. This is particularly true of the citation patterns. In the initial exploratory studies at ISI leading to the creation of the JCRs, it was found that of the 206 SCI journals most highly cited in 1969,169 or $82.0 \%$ remained in the top 206 most highly cited in 1974 (Garfield 1976,609). This finding was corroborated in a study done at the British Library Lending Division (BLLD) (Line 1984). Here there was found an $83 \%$ overlap between the 200 SCI journals with the most citations in 1975 and 1980 as well as a $78 \%$ overlap between the 200 SSCI journals with the most citations in 1977 and 1982. The stability extended further down the ranks, and for the top 500 journals there was an $87 \%$ overlap between the $S C I$ journals and an $80 \%$ overlap between the SSCI journals in the same 5-year comparison period.

Despite the consistency in these findings, Garfield (1996) felt compelled to return to this topic in order to dispel the myth of an ever-rising tide of scientific journals. Garfield demonstrated the stability of the concentration of citations over time by pointing out that in both 1989 and 1994 a mere $500 S C I$ journals accounted for more than $70 \%$ of all citations. He then utilized data from the $S C I$ JCRs to show that 48 of the 50 science journals most highly cited in 1989 were still among the 50 most highly cited science journals in 1994. It should be pointed out that the above studies were done on a global basis without breaking down the journals into subject sets, thereby indicating not only the stability of citation patterns within disciplines but also among disciplines. This corroborates the finding of Metz and Litchfield (1988) 
with respect to the stability of the subject patterns in library use at VPI.

In comparison with the stability of the top of the journal citation distributions, the zero citation class-or "uncitedness," as it is known in the literature-is a much more complex phenomenon. Similar to the zero class in library use or any other distribution, it is extremely difficult to determine the extent of uncitedness, because in essence one is measuring a phenomenon that is not manifesting itself and consequently one does not know what truly belongs in this class or what might be there for other reasons. Price $(1986,107)$ made one of the first attempts to assess this phenomenon, estimating that $10 \%$ of all published papers would never be cited. Stern (1990,193-94) reviewed 8 studies of uncitedness published from 1974 to 1983 , and the uncitedness rate found by these studies ranged from $0.45 \%$ in chemistry to $49.9 \%$ in pharmaceutical literature-the latter being so high that Stern considered it an outlier.

Uncitedness attracted public attention when the journal Science reported the results of an ISI study indicating that $55 \%$ of the scholarly papers published between 1981 and 1985 had received no citations in the five years after they were published (Hamilton 1990). The controversy that swirled around the reporting of this "fact" reveals the importance of proper set definition in library and information science. In a follow-up study done at ISI and again reported in Science (Hamilton 1991), the rate of uncitedness was found to be $47.4 \%$ in the hard sciences including engineering and medicine, $74.7 \%$ in the social sciences, and a stunning $98 \%$ in the arts and humanities.

However, it turned out that included in these studies were such "papers" as meeting abstracts, editorials, obituaries, letters, etc., and, when these were excluded, the rates of uncitedness dropped to $22.4 \%$ in the hard sciences, $48.0 \%$ in the social sciences, and $93.1 \%$ in the arts and humanities-still nothing to stand up and cheer about. A further breakdown by nationality in the hard sciences revealed that U.S. authors had an uncitedness rate of $14.7 \%$ and that foreign authors had a rate of $28.0 \%$ (Pendlebury 1991).

The zero citation class has not been studied to any great extent, and much research remains to be done on it. However, two general features can be described. The first pertains to set definition. Not only does the rate of uncitedness vary from discipline to discipline-as is evident from the findings described above-but it also varies within disciplines and between disciplines on the basis of whether the intention of the publication is basic research or application. Narin, Pinski, and Gee (1976) found that in biomedicine basic research journals and disciplines have a significantly higher citation "influence"-i.e., receive more citations than they give-than clinical journals and disciplines. In the measures constructed by Schwarz (1997) on the basis of ISI data, the uncitedness rate in engineering is 1.6 times the average for the physical sciences, while the uncitedness in library science is 1.5 times the average of its subject group, the social sciences.

The second general feature relates to the operation of the social stratification system of scholarship. Garfield (1991) noted that a paper is more likely to be cited if it is published in a highly cited journal than in lowly cited one, and Pendlebury (1991) points out that articles published in prestigious journals such as Science are almost never left uncited. In his study of the Journal of the American Chemical Society, Ghosh (1974) found that only 1 of 222 test papers $(0.45 \%)$ published in 1965 remained uncited in the following six years. Ghosh (1975) did another study of uncitedness, this time with Nature, and his data show that of the 75 lead articles published in 1965 , only $3 \%$ or $4 \%$ remained uncited through 1970 . In their study of uncitedness in sociology, Bott and Hargens (1991) found that the average citation levels of journals were highly correlated with other measures of journal stature, and their figures showed that the percentage of uncited articles rose in almost inverse lock step with the drop in the average citation rate.

Revelations by ISI of the extent of the 
zero citation class confirmed the worst suspicions some people have about scientists and scientific publishing. These suspicions were once tersely summarized by Broad and Wade (1982, 221-22) with respect to what they describe as "the ocean of unread and unreadable articles of which the scientific literature is so largely composed":

A problem that affects research in general is the excessive proliferation of scientific papers. Too many scientific articles are published. Many are simply worthless. Moreover the worthless papers clutter up the communications system of science, preventing good research from receiving the attention it deserves and protecting bad research from scrutiny.

In the first Science article reporting ISI's findings on uncitedness, references were made to the need to pad resumes, the struggle for grants and promotions, etc., and MIT biology professor Richard Young was quoted as doubting whether the scientific enterprise would suffer if the bottom $80 \%$ of the literature would just vanish (Hamilton 1990). More ominously, in a Newsweek article subtitled "Does the Country Really Need All those Scientists?" Begley (1991) made reference to the ISI findings and questioned the need for constantly increasing the federal science budget. In the same article the declaration that "scientists ... with their belief in their God-given right to taxpayer dollars are little more than "welfare queens in white coats" was attributed to the materials scientist Rustum Roy, professor at Penn State.

However, Seglen (1992) was perhaps correct when he ascribed the skewed pattern of citations to the operation of a basic probability distribution. He theorized that the skewness implies that there will always be a large fraction of uncited articles that will be impossible to eliminate for statistical reasons. The zero class is probably a necessary part of the cost of doing science and technology; the only question may well be how best to handle this class from the economic point of view.
Having thus set forth the theoretical principles underlying the functioning of the ST serials system, it is now time to demonstrate how this theory can be put into practice to evaluate the ST serials holdings of an actual university.

\section{Theory into Practice: SetTing UP THE Serials Evaluator}

\section{DESCRIPTION OF THE SERIALS EVALUATOR}

The Serials Evaluator is a computer program designed to put the scholarly, scientific, or technical value of journals in relationship to their price, thus taking advantage of the skewed distributions in these areas and maximizing the amount of value purchased. The program does this mainly by set definitions and comparison of sets. The Evaluator first defines serials by subject; this step is considered so basic that the Evaluator was intentionally structured so as to make it impossible to proceed further until this task has been performed. Not only is set definition by subject important in the statistical sense, it is also politically necessary to protect the smaller disciplines from drowning in the global mass of numbers as a result of fewer persons generating data for the measures of value. Within these subject sets the Evaluator then ranks serials in descending order by both price and value. Value can be measured in three ways-expert ratings, total ISI citations, and library use - and each of these methods has its strengths and weaknesses, which will be discussed below. With the subject sets defined and the serials measured in terms of cost and value, the Evaluator can then be used to define subsets that contain the maximum amounts of cost and value. The user is given the capability to set the amounts of cost and value within the subsets. Having performed these functions, the Evaluator can then merge the cost and value subsets and print out a list of serials high in cost but low in value for either cancellation or nonpurchase. The Evaluator was used to process data gathered by the SRP, and the procedures and results are discussed in the following sections. 
Set Definition, ACademic Units, AND THE LC CLASSIFICATION

SCHEDULES

The 392 LSU faculty members responding to the SRP named 3,231 serial titles as useful to their research and teaching. Although these faculty members were concentrated in science and technology, their selections ranged over all 21 main subject groups of the LC class schedules from A (General Works) to Z (Bibliography; Library Science). However, of these 21 subject groups, 6 (28.6\%) contained 2,906 $(89.9 \%)$ of the titles selected by the faculty. These subject groups were as follows: Q (Science)-1,498 titles (46.4\%); T (Technology)-469(14.5\%); H (Social Sciences)-316 (9.8\%); S (Agriculture)-295 (9.1\%); G (Geography; Anthropology; Recreation)-176 (5.5\%); and R (Medicine)-152 (4.7\%).

Three basic factors account for the broad subject spread of the serials named by the LSU faculty in the SRP. First, there is the nature of the LC class schedules. The LC classification system tends to split subjects according to their different facets. For example, fishery materials are located in HD9450-9472 (Fishery Product Industry; Fish Trade Aquaculture Industry; Seafood Industry; Shellfish Industry), QL401-432 (Mollusca), QL435-448 (Crustacea), QL614-638.8 (Fishes), or SH1-400.8 (Aquaculture; Fisheries) in accordance with their economic, scientific, or technical aspects.

Second, there is the character of the academic units surveyed in the initial phase of the SRP and the relationship of these units to the LC classification system. Although organizationally located in the ST part of the university, some of these units (such as the Department of Agricultural Economics \& Agribusiness and the School of Vocational Education) are actually engaged in the social sciences, and their materials are largely classed in HD (Economic History and Conditions) in the former case and $L$ (Education) in the latter case. Moreover, there is the problem of what can be termed "segmented" units (units that encompass different disciplines). A quintessential example of such a unit is the Department of Geography \& Anthropology. Not only does this unit encompass two academic disciplines-anthropology and geography-but geography itself is segmented into the mapping sciences (cartography and remote sensing), human geography, and physical geography (climatology, geomorphology, and coastal, as well as biogeography and environment) with interests ranging from the social sciences to the sciences. Another example of a segmented unit is the School of Human Ecology, which gives courses in the following areas ranging from the social sciences to technology: apparel, textiles, and merchandising; family, child, and consumer sciences; as well as human nutrition and food. The third factor that accounted for the broad subject spread of the serials selected was the operation of Bradford's law of scattering, which states that articles on a given subject will be found in journals dedicated to other subjects.

There are two basic ways to handle faculty survey data on serials such as those generated by the SRP. One can deal with the data academic unit by academic unit. In this case, one encounters Bradford's law of scattering and finds a core of journals on which everyone is agreed together with a long tail of other journals on which there is little agreement. It is almost impossible to evaluate the importance of the journals in the long tail. The other way is to take advantage of Garfield's law of concentration. To do this, one defines the academic units or their segments as "disciplines" in the sociological, Kuhnian sense of groups of scholars or scientists studying given "subjects" defined by some classification scheme, such as the LC schedules. In this case, one should find cores of journals on which the various disciplines agree, letting the various disciplinary tails interlock with each other over these cores. Such a method not only handles the disciplinary tails but improves the evaluation of the journals in the various subject cores by measuring their importance to other disciplines. Due to these advantages, it was decided to opt for the latter system, using the LC schedules to define the subject cores.

The LC classification system suffers 
from all the faults listed above for any library classification system. In addition, it is a system that was not intended to be universalistic but was designed starting around the turn of the twentieth century specifically for the collections at the Library of Congress, and it is somewhat incoherent due to the separate development of the various subject schedules by different groups of persons working more or less independently from each other (Chan 1990, 5-22). Nevertheless, LC class numbers are among the most readily available subject codes for thousands of serials, and it was deemed important to test the applicability of the LC schedules to define sets in the statistical sense.

The first step in the process of defining subject sets was to narrow the focus of the analysis to the three major LC classes-Q (Science), S (Agriculture), and T (Technology)-corresponding to the three main academic units surveyed in the $S R P$ : College of Basic Sciences, College of Agriculture, and College of Engineering. These three LC classes accounted not only for the bulk of the titles selected by the faculty-2,262 of $3,231 \quad(70.0 \%)-$ but, more importantly, the vast bulk of the cost of these serials- $\$ 1,356,863$ of $\$ 1,569,658(86.4 \%)$. Serials in the Q class alone accounted for $\$ 1,055,486(67.2 \%)$ of the costs. The other three of the six major LC classes containing the bulk of the titles named by the faculty- $\mathrm{G}$ (Geography; Anthropology; Recreation), H (Social Sciences), and R (Medicine)—were not analyzed, because it was thought that the serials in these classes had to await the results of the forthcoming survey of LSU's social science units to be properly evaluated. With the analysis thus focused, the serials were identified that were on current subscription at LSU Libraries in LC classes Q, S, and T but not named by the faculty surveyed during the SRP. This zero class consisted of 207 titles costing $\$ 70,917$.

The method used to define subject sets for the Evaluator was the one pioneered by McGrath and Durand (1969) at the University of Southwestern Louisiana, i.e., classifying the academic units surveyed by the initial phase of the SRP with the LC schedules Q, S, and T. For this purpose, the Louisiana State University General Catalog for 1995-96 was used, and LC class groups were assigned to the various academic units based on the department purposes and course descriptions given in this catalog. As a result of this process, 33 "curriculum cores" were defined and given computer codes for manipulation by the Evaluator. Serials were assigned to these curriculum cores on the basis of their LC call numbers.

A detailed description of the process of assigning LC class groups to the various academic units will not be given, for the problems encountered here were basically the same as those faced by any cata$\log$ librarian assigning class numbers to library materials. We will limit ourselves merely to outlining the more general problems and the solutions we adopted for them.

First, there was the problem of segmented units such as the School of Forestry, Wildlife, \& Fisheries, the School of Human Ecology, the Department of Physics \& Astronomy, the Department of Geography \& Anthropology, and the Department of Electrical and Computer Engineering. The solution was to treat the segments as disciplines and not the units as a whole. For example, forestry, wildlife, and fisheries were treated separately; the three curricula of the School of Human Ecology concerning apparel, family, and human nutrition were handled individually; climatology was broken out of the Department of Geography \& Anthropology; physics and astronomy were isolated from each other; and a differentiation was made between computer engineering and electrical engineering.

Second, there was the problem of the low response rate to the SRP survey on the part of faculty in certain units such as the Departments of Horticulture and Computer Science. Horticulture's LC class groups were merged into the LC class groups that covered agronomy, and the LC class groups on computer engineering and computer science were combined-a procedure that appeared justified by the heavy overlap in the serials selections by the Departments of 
Computer Science and Electrical \& Computer Engineering.

Third, faculty members selected materials that were classed in those parts of the LC schedules for subjects not taught at LSU. This problem mainly concerned 12 titles in class group TN (Mining Engineering; Metallurgy), and, due to their high average cost, it was decided to subject these 12 titles to analysis by allocating them to other curriculum cores on the basis of the departmental origins of the majority of the faculty selecting them.

Fourth, there was the problem of those parts of schedules Q, S, and T, that related to units not surveyed during the SRP, such as those on agricultural economics, vocational education, and landscape architecture. It was decided to exclude these parts from analysis pending further survey data from the social science units. This rule, though, was violated for two such class groups-QA273-280 (Probabilities; Mathematical Statistics) and T57-57.97 (Applied Mathematics; Quantitative Methods) - which were affected by the lack of survey data from the Department of Quantitative Business Analysis in the College of Business Administration. Due to their importance, it was decided to include these groups in the analysis to obtain a preliminary evaluation of the serials contained in them.

Fifth, there was the problem of small LC class groups forming curriculum cores such as those for nuclear science, dairy science, and poultry science. There were not enough serials in these cores for statistical analysis, and the problem was handled by collapsing these small curriculum cores into larger ones with nuclear science being merged into physics and dairy science and poultry science going into animal science.

Sixth, there was the problem that the LC classification system makes a clear distinction between science and applied technology with science materials being classed in $Q$ and applied technology being classed in $S$ and $T$. As the example of fishery materials above illustrates, this distinction causes materials on the same subject to be classed in different areas, but, because this distinction conformed to the distinction between the academic units surveyed, it was decided to maintain it by allocating the Q classes to the College of Basic Science curriculum cores, the $\mathrm{S}$ materials to the College of Agriculture curriculum cores, and the $T$ materials to the College of Engineering curriculum cores. This rule was broken only with respect to entomology, where the $Q$ and $S$ groups were combined into one curriculum core.

Finally, certain sections of LC schedules $Q, S$, and $T$ pertain to many different academic units and cannot be allocated to any particular one. This happens not only at the beginning of these schedules, which are dedicated to the general aspects of their respective subjects, but also in biology. In the latter case, the main LC class group $\mathrm{QH}$ covers the general aspects of biology, before the classification system splits along the lines of botany $(\mathrm{QK})$ and zoology (QL, QM, and $\mathrm{QP}$ ), whereas the LSU organizational structure maintained a strict division along the botany and zoology lines. As a result of this, it was deemed necessary to create general curriculum cores not specifically related to any LSU academic unit not only for science, agriculture, and technology, but also for biology.

The final product of the above effort was the creation from LC schedules Q, S, and $T$ of 33 curriculum cores related to the LSU academic units (see table 2).

Throughout the process of assigning serials to the various curriculum cores, cases of apparently misclassified titles were observed, but, except for a few egregious examples, the temptation to reclassify them was resisted, because part of the purpose of the project was to verify whether the LC classification system could be utilized to define statistical sets.

Three curriculum cores-Mechanical Engineering, Chemistry, and Agronomy-were selected to test the efficacy of the above method in capturing the subject interests of the faculty in the various academic units surveyed in the SRP. These cores were deliberately selected as representative of the three major academic units covered by the survey-the Colleges of Basic Sciences, Agriculture, and Engineering. The cores were created 
TABLE 2

RELATIONSHiP OF THE 33 CURRICULUM CORES DERIVED FROM LC Class Schedules Q, S, AND T to the MaIn LSU ACAdemic UNITS IN SCIENCE AND TECHNOLOGY

\begin{tabular}{|c|c|}
\hline LSU Academic Unit & LC-Derived Curriculum Cores \\
\hline \multirow{4}{*}{$\begin{array}{l}\text { General Curriculum Cores } \\
\text { Related to } 2 \text { or More Units }\end{array}$} & General Science \\
\hline & Biology \\
\hline & General Agriculture \\
\hline & General Technology and Engineering \\
\hline \multirow[t]{10}{*}{ College of Agriculture } & Agronomy \\
\hline & Animal Science \\
\hline & Entomology \\
\hline & Experimental Statistics \\
\hline & Fisheries \\
\hline & Food Science \\
\hline & Forestry \\
\hline & Human Nutrition \& Food \\
\hline & Plant Pathology \& Crop Physiology \\
\hline & Wildlife \\
\hline \multirow[t]{2}{*}{ College of Arts \& Sciences } & Climatology \\
\hline & Mathematics \\
\hline \multirow[t]{9}{*}{ College of Basic Sciences } & Astronomy \\
\hline & Biochemistry \\
\hline & Chemistry \\
\hline & Computer Science \\
\hline & Geology \& Geophysics \\
\hline & Microbiology \\
\hline & Physics \\
\hline & Plant Biology \\
\hline & Zoology \& Physiology \\
\hline \multirow[t]{7}{*}{ College of Engineering } & Biological \& Agricultural Engineering \\
\hline & Chemical Engineering \\
\hline & Civil and Environmental Engineering \\
\hline & Electrical Engineering \\
\hline & $\begin{array}{c}\text { Industrial and Manufacturing Systems } \\
\text { Engineering }\end{array}$ \\
\hline & Mechanical Engineering \\
\hline & Petroleum Engineering \\
\hline $\begin{array}{l}\text { Office of Research and Economic } \\
\text { Development }\end{array}$ & Environmental Studies \\
\hline
\end{tabular}


by merging LC class groups in the following manner: Chemistry-QD1-412.5 and QD450-999; Agronomy-S589.7-599.9, S602.5-604.37, S631-667, S950-954, and SB1-467.8; and Mechanical Engineering-TJ1-1475, TJ1501-1570, and TL1-4050. In general, the tests can be regarded as a success, and the results not only demonstrated the truth of Bradford's law of scattering but replicated the findings of Narin, Pinski, and Gee (1976) with biomedical citations as well as of Metz (1983, 32-41, 85-87) in VPI library use that while technology is dependent upon the literature of science, the relationship is not reciprocated.

The results of the tests are shown in table 3. Of the 191 serials named by the Department of Chemistry, 99 or $51.8 \%$ were classed in the Chemistry core, with the next highest number being the 22 or $11.5 \%$ located in the Physics core. Only 5 (2.6\%) of the Department of Chemistry's selections were classed in the Chemical Engineering core. In contrast, of the 183 serials named by the Department of Agronomy, 38 or $20.8 \%$ were classed in the Agronomy core and 33 or $18.0 \%$ were in the Plant Biology core. All told, 49 or $26.8 \%$ of the Department of Agronomy's selections were in the College of Agriculture cores, but 58 or $31.7 \%$ were in the College of Basic Sciences cores. A similar phenomenon was observed in the selections of the Department of Mechanical Engineering. Of the 108 serials named by this department, 32 or $29.6 \%$ were classed in the Mechanical Engineering core with the next highest number being the 17 titles or $15.7 \%$ found in the Physics core. However, unlike the Department of Agronomy, the Department of Mechanical Engineering concentrated its selections more in the cores of its own college with 48 or $44.4 \%$ of its choices in these cores as against 23 or $21.3 \%$ in those of the College of Basic Sciences.

CONSTRUCTION AND VALIDATION OF ST Value Measures

Type and Nature of ST Value Measures The Serials Evaluator was designed to utilize three different measures of scholarly and ST value: expert ratings, ISI citations, and library use. Each of these measures has its strengths and weaknesses, and total reliance should not be put on any one of them. Of these measures, the one under investigation, expert ratings, is politically the most sensitive one on a university campus, where the expert ratings are done by the faculty. This political problem has been pithily summed up by Sapp and Watson $(1989,286)$ in the following passage:

In any college or university ... there will inevitably be a clash of interests between the academic librarians who must cancel journal subscriptions to stay within budget and the scholars who rely on these journals for their livelihood. Thus, when initiating journals cancellations, the library has a strong interest in soliciting faculty input and support early and in following this with positive steps to maintain frequent communication throughout the process.

Theoretically, faculty ratings should be a good measure of value. It is a global one, because the faculty should be able to take into account all aspects of a given serial-its value in research, instruction, and for general information - in assigning it a rating. However, in practice it has been found that the faculty tend to emphasize the research aspect of serials, and librarians have been forced to take measures to protect general periodicals and those more suitable for use by undergraduate students (Joswick and Stierman 1995; Sapp and Watson 1989, 287). The problem of underemphasizing general and undergraduate periodicals was not encountered in the SRP due to the nature of the LC class groups under analysis. Nevertheless, major flaws requiring corrective action were discovered in faculty ratings even from the research point of view, and they will be discussed below.

An interesting feature of faculty ratings is that there appears to be a high degree of consensus among faculty members in the same discipline but at different universities and colleges about the relative importance of individual serials. This was found by Goehner (1984a; $1984 \mathrm{~b})$ in a survey of 178 faculty mem- 


\section{TABLE 3}

Journal SELECTIONS OF THE DEPARTMENTS OF AGRonomy, Chemistry, AND MeChanical EngineERING By CuRriculum Cores DERIVED From the Library of CONGRESS Class Schedules Q, S, and T

\begin{tabular}{|c|c|c|c|c|c|c|}
\hline \multirow[b]{2}{*}{ Curriculum Cores } & \multicolumn{2}{|c|}{ Agronomy } & \multicolumn{2}{|c|}{ Chemistry } & \multicolumn{2}{|c|}{$\begin{array}{l}\text { Mechanical } \\
\text { Engineering }\end{array}$} \\
\hline & $\begin{array}{l}\text { No, } \\
\text { Titles }\end{array}$ & $\begin{array}{c}\% \\
\text { Titles }\end{array}$ & $\begin{array}{l}\text { No- } \\
\text { Titles }\end{array}$ & $\begin{array}{c}\% \\
\text { Titles }\end{array}$ & $\begin{array}{l}\text { No. } \\
\text { Titles }\end{array}$ & $\begin{array}{c}\% \\
\text { Titles }\end{array}$ \\
\hline \multicolumn{7}{|c|}{ General cores related to two or more curricula } \\
\hline General Science & 5 & 2.7 & 4 & 2.1 & 1 & 0.9 \\
\hline Biology & 18 & 9.8 & 8 & 4.2 & - & 一 \\
\hline General Agriculture & 17 & 9.3 & - & - & - & - \\
\hline $\begin{array}{l}\text { General Technology \& } \\
\text { Engineering }\end{array}$ & 2 & 1.1 & 1 & 0.5 & 18 & 16.7 \\
\hline \multicolumn{7}{|l|}{ College of Agriculture } \\
\hline Agronomy & 38 & 20.8 & - & - & - & - \\
\hline Animal Science & 1 & 0,6 & - & - & - & - \\
\hline Entomlogy & 1 & 0.6 & - & - & - & - \\
\hline Fisheries & 1 & 0.6 & - & - & - & - \\
\hline Human Nutrition \& Food & 1 & 0.6 & - & - & - & - \\
\hline $\begin{array}{l}\text { Plant Pathology \& Crop } \\
\text { Physiology }\end{array}$ & 5 & 2.7 & - & - & - & - \\
\hline Vocational Education & 1 & 0.6 & - & 一 & - & 一 \\
\hline Wildlife & 1 & 0.6 & - & - & - & - \\
\hline \multicolumn{7}{|l|}{ College of Arts \& Sciences } \\
\hline Climatology & 1 & 0.6 & - & - & 一 & 一 \\
\hline Mathematics & 一 & - & - & - & 6 & 5.6 \\
\hline
\end{tabular}

(Continued on next page)

bers at 26 different institutions in 6 disciplines. Such a finding should not be surprising, because faculty members function within the social structure of their disciplines, and this is one of the main reasons why the LSU chemistry faculty gave such high ratings to the journals of the American Chemical Society. In a survey conducted at California State University at Dominguez Hills, Broude $(1978,163)$ found that the public administration faculty there also highly valued association journals and suggested none of these for cancellation.

In contrast to expert ratings, ISI citations have a more restricted applicability, because in effect they primarily measure the importance of a journal for research but not for instruction or general information. Moreover, even in terms of research, ISI citations cannot be utilized as a measure of value in certain cases. For example, citations have not been found to be applicable in the humanities. Despite plans to the contrary, ISI has not developed a JCR for the Arts and Humanities Citation Index (Garfield 1980, 55), and citation-based measures were not employed in either the 1981 or the 1993 assessments of U.S. research-doctorate programs in the humanities, while they were ultimately used for all other fields. Nevertheless, for those disciplines where citations have become an established 
TABLE 3 (cont.)

Journal SElections of the Departments of Agronomy, Chemistry, AND MECHANICAL ENGINEERING

\begin{tabular}{|c|c|c|c|c|c|c|}
\hline \multirow[b]{2}{*}{ Curriculum Cores } & \multicolumn{2}{|c|}{ Agronomy } & \multicolumn{2}{|c|}{ Chemistry } & \multicolumn{2}{|c|}{$\begin{array}{l}\text { Mecanical } \\
\text { Engineering }\end{array}$} \\
\hline & $\begin{array}{l}\text { No. } \\
\text { Titles }\end{array}$ & $\begin{array}{c}\% \\
\text { Titles }\end{array}$ & $\begin{array}{l}\text { No. } \\
\text { Titles }\end{array}$ & $\begin{array}{c}\% \\
\text { Titles }\end{array}$ & $\begin{array}{l}\text { No. } \\
\text { Titles }\end{array}$ & $\begin{array}{c}\% \\
\text { Titles }\end{array}$ \\
\hline \multicolumn{7}{|l|}{ College of Basic Sciences } \\
\hline Biochemistry & 4 & 2.2 & 31 & 16.2 & - & - \\
\hline Chemistry & 8 & 4.4 & 99 & 51.8 & 3 & 2.8 \\
\hline Computer Science & - & - & 1 & 0.5 & - & - \\
\hline Geology \& Geophysics & 6 & 3.3 & - & - & 1 & 0.9 \\
\hline Microbiology & 5 & 2.7 & - & - & - & - \\
\hline Physics & - & - & 22 & 11.5 & 17 & 15.7 \\
\hline Plant Biology & 33 & 18.0 & 5 & 2.6 & - & - \\
\hline Zoology \& Physiology & 2 & 1.1 & - & - & 2 & 1.9 \\
\hline \multicolumn{7}{|l|}{ College of Engineering } \\
\hline $\begin{array}{l}\text { Biological \& Agricultural } \\
\text { Engineering }\end{array}$ & 5 & 2.7 & - & - & - & - \\
\hline Chemical Engineering & 5 & 2.7 & 5 & 2.6 & 3 & 2.8 \\
\hline Civil Engineering & 5 & 2.7 & - & - & 2 & 1.9 \\
\hline $\begin{array}{l}\text { Electrical \& Computer } \\
\text { Engineering }\end{array}$ & - & - & - & - & 8 & 7.4 \\
\hline $\begin{array}{l}\text { Industrial \& Manufacturing } \\
\text { Systems Engineering }\end{array}$ & - & - & - & - & 3 & 2.8 \\
\hline Mechanical Engineering & - & - & 1 & 0.5 & 32 & 29.6 \\
\hline \multicolumn{7}{|c|}{ Office of Research \& Economic Development } \\
\hline Environmental Studies & 10 & 5.5 & 1 & 0.5 & 2 & 1.9 \\
\hline \multicolumn{7}{|c|}{$\begin{array}{l}\text { Cores unrelated to } L S U \text { curricula or outside } \\
L C \text { classes } Q, S \text {, and } T\end{array}$} \\
\hline Mining Engineering \& Metallurgy & 1 & 0.6 & - & - & 4 & 3.7 \\
\hline Outside LC Classes Q, S, and T & $7^{\mathrm{a}}$ & 3.8 & $13^{b}$ & 6.8 & $6^{\mathrm{c}}$ & 5.6 \\
\hline TOTALS & 183 & 100.3 & 191 & 99.8 & 108 & 100.2 \\
\hline
\end{tabular}

a One in A (General Works), three in G (Geography, Maps, Anthropology, Recreation), two in H (Social Sciences), and one in $\mathrm{R}$ (Medicine).

${ }^{\mathrm{b}}$ All thirteen in R (Medicine).

c All six in R (Medicine).

practice, citations are an excellent measure of research quality as well as of the importance of serials in the overall social structure of their respective disciplines.

A complicating factor in the utiliza- tion of $J C R$ citation data is the distinction between total citations and impact factor. Total citations can be roughly defined as the total number of citations received in a given year by a journal, including its 
entire historical backfile. On the other hand, impact factor was developed at ISI in 1973 to create a normalized measure of value by controlling the citation frequency of a serial for age and size for the purpose of comparing small journals to large journals as well as to compare journals within small or large research disciplines (Garfield 1997). This is done by limiting the backfile of a serial to the two years preceding the processing year of the JCR and then dividing the references given during the processing year to this two-year backfile by the number of source items in this backfile. This creates an average citation rate per citable unit.

In the analysis of the survey data gathered by the 1993 pilot project with the LSU Department of Chemistry (Bensman 1996), a good correlation- 0.72 -was found between faculty ratings of serials and their total citation rates. However, the correlation between faculty ratings and impact factor was only 0.27 , and two basic reasons were found for this: (1) impact factor is distorted by the higher average citation rates of review articles, and (2) faculty ratings are heavily influenced by size-one of the very things for which impact factor controls. The utility of impact factor was further diminished by the finding that size is one of the major elements that determines the price of serials, and therefore direct comparisons between impact factor and price cannot be made. Further consideration also led to the conclusion that impact factor cannot be utilized in precise comparisons with library use because logically the latter also has to be influenced by size. However, as will be shown below, once one is aware of the basic characteristics of impact factor, one is able to design statistical techniques capable of properly using it as a measurement of utility and value. Such techniques are of great practical benefit, because the JCRs rank journals within subject sets by impact factor only. Such a method of presentation is necessary, because impact factor is greatly affected by the average number of references in the citing papers and the average age of the papers being referenced-variables that differ considerably from discipline to discipline (Garfield 1997).
The final measure of value used by the Serials Evaluator is library use. In theory, library use should be the best measure of all, because it is the final expression of the operation of all the causal variables. However, library use suffers from two major handicaps. First, use data are notoriously difficult to collect, especially for use that takes place within the library and cannot be captured by any of the monitoring systems. Second, there may be a great deal of random error in library use, particularly at institutions such as LSU with large undergraduate populations. This is evident in the inability of Ravichandra Rao to fit the NBD to undergraduate use data as well as in the finding by Metz $(1983,81)$ that knowledge of an undergraduate's major was significantly less predictive of the library materials the undergraduate would borrow than knowing the departmental affiliation of a faculty or graduate student borrower.

Constructing the Faculty Score Measure and Defining Serials Universes

Quantifying the SRP survey data into a measure of ST value named "faculty score" involved two basic steps. First, the faculty were instructed to rank in order of importance up to 45 serials. These rank order lists were divided into quintiles with each quintile being assigned points from 5 to 1 in accordance with the descending order of the quintiles. If a faculty member listed more than 45 serials, the serials over 45 were included but assigned a score of zero. On the other hand, if a faculty member listed only a small number of journals--say 15 or less-all the journals were given the highest scores possible. Second, if faculty members designated a serial with an S (Subscription) as being necessary on campus, the serial was given an extra 5 points. If a serial was designated DD (Document Delivery), it was given no extra points. Thus the highest number of points a faculty member could give a serial was 10 for both being in the top quintile and necessary on campus. Dividing a serial's total faculty score by 10 made it possible to determine an equivalent number of professors who assigned that serial top priority. For example, the highest ranked 
serial was Science with a faculty score of 762 , which was equivalent to having 76.2 professors give it top priority.

With the subject sets defined as curriculum cores and the measure of ST value quantified as faculty score, two databases were constructed. The first was called the "desired universe." It consisted of all those serials named by the faculty in the SRP survey and classed in one of the 33 curriculum cores derived from LC schedules Q, S, and T. Evaluator computer runs were made to determine the serials that were necessary to have LSU's serials holdings at $75 \%$ of the ST value perceived by the faculty in the desired universe of each curriculum core. The level of $75 \%$ of perceived ST value was chosen both because prior work with informetric distributions had indicated this as an optimal level and because anecdotal evidence suggested that such a level was politically palatable to the LSU faculty. Next, the desired universe of serials was checked to determine those that were on subscription at any of the libraries on the LSU campus. Furthermore, LSU Libraries' ST serials holdings also were investigated to discover those serials that were on current subscription in LC classes $Q, S$, and $T$, but not named by any faculty member in the SRP survey. Such serials were given a faculty score of zero and assigned to their proper curriculum cores on the basis of their LC call numbers.

From this information we constructed a second database called the "working universe," which consisted of all serials on current subscription at LSU libraries, including the zero class-i.e., either those not named at all by the faculty or those listed by them above the 45-title limit set in the SRP questionnaire-plus those serials not on subscription on the LSU campus but necessary to bring LSU's serials holdings up to $75 \%$ of the ST value perceived by the faculty in the desired universe of each curriculum core. The purpose of the exercise was to determine whether the working universe still contained enough resources after the massive cancellations of the 1980s and 1990s to bring LSU's serials holdings up to $75 \%$ of the ST value perceived by the faculty in the desired universe of each curriculum core.

\section{Testing Faculty Score against Citations} However, before carrying out the exercise, the faculty scores were checked for validity by two different methods. The first method was to determine the correlation of faculty score with total ISI citation rate. This method was not just a test of how well the opinion of the LSU faculty corresponded to the research and social importance of serials in science and technology as a whole. It would also authenticate whether the LC classification system could be used to construct subject sets, as poor subject set definitions could lead to the inclusion of numerous outliers and negate any significant results.

The second method was to utilize the correlation technique to see whether faculty score was valid over time. Stability over time was considered essential because if it were nonexistent, the entire SRP could be considered an exercise in futility as any steps made to improve LSU Libraries' serials holdings in the present would be counterproductive in the future. High stability of the ST value distributions over time was expected due to the operation of the probability structure underlying the social stratification system of science and technology as well of the journal system based upon it.

For validating faculty score with the correlation technique, Chemistry, Agronomy, and Mechanical Engineering were again selected as the test curriculum cores. To obtain the serials for the tests, we used the faculty score lists generated by the Evaluator computer runs on the desired universe of serials. These lists ranked serials in descending order by faculty score, and a systematic sample for each test core was taken by selecting every third serial, starting with the highest ranked title. In this way we sought to capture samples representative of every stratification level of the test curriculum cores. The serials so chosen were compared to those covered in the 1985 and 1994 SCI JCRs. If a serial was not covered in both these JCRs, it was rejected, and another one was selected from the Evaluator lists among those near it in faculty score.

The 1985 JCR was picked because a decade was considered a reasonable 
amount of time for a test of stability, both in terms of the basic fairness of the test and of the effort required for a repetition of a project similar to the SRP. The $1994 J C R$ was selected because it was the latest one available at the time of the test. Total citation counts were derived for the selected serials for each year. The final sample sizes were the following: Chemistry-38; Agronomy-17; and Mechanical Engineering-13. Given the problems of set definition, errors inevitable in the collecting of such massive amounts of data, and the different subject emphases at LSU in comparison with science and technology as a whole, we decided that positive correlations of 0.50 and above would be considered a validation of the faculty score measures.

To prepare for the correlation tests, the nature of the probability distributions underlying the data was first investigated. As was expected, the variances of all the distributions were found to be significantly greater than the respective means, indicating the presence of the negative binomial. This called for the logarithmic transformation of the variables in order to use the parametric Pearson product-moment correlation. Therefore, the natural $\log$ or $\ln$ transformation of the data was performed.

With the proper mathematical transformation of the data implemented, plots and residuals were then examined for influential observations and influential outliers. Simply defined, an influential observation is one that plays a major role in determining the size of the correlation coefficient, and it may or may not be an outlier. To obtain the residuals, the correlations were treated as regressions with one independent variable. Where faculty score was involved, it was treated as the dependent variable, because it was assumed to have the most error, and in the correlations between total citations, the 1994 citations were made the dependent variable, because the logic of cumulative advantage dictated that they should be a function of the 1985 citations. As a general rule, the observations highest in faculty score and total citations were the influential ones, although this role was sometimes played by those at the lowest end of the distributions. This appears to indicate that both the nature and stability of the distributions appear to be anchored at the extremes of the distributions-a logical consequence of the double-edged Matthew Effect.

Two basic types of influential outliers were found. The first was the result of subject factors, and there were two of these, both of which manifested higher citations than warranted by their faculty scores. One of these was the agronomy title, American Potato Journal, which suggested that the topic involved was a specialty more important to the field as a whole than to the LSU faculty. The other subject outlier, Scripta Metallurgica et Materialia, affected Mechanical Engineering and represented a problem of set definition. By its original call number, this serial was classed in TN (Mining Engineering; Metallurgy), and it was published under the sponsorship of the American Society of Metals International and American Institute of Mining, Metallurgical, and Petroleum Engineers. This serial was one of the 12 TN titles artificially allocated among the curriculum cores on the basis of the departmental origins of the faculty selecting them, and its appearance in the Mechanical Engineering core thus appears to be a function of Garfield's law of concentration. It was decided to perform the correlations both with and without these subject outliers in order to check the effect of subject problems on the correlation coefficients.

The second type of influential outlier was the result of time factors, and involved the appearance of new journals. These affected the correlations of the 1985 total citations with the 1994 total citations, and the latter were much higher than the former due to the buildup of backfiles in the intervening period. There were again two of these. The first was a chemistry journal called Langmuir, which was started by the American Chemical Society in 1985 . The second one was a mechanical engineering journal called International Journal of Robotics Research, which began publication by MIT Press in 1982. Given the connections of their pub- 
lishers, the rapid rise of these journals in the citation ranks might perhaps be attributed to their being new extrusions of the ST elite. To handle these time outliers, it was decided to exclude them from the correlation of faculty score with 1985 citations, because it seemed illogical to compare their 1995 faculty score with their 1985 total citations under such conditions. However, with respect to the correlation of the 1985 and 1994 total citations, it was decided to retain them in the first correlations and then remove them in another correlation test to see how the appearance of new, elite journals affect the distributions of ST value over time.

In general, the correlation tests to validate faculty score and the stability of ST value distributions across time proved to be satisfactory. For Chemistry, the correlation of the 1995 faculty score with 1985 total citations was 0.51 (without the time outlier Langmuir) and 0.56 with 1994 total citations (with Langmuir). Concerning stability across time, with the inclusion of Langmuir, the correlation of 1985 and 1994 total citations in Chemistry was 0.85 , which rose to a rock-solid 0.97 upon the exclusion of this time outlier. With respect to Agronomy, the correlation of 1995 faculty score with 1985 total citations was 0.61 and with 1994 total citations it was 0.58 , including the subject outlier American Potato Journal. The exclusion of this subject outlier raised the correlation of the Agronomy faculty score to 0.71 with the 1985 total citations and to 0.66 with the 1994 total citations. As for stability across time, the correlation of the 1985 and 1994 total citations in Agronomy was a steady 0.85 .

Mechanical Engineering serials manifested similar characteristics of fairly good correlations of faculty score with total citations and high stability across time. With the inclusion of the subject outlier Scripta Metallurgica et Materialia, the correlation of 1995 faculty score was 0.80 with 1985 total citations and 0.71 with 1994 total citations. These correlations rose respectively to 0.89 and 0.77 upon the exclusion of this subject outlier. A high stability across time manifested itself in Mechanical Engineering with a corre- lation of 0.96 between 1985 and 1994 total citations even with the inclusion of the time outlier International Journal of Robotics Research. The exclusion of this time outlier raised this correlation a small bit to 0.98 . What is most interesting is that the correlations of 1995 faculty scores were in the same range with 1985 total citations as with 1994 total citations, again demonstrating the stability of the ST value distributions across time. All the above correlations were significant at the 0.05 level.

\section{Testing Faculty Score against External Libraty USE}

The second method of validating faculty score was to check its relationship to UnCover use. An analysis of faculty score as an indicator of library use was considered essential, because previous researchers had given mixed reviews to expert ratings as predictors of library use. For example, Wenger and Childress (1977) found at the National Oceanic and Atmospheric Administration Library that a journal fell into the low-use category $13.7 \%$ of the time when recommended by one or more scientists, but only $5.5 \%$ of the time when recommended by two or more scientists. However, Bustion and Treadwell (1990) concluded from study done at Texas A\&M that a high ranking of a serial by the faculty did not prove to be a predictor of high use. In their opinion, there appeared to be a very weak relationship between the value of a periodical perceived by the faculty and its subsequent use.

Before undertaking the analysis of faculty score as an indicator of UnCover use, it is necessary to clarify the true nature of the interlibrary use of serials. Interlibrary loan use of serials is not the random use of rare and unimportant titles. On the contrary, it manifests the same characteristics of serials use within a library and is dominated by the same titles. This is evident in the report by Pilling (1986) on a study of 1983 serials demand at five major document supply centers in Europe and the U.S.-British Library Document Supply Centre (BLDSC), Centre de Documentation Scientifique et Technique (CDST), Chemical Abstracts Service 
(CAS), National Library of Medicine (NLM), and Online Computer Library Center (OCLC) - in which it was found that $70 \%$ of requests for all the organizations were met by between $15 \%$ and $32 \%$ of the titles. Moreover, despite the widely differing functions of the five document supply centers, there was a fair amount of overlap among their highly requested titles, and it was possible to construct a model "composite" document supply center where a mere 514 titles would meet $20 \%$ of the composite demand.

The first U.S. analysis of the interlibrary loan use of ST journals was done by Kurth (1962) with respect to the 77,698 requests made to the National Library of Medicine (NLM) by 1,780 domestic and foreign libraries during 1959. Although the NLM held around 37,000 serials titles, it required only 4,347 titles to fill $100 \%$ of the requests, meaning that the 1959 NLM zero class was around $88 \%$. Of the 4,347 titles borrowed in 1959,161 titles $(3.7 \%)$ accounted for $30,203(38.9 \%)$ of the loans. Among the top 15 titles borrowed from the NLM in 1959 were such present-day stalwarts as Lancet, British Medical Journal, Journal of the American Medical Association (JAMA), Journal of Biological Chemistry, New England Journal of Medicine, Science, and Nature.

A similar pattern of interlibrary loan use manifested itself in a study conducted during the 1960s at the Chemical Abstracts Service (CAS) of the American Chemical Society (ACS) to determine the availability in the U.S. of primary ST documents in serials and conference proceedings. As reported by Wood (1969), this study naturally focused on chemistry and chemical engineering literature, but its results were found applicable to other ST disciplines. Unlike the NLM study, the CAS study was not an analysis of requests to a single document supply center, but it was based on a sample of 70,686 interlibrary loan requests provided by 19 resource libraries distributed evenly throughout the U.S. These requests originated from persons in some 3,363 U.S. organizations. The bulk of them were made in 1967, although some related to the latter part of 1966 and first part of 1968 . The requests were for documents in 12,282 serial and conference proceeding titles, and, once again, a small percentage of the titles provided a large part of the documents. Thus, $195(1.6 \%)$ of the titles accounted for $17,777(25.1 \%)$ of the requests; $850(6.9 \%)$ of the titles accounted for $35,671(50.5 \%)$ of the requests; and $2,662(21.7 \%)$ of the titles accounted for $53,102(75.1 \%)$ of the requests.

Included in Wood's report was a ranking of the 850 titles accounting for $50.5 \%$ of the requests. It was a multidisciplinary list, and the top chemistry title ranked third in number of interlibrary loan requests. This title was the Journal of the American Chemical Society-the title with the greatest faculty score in desired universe of the Chemistry curriculum core resulting from the LSU SRP survey in 1995. Of the top 15 titles accounting for some $50 \%$ of the faculty score in this core, 10 were in existence in 1967. All 10 were among the 850 titles listed by the ACS study as highest in interlibrary loan requests. These 10 titles represented $0.08 \%$ of the titles in the ACS study but accounted for $1,241(1.8 \%)$ of the interlibrary loan requests, a favorable ratio of about 22.5 to 1 . Four of these 10 titles were U.S. association journals - 3 of the American Chemical Society and 1 of the American Institute of Physics. Of the 5 titles not in existence in 1967, 3 were subsequently established by the American Chemical Society.

The findings of these U.S. analyses of interlibrary loan use were replicated in a series of studies conducted at the British Library Lending Division (BLLD), the former name of the present British Library Document Supply Centre (BLDSC). Although the BLLD was a central interlibrary loan library, the use of its holdings appeared to be typical of that of any large general academic library, and a close relationship was found to exist between use at the BLLD and at Newcastle University Library. The first BLLD study was done in 1975 and was based on a sample of 61,333 serials requests constructed by selecting every sixth request during the first three months of that year (BLLD/SINFDOK 
1975; Bower 1976; Line and Wood 1975). Of these requests, 59,617 were for 14,718 serials titles held by the BLLD, and a further 1,716 requests were for titles not held there. As usual, demand concentrated on a very few titles, leaving a large zero class. In the case of requests for titles held by the BLLD, $50 \%$ were in just over 1,300 titles in spite of the fact that BLLD was then currently receiving 45,000 titles and held more than 100,000 titles altogether. Only $34 \%$ of the requested titles accounted for $80 \%$ of the demand. This $34 \%$ comprised a mere $10 \%$ of titles then currently received by the BLLD and represented only $5 \%$ of all titles held.

An extremely interesting phenomenon was that the degree of use concentration differed in science and technology, the social sciences, and the humanities, perhaps reflecting the differing structures of these areas in terms of Kuhnian paradigms. Whereas science and technology requests were concentrated on a relatively few titles $(50 \%$ of the requests were in only $8 \%$ of the requested titles in this field), social science requests were rather more widely spread $50 \%$ of them being in $12 \%$ of the requested social science titles), and the humanities requests were even more dispersed over the collection ( $50 \%$ being in $21 \%$ of the requested humanities titles).

However, what puzzled the researchers the most was the nature of the highly requested titles. Nearly all were in science, and "pure" science at that; many had large circulations; all appeared to be high-status journals; and most were widely held by British libraries. Line and Wood (1975) constructed from the survey data a list of 81 titles that by extrapolation would have had 300 or more requests annually over the preceding three years, and a glance at the top 15 titles on this list reveals what looks to be a roundup of the usual suspects. These 15 included not only the four medical titles most highly requested from the NLM in 1959British Medical Journal, JAMA, Lancet, and New England Journal of Medicine-but also such titles as Analytical Biochemistry, Analytical Chemistry,
Biochimica et Biophysica Acta, Joumal of Biological Chemistry, Journal of Chromatography, Journal of the American Chemical Society, Nature, Proceedings of the National Academy of Science, Science, and Scientific American that were highly ranked by the LSU faculty in the 1995 SRP survey. The most requested social science title at the BLLD in the 1975 sample was the American Sociological Review, and the most requested humanities title was Past and Present (Bower 1976, 33-34).

A second study of interlibrary loan use was conducted by the BLLD in 1980. As described by Clarke (1981), in contrast to the 1975 survey, the second study was not based on a sample of every sixth request gathered over a three-month period but on all valid serial requests collected over 10 consecutive working days in May 1980 , which totaled 66,430 requests for 18,975 titles. Results from the 1980 survey revealed the same characteristics of interlibrary loan use as had the 1975 study, and two lists were produced that ranked titles by order of the requests for them in their respective years. A comparison of the two lists revealed an apparent instability in library use. Thus, there was only a $60 \%$ overlap among the top 100 titles requested in 1975 and 1980, and this overlap gradually decreased as one went down the ranks until only 2,591 titles $(52 \%)$ were common to the top 5,000 titles on both lists. Clarke (1981, 111) summed up the conclusion derived at the BLLD from this overlap analysis thusly: "This inconsistency of rank lists sheds doubt on the continuing value of core lists of serials, which might decrease substantially in validity over a relatively short period."

The melancholy conclusion reached at the BLLD as to the validity of core lists of serials over time drew a hilarious response from Urquhart (1982), who in the role of Sherlock Holmes, set out to solve the statistical crimes committed at this institution. In going over the BLLD overlap analysis, Urquhart found a number of major faults in method and reasoning: (1) changes in title status such as births, deaths, marriages, and divorces were not taken into account; (2) the 1975 and 1980 
sample sizes were different; (3) the sampling periods were different, raising the possibility that variation in use levels might have been greater because of peaking of demand over short periods; and (4) natural variations can be expected from one survey to the next without any real change in behavior, and these variations can be surprisingly pronounced for individual titles. Even without taking into account possible peaking effects in short time periods, Urquhart calculated that the expected overlap of the upper 5,000 titles in 1975 and 1980 use could only have been $64 \%$, and he pointed out that this compared favorably to the $52 \%$ figure reached by BLLD. Urquhart therefore rejected the conclusions reached at the BLLD regarding the instability of library use.

In 1983, a third study of the interlibrary loan requests was conducted at the BLLD. As reported by Merry and Palmer (1984), the methods used in 1983 were the same as those in the 1980 study, and the sample consisted of all serials requests for ten working days in May. This time the number of requests amounted to 66,720 , of which 61,946 were for 18,465 titles held by the BLLD. The results were basically the same, and a relatively small number of serials-2,158-accounted for $50 \%$ of the demand. In one interesting measure, it was determined that the concentration of use had increased over the years and that the percentage of titles (current or ceased) satisfying $100 \%$ of demand shrank from $15 \%$ of all titles held by the BLLD in 1975 to $14 \%$ in 1980 to $11 \%$ in 1983.

Another overlap analysis-this time between lists ranked by interlibrary loan requests in 1980 and 1983 - revealed that about $60 \%$ of the titles were common to both lists, regardless of whether the top 100 or the top 5,000 were compared. Despite Urquhart's riposte, the apparent instability of interlibrary loan use indicated by these overlap figures continued to concern the BLLD staff, and a similar overlap analysis was conducted with respect to rank lists of journals constructed from citation data from different years of the $S C I$ and SSCIJCRs. The JCR overlap percentages were much higher than the BLLD overlap percentages, and the BLLD director, Line (1984), speculated on the reasons for this, calling for more research into this matter.

Here two points should be made. First, the studies at the BLLD were done on a global basis, without any breakdown into subject sets, and a much higher pattern of stability might have been found within the subjects sets once possible surges among different subject groups had been controlled for. Second, even if library use of ST literature were more unstable than that of its citation patterns, library use-as the subject interests of the patron population shift-might only move within the overall stable framework of ST literature as this framework is defined by the social stratification system of science and technology being measured by citations.

This review of earlier studies of interlibrary loan use-with its similarity to internal library use, its concentration on well-known titles, its large zero classes, its apparent stability over time-indicates that there may be a definite bottom to ST serial literature and that this bottom may not be very deep. This bottom may have been found at both the University of Illinois at Urbana-Champaign (UIUC) Chemistry Library and Montana State University (MSU) Libraries. Concerning UIUC, Chrzastowski (1991) and Chrzastowski and Olesko (1997) describe three usage studies undertaken at the Chemistry Library there in 1988, 1993, and 1996. During this period, the UIUC Chemistry Library canceled over 180 chemistry journals or approximately $25 \%$ of its serials holdings. Despite the massive cancellations, the serials holdings of the UIUC Chemistry Library remained relatively unscathed. This was established by two studies - one of document deliveries and the other of interlibrary loan use.

Chrzastowski and Anthes (1995) conducted the first study. For six and one-half months from October 15, 1993, to April 30, 1994, the UIUC Chemistry Library experimented with supplementing its serials collection with document deliveries from the Chemical Abstracts 
Service (CAS). Of the 234 requests for documents, 176 were for articles from 136 journals. The majority of the requested titles-111 (81.6\%)-had never been owned by UIUC, and these titles accounted for $145(82.4 \%)$ of the requested articles. Only 31 (17.6\%) of the requests were for articles from the 25 titles (18.4\%) that had been previously canceled by the university.

The fundamental soundness of the serials holdings of the UIUC Chemistry Library was corroborated by Chrzastowski and Olesko (1997) with a title-by-title analysis of 1996 interlibrary loan requests made from this library. Of the 94 journals requested, $72(76.6 \%)$ were titles never owned by the UIUC Chemistry Library, and from 64 of these serials only a single article each was requested. Seven titles were requested 2 times, and 1 was requested 3 times. Of the remaining 22 journals held by the UIUC Chemistry Library and requested on interlibrary loan, only $8(8.5 \%$ of the total sample of 94$)$ were titles previously canceled; 13 $(13.8 \%)$ were for issues out at the bindery or otherwise unavailable; and $1(1.1 \%)$ title was a recent subscription for which the library lacked the early volumes.

The lack of damage to the UIUC Chemistry Library serials holdings from the cancellations appears to be largely the result of the stability of the skewed distributions of journal use over time. For example, the top 10 journals accounted for $32.9 \%$ of the use in 1988 and $38.9 \%$ of the use in 1996 , a rise of $18.2 \%$. Eight of the top 10 were the same in both 1988 and 1996. The 2 titles dropping out of the top 10 fell only two places to numbers 11 and 12 , and these 2 were replaced by titles previously in the top 15 (Chrzastowski and Olesko 1997).

For their part, MSU Libraries undertook a project in the cooperative collection of science serials with four other universities in the Pacific Northwest. This project was described by Price and Carey (1993), who analyzed some of its results. Implementing this project, MSU Libraries purchased 86 science serials with a pledge to make them readily available to the other universities. Both local and in- terlibrary loan use was monitored on 84 of these titles. Of the 84 titles, 30 (costing a total of $\$ 10,350$ ) had no local use, and- to the evident surprise of the researchers -no interlibrary loan use, either. A number of calculations indicated that it would have been far more cost effective to have utilized document delivery through UnCover, and serious doubts were raised about the wisdom of the cooperative collection of science serials.

Having clarified the general nature of interlibrary loan use, it is now possible to examine with greater understanding the findings on the relationship of LSU faculty score to UnCover use. The sample for this analysis included all documents delivered to LSU Libraries by UnCover between July 1, 1994 and June 30, 1996 from serials classed in LC subject groups Q, S, and T. From these titles were weeded all those that were classed in parts of LC class schedules $Q, S$, and $T$ that did not pertain to the curriculum cores under consideration. The resulting sample comprised 847 serials accounting for 2,909 document deliveries.

Despite titles on current subscription at LSU Libraries being blocked from the UnCover system, there was a considerable amount of leakage in the system. Of the 847 titles from which UnCover delivered documents in the two-year period, 135 (15.9\%) were on current subscription at LSU Libraries, and these 135 titles accounted for $250(8.6 \%)$ of the document deliveries. These titles were also weeded, leaving a final sample of 2,659 documents delivered by UnCover from 712 titles classed in LC subject schedules Q, S, and $\mathrm{T}$ during the study period.

To save labor, it was decided to test faculty score against UnCover use on a global basis, i.e., without breaking the UnCover titles into subject sets defined by the curriculum cores. This decision dictated statistical techniques not only resistant to outliers but also unaffected by the highly skewed distributions basic to any set of library data. Two such tests-both nonparametric-were chosen. The first was the chi-square test of independence (sometimes called the chi-square test of association or homogeneity), which 
operates on the nominal level (Snedecor and Cochran 1989, 76-79, 124-29, and 196-212; Hatcher and Stepanski 1994, 155-70; Stokes, Davis, and Koch 1995). For this test, "classification" variables are constructed by grouping the data into broad classes or groups. Then within these classes "expected" frequencies are calculated and compared to actual or "observed" frequencies. The null hypothesis is that there is no association between the variables, and this is tested by calculating and summarizing the differences between the "expected" and "observed" frequencies in a statistic called chi-square. If the chi-square is small, the null hypothesis of no association is accepted; if the chi-square is large, the null hypothesis of no association is rejected, and there is a high probability that the variables are related. The second statistical method chosen to analyze the relationship of faculty score to UnCover use was Kendall's tau-b, which operates at the ordinal level (Gibbons 1993; Schlotzhauer and Littell 1987, 371-76). Kendall's tau-b is similar to the Spearman rank correlation coefficient in that its values range from -1 to 1 , with - 1 indicating a strong negative association, zero showing no association, and 1 demonstrating a strong positive association between the variables.

For purposes of the test, UnCover use was grouped into three ordinally ranked classes. The first class, "low," consisted of the 310 titles $(43.5 \%$ ) that had been used to supply one document each for a total of $310(11.7 \%)$ of the 2,659 documents requested. The second class, "medium," consisted of those 323 titles (45.4\%) that had been used to supply 2 to 6 documents, summing up to $977(36.7 \%)$ of the documents requested. The third class, "high," contained the 79 titles $(11.1 \%)$ that had been used to supply 7 to 198 documents each for a total of $1,372(51.6 \%)$ of the documents requested. Given such a structure, it was not surprising that the variance of the UnCover use was found to be significantly greater than the mean, rejecting the null hypothesis of randomness and indicating the effect of the stochastic processes of qualitative inhomogeneity and contagion.
Faculty score was also divided into three ordinally ranked classes. These classes were based upon the rank of their constituent titles after the latter had been arranged in descending order by faculty score within each of their respective curriculum cores in the desired universe. The first class, "zero or low," comprised those titles that either had not been named by the faculty in the SRP survey, had been listed beyond the 45-title limit set in the survey questionnaire, or were in the bottom $25 \%$ of the aggregate faculty score of their respective curriculum cores. The second class, "medium," consisted of those titles that had an aggregate faculty score that placed the titles in the $51 \%$ to $75 \%$ range of the aggregate faculty score of their respective curriculum cores. The third class, "high," comprised those titles that accounted for the top $50 \%$ of the aggregate faculty score of their respective curriculum cores.

Here something important must be pointed out. Due to the high positive skew and exponential structure of informetric distributions, the interval distances between elements ordinally ranked in descending order by any informetric measure rapidly decreases as one goes down the ranks until there is little or no difference in absolute terms between the elements falling just above or just below the divide separating the top $75 \%$ from the bottom $25 \%$ of the aggregated informetric measure. Couched in economic terms and applied to ST serials, this dictates that the marginal utility of ST serials - or the utility added by each additional serial-diminishes with brutal rapidity. For example, on the average it took 9.9 titles $(15.6 \%)$ to account for the top $50 \%$ of the aggregate faculty score in each of the 33 curriculum cores, but it took an average of another 11.9 titles (18\%) to increase the aggregate faculty score another $25 \%$ to $75 \%$.

From this perspective, it was possible to make a preliminary assessment that LSU Libraries' ST serials holdings were not heavily but only moderately damaged despite a full decade of adding no new subscriptions and undergoing massive cancellations. Of the 326 titles perceived 
TABLE 4

3x3 CONTINGENCY TABLE FOR THE RELATIONSHIP OF FACULTY SCORE TO UNCOVER USE ${ }^{*}$

\begin{tabular}{|c|c|c|c|c|c|}
\hline & & $\begin{array}{c}\text { Low } \\
1 \text { Use per Title } \\
\text { (310 Uses; } \\
11.7 \% \text { of Use) }\end{array}$ & $\begin{array}{l}\text { UnCover Use } \\
\text { Medium } \\
\text { 2-6 Uses per Title } \\
\text { (977 Uses; } \\
36.7 \% \text { of Use) }\end{array}$ & $\begin{array}{c}\text { High } \\
\text { 7-198 Uses per Title } \\
\text { (1,372 Uses; } \\
516 \% \text { of Use) }\end{array}$ & TOTALS \\
\hline $\begin{array}{l} \\
0 \\
5 \\
0 \\
0 \\
\text { is } \\
2 \\
\pm \\
3 \\
0 \\
5 \\
5\end{array}$ & $\begin{array}{l}\text { Zero or Low } \\
\text { Titles either not } \\
\text { named by faculty or } \\
\text { accounting for } \\
\text { bottom } 25 \% \text { of } \\
\text { faculty score in each } \\
\text { curriculum core } \\
\text { Medium } \\
\text { Titles accounting for } \\
\text { mid } 25 \% \text { of faculty } \\
\text { score in each } \\
\text { curriculum core } \\
\text { High } \\
\text { Titles accounting for } \\
\text { top } 50 \% \text { of faculty } \\
\text { score in each } \\
\text { curriculum core }\end{array}$ & $\begin{array}{l}279 \% \\
263.0 \\
46.2 \% \\
90.0 \%\end{array}$ & $\begin{array}{c}277 \\
274.0 \\
45.9 \% \\
85.8 \%\end{array}$ & $\begin{array}{c}48 \\
67.0 \\
8.0 \% \\
60.8 \%\end{array}$ & $\begin{array}{c}79 \text { titles } \\
11.1 \% \text { of } \\
\text { faculty score } \\
\text { titles } \\
\\
29 \text { titles } \\
4.1 \% \text { of } \\
\text { faculty score } \\
\text { titles }\end{array}$ \\
\hline & TOTALS & $\begin{array}{l}310 \text { titles } \\
43.5 \% \text { of } \\
\text { use titles }\end{array}$ & $\begin{array}{l}323 \text { titles } \\
45.4 \% \text { of } \\
\text { use titles }\end{array}$ & $\begin{array}{l}79 \text { titles } \\
11.1 \% \text { of } \\
\text { use titles }\end{array}$ & $\begin{array}{c}712 \text { titles } \\
100 \% \text { of } \\
\text { titles }\end{array}$ \\
\hline
\end{tabular}

"Chi-square $=48.7$. Null hypothesis rejected at less than the 0.0001 level of significance. Kendall's tau-b $=$ 0.181 . Significant at less than the 0.0002 level.

" Cell Numbers in Descending Order = Observed Frequency; Expected Frequency; \% Faculty Score Titles in Its Row; \% UnCover Use Titles in Its Column.

by the faculty in the SRP survey as necessary for LSU Libraries' serials holdings to be at $50 \%$ of the ST value of the desired universe of all 33 curriculum cores, 53 or $16.3 \%$ were not on current subscription.

The results of the analysis of the relationship of faculty score to UnCover use are shown in table 4 , which is a $3 \times 3$ contingency table constructed from the above classification variables. This table shows that faculty score is definitely associated with UnCover use. First, the calculated chi-square of 48.7 was highly significant $(\mathrm{p}<0.0001)$, and, second, the significant Kendall's tau-b of 0.181 demonstrates that this association was positive. An inspection of the expected and observed frequencies in the various cells of the table corroborates this conclusion. Thus, the observed frequency of zero or low fac- ulty score titles is higher than expected in the low UnCover use class, approximately the same as expected in the medium UnCover use class, and lower than expected in the high UnCover use class. In contrast, the observed frequency of medium faculty score titles was lower than expected in the low UnCover use class, about as expected in the medium UnCover use class, and more than twice as expected in the high UnCover use class.

High faculty score titles manifested the same behavior as medium faculty score titles, only more so. The observed frequency of high faculty score titles was less than half than expected in the low UnCover use class, about as expected in the medium UnCover use class, and about 3.8 times higher than expected in the high UnCover use class. Twelve 
(41.4\%) of the 29 high faculty score titles were in the high UnCover use class. The tendency of the medium and high faculty score titles to cluster near the top of the UnCover use distribution can be seen in the following average uses per title of the different faculty score classes: about three uses per title in zero or low faculty score class, 5.3 in the medium faculty score class, and 15.3 in the high faculty score class.

The average use per title in the medium and high faculty score classes was artificially depressed because many of them $(36.7 \%$ in the medium, $55.2 \%$ in the high) had backfiles at LSU Libraries even though they were not on current subscription. When those with backfiles were excluded, the average use per title rose to 6.9 in the medium faculty score class and to 27.2 in the high. Although the total number of medium and high faculty score titles was $108(15.2 \%)$ of the 712 UnCover titles, they accounted for $865(32.5 \%)$ of the documents supplied in the two-year period. The 29 high faculty score titles alone accounted for $4.1 \%$ of the titles but $16.7 \%$ of the use-more than the 79 medium faculty score titles, which accounted for $11.1 \%$ of titles and $15.8 \%$ of the use.

ANALYZING THE FhWW IN FACULTY SCORE WITH Citation-Based Measures and INTERnaL

LibRARY UsE

Despite the success of faculty score as a predictor of library use, there was one troubling feature that emerged from the analysis of its relationship to UnCover use, i.e., the low overlap between what was perceived as important by the faculty and what was being heavily borrowed through UnCover. Thus, among the 79 high UnCover use titles there were only $31(39.2 \%)$ medium and high faculty score titles. This indicated that although faculty score was a highly accurate measure within the sphere perceived by the faculty, important processes were taking place in library use outside the perception of the faculty. Suspicions of this nature were confirmed when an inspection of the NOTIS circulation records of the titles on subscription at LSU Libraries but in the zero faculty score class revealed extremely high use of some of these titles. Cancellation of these titles on the basis of faculty score alone had the potential of extreme damage to the ST serials holdings of LSU Libraries. Moreover, Kleiner and Hamaker (1997, 367-68) studied UnCover use at LSU from November 1995 through May 1996 and revealed another flaw of faculty ratings: on an individual basis, the faculty tended to see importance where no importance existed. This flaw manifested itself in the extremely small overlap between the titles recommended for subscription by faculty members taken individually and those actually used one or more times through UnCover.

As a result of these findings, we decided to create a citation-based measure both to analyze the processes occurring in library use beyond the perception of the faculty and to serve as a corrective in decisions concerning cancellations and new subscriptions. Construction of total citation measures had proved to be a laborious process in the analysis of the data from the 1993 pilot project with the LSU Department of Chemistry, and further research was considered necessary on the time value of ST information before a more efficient method for constructing such a measure could be developed. Given the purpose of creating a corrective for faculty score, it was considered essential to develop the citation-based measure within the context of sets defined by subjects, and impact factor was the only citation measure in the JCRs that satisfied this condition.

The citation data collected for the study based upon the 1993 SRP pilot project with the LSU Department of Chemistry (Bensman 1996) was again analyzed to determine whether impact factor could be converted into a measure applicable to library use. As noted above, the main fault of impact factor is that it is corrected for size, whereas library use of a given title logically has to be heavily affected by its size. The first part of the analysis was to do a nonparametric Spearman rank-order correlation of total citations with impact factor, and predictably this correlation 
turned out to be low-0.38-due to the fact that size was inherent in the former and excluded from the latter. However, inspection of the plot of total citations against impact factor revealed 11 outliers arising from the higher average citation rates of review journals. When these outliers were excluded, the Spearman correlation of impact factor with total citations rose to 0.47 , indicating a fairly good relationship of impact factor-or average citation rate- to total citation rate under these conditions.

Inspection of the plot revealed that if one divided the subject set ranked by impact factor at the median into two classes, the upper class would contain not only all the review journals-considered a plus from the library point of view--but also the vast majority of the serials highest in total citations. Such a method appeared ideal for the construction of citation-based, ordinally ranked classification variables to test against UnCover use with the chi-square test of independence and Kendall's tau-b. Accordingly, all UnCover titles were divided into three classification variables on the following basis: "not covered," those for which ISI provided no impact factor; "low," those below the median impact factor of their respective ISI subject groups; and "high," those above the median impact factor of their respective ISI subject groups. The 1994 SCI $J C R$ - supplemented where necessary by the 1994 SSCI JCR - was utilized for this purpose both to bring this analysis into line with the above correlation analysis of faculty score with total citations and to test whether citation-based measures could be used to predict future library use because the UnCover data ran from mid-1994 to mid-1996. Because ISI sometimes lists a title in several subject groups, a policy was established to use the impact factor ranking of the largest of the subject groups. If there was any systematic error caused by this method, it was that titles that would have been in the high impact category in applied fields with low citation rates such as engineering would be found in the low impact factor category as a result of being transferred to pure research fields with higher citation rates.
Table 5 was constructed for the purpose of analyzing the relationship of impact factor to library use. This is another $3 \times 3$ contingency table using the impact factor classification variables developed above together with the same UnCover use classification variables that were employed to test faculty score. Once again, the null hypothesis of no association between the variables was rejected (chi-square $=32.2, \mathrm{p}<0.0001$ ). The significant Kendall's tau-b of $0.153(\mathrm{p}<0.0002)$ again showed that this association was positive.

An examination of the observed frequencies against the expected frequencies in the different cells of the table shows that whereas high impact factor functioned very well as a predictor of library use, low impact factor performed less well. As a matter of fact, the performance of the low impact factor titles resembles that of the titles not covered by the JCRs. Thus, the observed frequencies of both the titles not covered in JCRs and the low impact factor titles were greater than the expected frequencies in the low UnCover use class, about as expected in the medium UnCover use class, and lower than the expected in the high UnCover use class. In contrast to this, the observed frequencies of the high impact factor titles were lower than the expected frequencies in the low UnCover use class, about as expected in the medium UnCover use class, but 1.7 times greater than expected in the high UnCover use class. These differences manifested themselves in the average use per title in the different impact factor classes and the total UnCover use for which these classes were responsible. Whereas the average uses per title of the serials not covered by the JCRs and in the low impact factor classes were respectively 2.2 and 2.9 , the average use per title of the high impact factor serials was 5.7 , or roughly double. Concerning total UnCover use, the $238(33.4 \%)$ titles not covered in the JCRs accounted for $20.1 \%$ of UnCover use, and the $212(29.8 \%)$ low impact factor titles were responsible for $23.5 \%$ of UnCover use. In both instances the percentage of total titles was higher than the percentage of total use. The 
TABLE 5

3X3 CONTINGENCY TABLE FOR THE RELATIONSHIP OF IMPACT FACTOR TO UNCOVER USE*

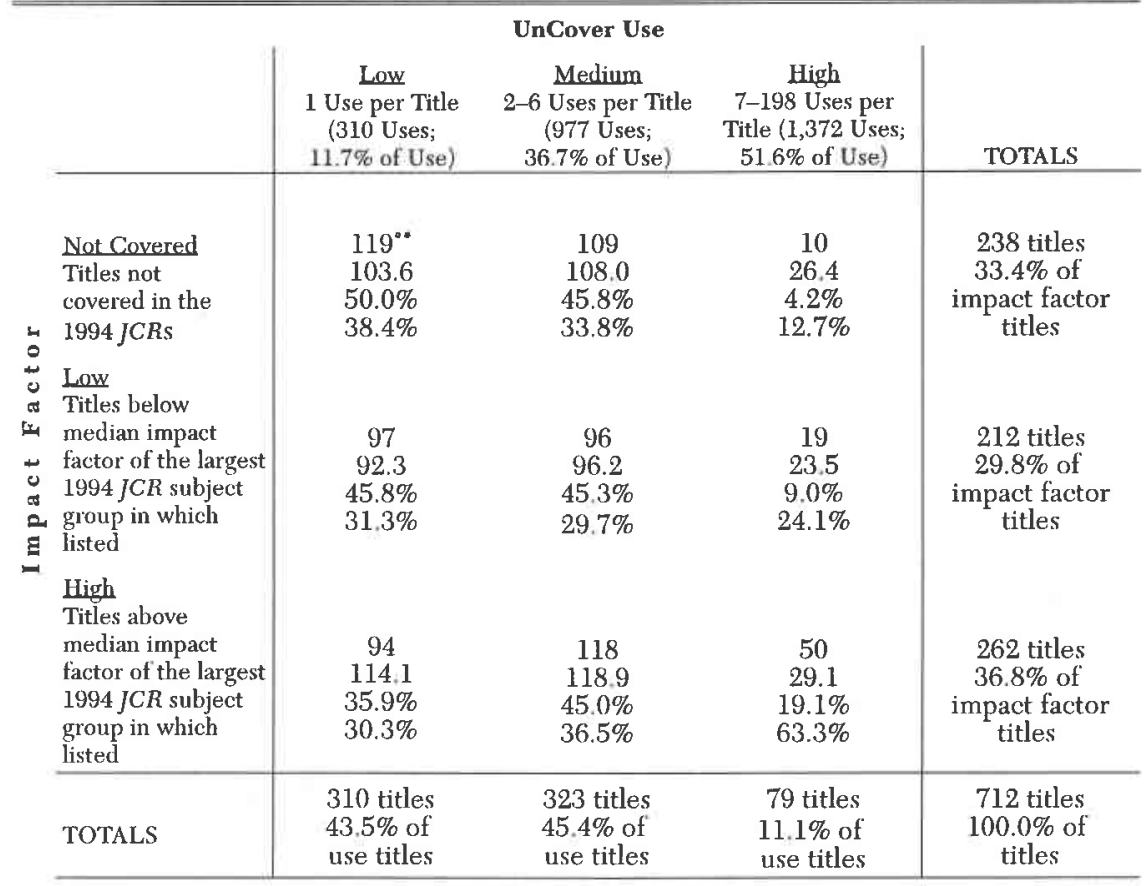

-Chi-square $=32.2$; null hypothesis rejected at less than the 0.0001 level of significance. Kendall's tau- $b=0.153$; significant at less than the 0.0002 level.

" Cell Numbers in Descending Order = Observed Frequency, Expected Frequency, \% Impact Factor Titles in Its Row, \% UnCover Use Titles in Its Column.

opposite was the case with the high impact factor titles, which had $262(36.8 \%)$ titles accounting for $56.4 \%$ of UnCover use. Moreover, the high impact factor titles covered the crucial high UnCover use class better than both the medium and high faculty score titles taken together. Of the 79 titles in the high UnCover use class, the high impact factor titles represented $50(63.3 \%)$, whereas both the medium and high faculty score titles accounted for only $31(39.2 \%)$. From this analysis it is evident that the social stratification system of science and technology is operative in library use in a sphere beyond the perception of the faculty.

An extremely interesting picture emerges once the UnCover use of the 135 titles on current subscription at LSU Libraries is taken into consideration. Of these titles, $45(33.3 \%)$ were high faculty score titles, and $109(80.7 \%)$ were high impact factor titles. With their addition, the number of high faculty score titles rose from $29(4.1 \%)$ of the sample titles to 74 or $8.7 \%$, and the number of high impact factor titles rose from 262 or $36.8 \%$ of the sample titles to 371 (43.8\%). Combined into one set without any overlap, the high faculty score and high impact factor titles represented 110 (81.5\%) of the 135 titles on current subscription that affected UnCover use, and they accounted for $85.6 \%$ of the UnCover use caused by this set. As separate sets, the high faculty score titles-both on subscription and not on subscription-accounted for $18.9 \%$ of overall UnCover use, and the high impact factor titles-both on subscription and not on 
subscription-were responsible for $58.9 \%$ of overall UnCover use. This finding brings into sharp focus those of previous studies of interlibrary loan use, and its implication is clear: the influence of the science and technology social stratification system is so strong that it dominates not only internal library use but also interlibrary loan use. Good ST information is indeed a rare commodity.

The final test of faculty score was to investigate the internal use of the titles on subscription at LSU Libraries but found in the zero class of this measure. These were the titles in the working universe of the curriculum cores either not named by the faculty during the SRP or listed beyond the 45-title limit set in the questionnaire. They numbered 279 titles costing $\$ 101,997$. For this analysis, use data were collected from the NOTIS circulation records on the volumes of these titles dating from 1988 through the end of 1996 . These years were deliberately selected to make the backfile of these serials roughly equivalent to the backfile of the serials held by UnCover, whose holdings dated mainly from 1989 forward. However, whereas the UnCover use was over a 2-year period on roughly a 7.5-year backfile, NOTIS use was calculated to be the average over a 7.5-year period on a 7.5-year backfile, because use of unbound issues-and, it must be added, much in-house use-was not captured by the NOTIS circulation system. For comparative purposes, a formula was developed to standardize NOTIS use against UnCover use. This formula took into account not only the difference in time periods but also possible in-house use of the titles in the zero class of faculty score. Basically, it worked out to multiplying the recorded NOTIS use by 0.3 .

Contrary to expectations, the use of the titles in the zero class of faculty score was found to be shockingly high, ranging up to 128 uses per title for a total of 1,967 uses. Only $56(20.1 \%)$ of the 279 faculty score zero class titles had zero use. However, as usual, use was heavily concentrated on a few titles. Of the 279 titles, 80 (28.7\%) accounted for $80.2 \%$ of the use, and $96(34.4 \%)$ had zero or one use, amounting to 40 uses ( $2 \%$ ) of the use. Pre- dictably the variance of the NOTIS use of the faculty score zero class titles was found to be greater than the mean, rejecting the null hypothesis of randomness and indicating the presence of the NBD or a related contagious distribution.

Under these circumstances it was decided to investigate the processes operative in the NOTIS use of the titles in the zero class of faculty score by testing NOTIS use against impact factor. The method adopted for this was again the chi-square test of independence. NOTIS use was defined in two classification variables: "low" NOTIS use-the 199 (71.3\%) of the faculty score zero class titles that accounted for $19.8 \%$ of NOTIS use; and "high" NOTIS use-the $80(28.7 \%)$ of the zero class titles that accounted for $80.2 \%$ of this use. The entry level for high NOTIS use was 7 uses, which standardized into 2.1 UnCover uses, or roughly the dividing line between low and medium UnCover use. Such a division was considered appropriate, because neither NOTIS use nor the UnCover use of titles not on subscription at LSU Libraries concerned extremely high status titles such as Journal of the American Chemical Society, Nature, and Science.

Once NOTIS use variables had been defined, the 1995 SCI JCR was employed to construct two impact factor classification variables in the manner outlined above, except that both titles not covered by the $J C R$ and low impact factor titles were lumped into one class. The result of this operation was 204 "low" impact factor titles and 75 "high" impact factor ones. Both the NOTIS use and impact factor variables could be ordinally ranked, and they were cast into a $2 \times 2$ contingency table with familiar results. The null hypothesis of no association between the NOTIS use and impact factor variables was resoundingly rejected by the large calculated chi-square of 24.3 , a size with less than a one in 10,000 chance of occurring under conditions of the null hypothesis, and the Kendall tau-b was a positive 0.295 significant at below the 0.0002 level.

These results were verified by checking the observed frequencies against the expected frequencies in the tables cells. 
For the low impact factor titles, the observed frequency of 162 in the low NOTIS use class was above the expected frequency of 145.5 , and their observed frequency of 42 in the high NOTIS use class was far below their expected frequency of 58.5. As for the high impact factor titles, their observed frequency of 37 in the low NOTIS use class was $30.8 \%$ below their expected frequency of 53.5 , and their observed frequency of 38 in the high NOTIS use class was $76.7 \%$ above their expected frequency of 21.5 . These findings once again confirmed that the social stratification system of science and technology influenced library use in a sphere beyond the perception of the faculty, making it necessary to apply correctives to faculty score in any decisions concerning serials cancellations and new subscriptions.

An inspection of the faculty score zero class titles underlying high NOTIS use revealed that two interrelated causal elements played a large role in the failure in faculty perception. One was the large and complicated bibliographic structure of the publications of the Institute of Electrical and Electronics Engineers (IEEE). The numerous and complex titles of the IEEE publications made them difficult both for the faculty to name as well as for the library staff to identify and score. This difficulty was compounded by the low response rate of the Department of Computer Science (4 of 15 faculty members, or $26.7 \%$ ) to the SRP survey. Of the 80 titles accounting for $80.2 \%$ of NOTIS use, 8 titles were classed in the Computer Science curriculum core, and these 8 titles accounted for 312 (19.8\%) of the 1,578 uses of the top 80 titles. All in all, there were 12 Computer Science titles with 317 total NOTIS uses in the faculty score zero class. Of these 12 serials, 6 were IEEE tithes accounting for 147 (46.4\%) of the 317 Computer Science NOTIS uses, and 4 were publications of the Association for Computing Machinery (ACM) accounting for $165(52.1 \%)$ of the uses attributable to this curriculum core. Together the titles of these two U.S. associations were responsible for $98.5 \%$ of NOTIS uses in Computer Science. In addition to the Computer Science titles, there were two more IEEE titles that belonged to the Electrical Engineering curriculum core in the faculty score zero class, and these titles had a total of 11 NOTIS uses. Alone, the ACM and IEEE titles in Computer Science and Electrical Engineering numbered only $12(4.3 \%)$ of the faculty score zero class titles, but they accounted for $16.4 \%$ of the NOTIS use of this class.

\section{The Exercise}

TESTING THE SERIals Evaluator's ALGORITHMS ON UIUC CHEMISTRY LIBRARY USE

\section{The Serials Evaluator's Algorithms and THE UIUC DATA}

The Serials Evaluator offers two algorithms for determining which serials should either be canceled or not purchased. One algorithm fully exploits any divergence of cost from $S T$ value by selecting for cancellation or nonpurchase any title whose percentage of total cost exceeds its percentage of total ST value. The other algorithm allows the user to set goals in terms of cost reduction and ST value retention. In this algorithm the Evaluator forms two different sets-one from the titles with the highest prices, another from the titles with the highest ST value-and then compares these two sets to select for cancellation or nonpurchase only those high-price titles that are not in the high-value set. The latter option is more conservative, because it establishes controls only at the extremes of the distributions while allowing for random error at the lower ranges. This was deemed important because any set of library data contains considerable random error-particularly at the lower ranges of the distributions where the interval distances are extremely close. It was decided to utilize the second algorithm for the purposes of the exercise.

Investigation of the effect of employing this algorithm with all three of the Evaluator's measures of ST value-expert ratings, total ISI citations, and library use- - n actual library use as well as on the costs of this use was made possible when the UIUC Chemistry librarian supplied us with data from the three use studies that she had done in 1988, 1993, and 1996 
(Chrzastowski 1991; Chrzastowski and Olesko 1997). The 1993 UIUC Chemistry Library study (conducted from January 4 through March 31, 1993) was contemporaneous with the SRP pilot project of A pril 1993. A database of chemistry journals had been constructed as a result of the SRP pilot project that contained ratings by the LSU chemistry faculty, 1993 SCI citation measures and prices, as well as their publisher type and country of publication (Bensman 1996).

There were 120 titles costing $\$ 160,226.10$ that were common to both the UIUC and LSU sets. UIUC use was compiled by having student workers count titles as journals were reshelved, returned from a two-hour loan period, or circulated via interlibrary loan. Both bound and unbound use was counted, and use was classified by date of journal publication into the following temporal categories: pre-1960, 1960s, 1970s, 1980s, and 1990s. For purposes of our investigation, UIUC use (which had been collected over a three-month period) was annualized by multiplying it by four.

\section{Faculty Score, Citations, AND the}

SOCIOMETRIC CONCEPT OF LIBRARY USE

Acquisition of the UIUC data compelled a rethinking of the ST value measures utilized in the Evaluator's algorithms--especially with respect to library use. These measures had been conceptualized as sociometric ones, and they were based upon philosophic idealism, particularly Bishop Berkeley's contention that the essence of an object-in this case, ST value-is its being perceived. From this perspective, faculty ratings became the key measure, and total citations were accepted rather than impact factor, because total citations correlated better with faculty ratings by capturing the size as well as historical and social significance of the serials (Bensman 1996, 156-59). The good correlations of LSU faculty ratings with total citations were corroborated with 1994-95 SRP survey data in the test curriculum cores of Agronomy, Chemistry, and Mechanical Engineering, as shown above. Given this orientation, the equivalent sociometric measure in terms of li- brary use would be total use over the entire backfile of serials.

The first stage of the investigation of the effect of the Evaluator's second algorithm on library use and the costs of this use was done on the sociometric basis, i.e., with LSU faculty ratings, total citations, and total UIUC Chemistry Library use. Analyses conducted with UnCover data had shown that high LSU faculty ratings and high ISI citations were strongly associated with high library use. However, the UnCover analyses lacked set definitions and utilized the flawed citation measure of impact factor. This had necessitated the utilization of nonparametric statistics within broad categories to neutralize the effect of outliers. However, the happy coincidence of use data from the UIUC Chemistry Library together with LSU faculty ratings and total citation measures in the same subject set and in the same time period enabled the utilization of more powerful parametric statistical techniques.

As usual, the method of analysis was to compute the Pearson product-moment correlation coefficient between the variables in question, regress one variable on the other to determine the outliers, and then recompute the Pearson product-moment correlation with the outliers excluded. With respect to faculty score, the initial correlation between it and total UIUC use was 0.73 . To find the outliers, faculty score was regressed on total UIUC use, and analysis of the residuals indicated 3 outliers. In all three cases, actual total UIUC use was far lower than that predicted by LSU faculty ratings. These outliers shared the same characteristics of being at the extreme lower end of the total UIUC use distribution and having a relatively narrow subject focus. Therefore the cause of their being outliers may have been either a lower interest in such subjects at Illinois than at LSU or a sporadic use pattern not fully captured by the three-month survey. Their exclusion raised the correlation between LSU faculty ratings and total UIUC use to $\mathbf{0 . 7 5}$.

The results were even better with total ISI citations, which had an initial correlation of 0.82 with total UIUC use. Four 
outliers were pinpointed by the regression of total ISI citations on UIUC use. With three of these, the actual use was again far below that predicted by ISI total citations, and two had also appeared as outliers with LSU faculty ratings. The third such outlier was of a similar nature in that it also was located at the extreme lower end of the UIUC use distribution and had a narrow subject focus. Much different was the fourth outlier, Chemical and Engineering News, which had an observed use far above its predicted use- 792 to 55 . This result was natural, because citations are a measure of research quality, whereas the purpose of Chemical and Engineering News is to serve as the chief informational publication of the American Chemical Society. With the exclusion of these outliers, the correlation between UIUC use and total ISI citations rose to 0.86 . For comparative purposes, the initial correlation of total UIUC use with impact factor was only 0.36 - a natural result, because impact factor is controlled for size and time whereas the library use was not.

The Pearson product-moment correlations of total UIUC use with LSU chemistry faculty ratings and total ISI citations were extremely high. Calculations of the coefficients of determination showed that $56.3 \%$ in total UIUC use was explained by LSU faculty ratings and $74.0 \%$ by total ISI citations. Two major conclusions can be drawn from these high correlations. First, when one controls for outliers by defining proper sets, there will emerge high correlations between library use on the one hand, and either expert ratings or total citations on the other. Second, the ability of LSU chemistry faculty ratings to predict so accurately total UIUC Chemistry Library use demonstrates that university chemistry departments belong to the same social stratification system and require basically the same set of journals.

The three sociometric measures of ST value were plotted against price. Given the high correlations, it was not surprising that all three plots revealed the same bifurcated pattern found previously by Bensman (1996, 166-67) with ST value concentrating on the serials of the U.S. as- sociations and costs concentrating on the serials of the commercial, largely foreign, publishers.

\section{The ACCounting CONCEPT OF LibraRy USE:}

COST-PER-USE

Despite these successes, it became apparent upon reflection that the sociometric measures of ST value are not direct measures of the effect of cancellations on actual library use and the costs of this use. Even if a serial subscription is canceled, the backfile is retained, and the costs in lost use and replacement relate to the future and not to the past.

To gauge these future costs, it was decided to use the accounting technique of a standard cost system based on estimated costs derived from average past experience (Plank and Blensly 1989, 134). The essence of the accounting technique is to normalize the use of serials on the same annual basis as their subscription prices, so that the two measures can be logically employed together. This was accomplished in the following steps. First, UIUC Chemistry Library use was restricted to the post- 1980 period to capture current trends, because science tends to concentrate on literature of the more recent period. Some of the serials dated back decades-even to the nineteenth century-and use over the earlier backfiles was estimated to be spotty, making the calculation of averages difficult. Moreover, pre-1980 use could be considered fully depreciated and essentially cost-free from an accounting standpoint. Post-1980 UIUC use accounted for $51,740(73.8 \%)$ of the 70,072 total uses, and the correlation between pre-1980 and post-1980 use was 0.81 , reflecting the stability of informetric distributions over time. Second, a use age was calculated by considering all serials predating 1980 to be 14 years old - 1980 through 1993-and all post-1980 serials to have a use age equivalent to the number of years in their backfiles. Third, the post-1980 use of the serials was divided by their use age to yield an estimated annual use or an estimate of the use that would be lost during the first year due to cancellation. Finally, the 1993 subscription price of the serials was 
divided by this estimated annual use to calculate the cost-per-use of the titles.

The creation of these accounting measures enabled us to analyze the cost-per-use structure of the chemistry journals under investigation. For this purpose, we used two methods of summarizing the cost-per-use of a set of serials. One was the mean title cost-per-use. This is simply the average cost-per-use of the titles. However, this method assigns equal weight to those journals with low use but high cost-per-use and therefore overestimates the cost-per-use of a set of serials. The other method was mean document cost-per-use, and this was done by summing up the subscription prices of the serials in a set of serials and then dividing this sum by the total estimated annual use of these serials. This method assigns the proper weight to the serials with high use and low cost-per-use and provides a good statistic to compare against some benchmark.

Overall, the title cost-per-use of the entire universe of the 120 chemistry serials common to the LSU and UIUC data sets ranged from $\$ 1.79$ to $\$ 4,079.27$. Their mean title cost-per-use was $\$ 247.49$, and their mean document costper-use was $\$ 41.30$. Breaking up this universe into sets defined by publisher type made some extremely revealing comparisons possible. In making these comparisons, it was considered necessary to exclude one U.S. association title that proved to be an anomaly. This title was not a U.S. association journal in the usual sense but a translation of a Russian journal published by a U.S. association. With this exclusion, the statistics for title cost-per-use for the different categories of publishers were as follows: U.S. commercial titles ranged from $\$ 29.47$ to $\$ 1,950.00$, with a mean of $\$ 343.51$; U.S. association titles ranged from $\$ 1.79$ to $\$ 45.50$, with a mean of $\$ 15.21$; foreign commercial titles ranged from $\$ 3.29$ to $\$ 4,079.27$, with a mean of $\$ 254.69$; and foreign association titles ranged from $\$ 16.50$ to $\$ 147.78$, with a mean of $\$ 67.68$. The difference between these means was statistically significant at the 0.0001 level.

With respect to mean document cost-per-use, the figures were as follows: U.S. commercial- $\$ 108.14$; U.S. association- $\$ 7.64$; foreign commercial$\$ 73.27$; and foreign association $-\$ 32.05$.

In considering these numbers, one should keep firmly in mind that cost-per-use figures are institutionally specific. Thus, in the fall of 1992, the UIUC chemistry program had 44 faculty members and 277 graduate students, whereas the LSU chemistry program had 35 faculty members and 100 graduate students (Goldberger, Maher, and Flattau 1995, 316 and 318). Due to this difference, LSU's cost-per-use figures would have been concomitantly higher.

\section{The Serials Evaluator, Sociometric}

MEAsures, and Results in COST-PEh-Use

Knowledge of the cost-per-use structure of a serials collection-or, at least, knowledge of the effect of one's actions on this structure-is essential in making any cancellation decisions that would result in a transition from ownership to access through document delivery. In general, researchers have demonstrated that whereas expensive journals with little in-house use are better accessed through document delivery, journals frequently used by patrons are best bought through subscription (Feguson and Kehoe 1993; Chrzastowski and Anthes 1995; Gossen and Irving 1995; Kingma and Irving 1996). For example, Gossen and Irving $(1995,49)$ estimated that if the University of Albany had switched totally to document delivery in 1992, it would have cost $\$ 2,900,456$ to provide the same access to journal literature that was provided by $\$ 1,273,531$ in annual subscription costs. To make judgments in these matters, some sort of benchmark is needed.

In a study jointly sponsored by ARL and the Research Libraries Group, Roche (1993) attempted to provide such a benchmark through an analysis of the costs involved in interlibrary loan transactions during 1991. Roche estimated that a research library spends an average of $\$ 18.62$ to borrow a document. However, examination of the bases of this estimate led to the conclusion that it did not pertain to the question under consideration 
because it did not take into account the actual cost of the document itself. The estimate only related to the cost of processing the document such as expenses for staff, network and communications, delivery, photocopy, supplies, equipment and software, etc. These types of expenses appear to be more than counterbalanced by the expenses of owning a serial other than its subscription price. The latter expenses include such items as technical processing and binding. In a study of science and mathematics serials, Kingma and Irving (1996, 1-2, 35-38) estimated that the annual cost of owning a title other than its subscription price averaged $\$ 62.96$, with an additional cost of $\$ 0.07$ for every use.

Given these facts and the extreme variation of the serials subscription prices by discipline, it was decided that the most reasonable way to use our cost-per-use figures derived by the accounting method was not to compare them against some universal standard but only against each other within defined subject sets. However, for general guidance, two figures can be used. First, it cost the UIUC Chemistry Library an average of $\$ 16.76$ per document during its experiment with the Chemical Abstracts Service (CAS) from October 15, 1993 to April 30, 1994 (Chrzastowski and Anthes 1995, 145). Second, the mean cost of the documents delivered to the LSU Department of Chemistry through UnCover from the start of the service in October 1, 1995 through June 30, 1997 was calculated. It was virtually identical-\$16.92. Only the mean document cost-per-use of the U.S. association titles at the UIUC Chemistry Library was beneath these guidance figures, raising serious doubts as to whether the CAS and UnCover would be able to maintain their pricing structures if heavy cancellations of serials by libraries forced publishers to rely on the sale of individual documents rather than subscriptions for their revenue.

Before testing for the effect of employing the Evaluator's second algorithm with the sociometric measures of ST value, it was considered necessary to gauge the strengh of the relationship of these sociometric measures of value to the accounting measure of value, estimated annual use. Again, the method of analysis was to compute the Pearson product-moment correlation coefficient between the variables in question, then regress one variable on the other-this time the sociometric measure on the accounting measure- to determine the outliers, and then recompute the Pearson product-moment correlation with the outliers excluded. The results were extremely encouraging.

With LSU faculty ratings as the sociometric measure, the initial correlation was 0.72 . Three outliers were found, of which two shared the same characteristics with the three outliers found in the correlation of LSU faculty ratings with total UIUC use, i.e., narrow subject focus, lower end of the use distribution, and actual use lower than predicted use. As a matter of fact, one of the titles appeared as an outlier in both correlations. The third outlier was different in that the actual use was much higher than the predicted use, and all could have been the result of either different subject interests at LSU and UIUC or the shortness of the use sampling period. Their exclusion raised the correlation of LSU faculty ratings with estimated annual UIUC use to 0.74 -almost the same as with total UIUC use.

Similar results were obtained when total ISI citations were used as the sociometric measure. Here the initial correlation was 0.76 , and regression of total ISI citations on estimated annual UIUC use revealed four outliers. One of these had the characteristics of narrow subject focus, lower end of UIUC use, and actual use lower than predicted use, and it had appeared as the same type of outlier in the correlation of total ISI citations with total UIUC use. The other three outliers had an actual use much higher than predicted use, and once again - as with total UIUC use-Chemical and Engineering News appeared in this role. As for the other two outliers of the latter type, they had a relatively narrow subject focus and could have been the result of differing subject interests at UIUC or the shortness of the use sampling period. With the exclusion 
of the outliers, the correlation of total ISI citations with estimated annual UIUC use rose to 0.82 -again virtually the same as with total UIUC use.

The correlation of the sociometric measure of total UIUC use with the accounting measure of estimated annual UIUC use can be dealt with briefly. Initially the correlation was 0.97 , and the exclusion of four outliers raised it to 0.98 , or virtual unity.

The lesson of these experiments was clear: the accounting measure of estimated annual UIUC use was practically the same as the sociometric measure of total UIUC use and interacted with the other sociometric measures of LSU faculty ratings and total ISI citations in virtually the same way. A plot of estimated annual UIUC use against price showed the same bifurcated pattern, with scientific value concentrating on U.S. association serials and costs concentrating in the serials of the commercial, largely foreign, publishers.

Tests of the effects of employing the Evaluator's second algorithm with all three sociometric measures of scientific value were made on the set of the $120 \mathrm{ti}$ tles common to the 1993 UIUC use study and SRP pilot project with the LSU Department of Chemistry. In these tests the SAS statistical program was utilized to simulate Evaluator runs with the second algorithm to avoid the complex task of loading the test set into the Evaluator and to keep open the option of exploring other algorithms. The simulated runs were done with the Evaluator default settings of trying to reduce costs by $75 \%$-in this case approximately $\$ 120,000$ - while trying to retain $75 \%$ of the scientific value of the serials collection. These default settings had been selected because long experience of working with informetric distributions had indicated them as approximately the maximum optimal levels. The result of each run was similar to the others.

Using LSU faculty score, 27 (22.5\%) of the titles costing $\$ 59,745.99$ (37.3\%) of the total costs were recommended for cancellation or nonpurchase. The loss in the sociometric measure of faculty score was $11.0 \%$ for a favorable ratio of percentage cost reduction (37.3\%) to percentage scientific value loss $(11.0 \%)$ of 3.4 to 1 . With respect to the accounting measure of estimated annual UIUC use, the loss in scientific value was $8.4 \%$ for a favorable ratio of 4.4. to $l$ in percentage cost reduction to value loss. With total ISI citations as the sociometric measure of scientific value, $30(25.0 \%)$ of the titles with $\$ 64,928.20$ ( $40.5 \%$ ) of the total cost were recommended for cancellation or nonpurchase. The loss in value measured by total ISI citations was $9.6 \%$ for a favorable ratio of 4.2 to 1 , and the loss in estimated annual use was $9.8 \%$, yielding a favorable ratio of 4.1 to 1 . Employing total UIUC use as the sociometric measure of scientific value, $35(29.2 \%)$ of the titles with $\$ 77,657.05$ (48.5\%) of the total cost were recommended for cancellation or nonpurchase. The loss in sociometric value measured by total UIUC use was $11.5 \%$, resulting in a favorable ratio of 4.2 to 1 , and the loss in estimated annual UIUC use was $12.1 \%$, giving a favorable ratio of 4.0 to 1 . In all cases, the sociometric results were similar to the accounting results in terms of cost reduction to value loss.

Much more importantly, the costper-use statistics of all three subsets of serials recommended for cancellation or nonpurchase were much higher than the equivalent statistics for the complete set of 120 serials, which had a mean title cost-per-use of $\$ 247.49$ and a mean document cost-per-use of $\$ 41.30$. Concerning the first measure, the mean title cost-per-use statistics of the subsets recommended for cancellation or nonpurchase were as follows for the three sociometric measures: LSU faculty score, $\$ 591.61$; total ISI citations, $\$ 544.36$; and total UIUC use, $\$ 484.59$. With respect to mean document cost-per-use, the statistics were the following: LSU faculty score, $\$ 182.99$; total ISI citations, $\$ 170.24$; and total UIUC use, $\$ 164.95$. The document means were all approximately 10 times higher than the average of $\$ 16.76$ that it cost the UIUC Chemistry Library for the delivery of a document during its experiment with the Chemical Abstracts Service 
from October 15, 1993 to April 30, 1994 , as well as the average of $\$ 16.92$ that LSU Libraries paid for documents delivered by UnCover to the LSU Department of Chemistry during the period of October 1 , 1995 to June 30, 1997.

An examination of the titles recommended for cancellation or nonpurchase reveals the dominant role of commercial publishers in the cost of ST serials. Of the 27 titles recommended for such treatment based on LSU faculty ratings, 20 $(74.1 \%)$ were those of foreign commercial publishers, and 6 (22.2\%) belonged to U.S. commercial publishers. With respect to the 30 titles recommended for such treatment with total ISI citations, 21 $(70.0 \%)$ were from foreign commercial publishers, and $8(26.7 \%)$ were those of U.S. commercial publishers. The same was the case with the 35 titles recommended for cancellation or nonpurchase with total UIUC use. Here, 24 (68.6\%) were from foreign commercial publishers, and $10(28.6 \%)$ were products of U.S. commercial publishers. Of these titles, 24 were common to all three cancellation or nonpurchase sets. One was a U.S. association serial, the Russian translation journal. It was the only U.S. association journal recommended for cancellation or nonsubscription, and it was consistently recommended for such treatment.

Although applicable in the management of serials collections, the very bases of the sociometric measures of ST value-particularly, total ISI citations -employed in the Evaluator's algorithms make them extremely dangerous for librarians from a political standpoint. This is because their utilization places the library at the very center of the promotion and tenure system. Symptomatic of this situation, as a result of his expertise in these measures, the principal author of this paper was asked by the LSU Graduate Council in the mid-1980s to write a report (Bensman 1985a) assessing the university's research-doctorate programs for possible termination. For this reason, it was decided to explore an accounting algorithm based upon cost-per-use for the Evaluator. The advantages of such an algorithm were perceived to be twofold.
Not only would it enable the library to base cancellations on politically less dangerous measures, but it would also provide information directly related to decisions to transfer from ownership to access.

The same set of 120 chemistry titles was used to test the accounting algorithm, and serials were selected for cancellation purely on the basis of descending order of cost-per-use as calculated above until approximately the same cost reduction had been achieved as had been by the second algorithm with the sociometric measure of total UIUC Chemistry Library use-in this case, $\$ 77,498.15(48.4 \%)$. The results spoke favorably of the cost-per-use method. Only with respect to number of titles canceled-44-did the accounting method fall behind the sociometric method, because many cheaper titles were brought up for cancellation, but in every other respect the accounting method proved to be more efficient. Thus, the percentage losses in value and the ratios of budgetary reduction to value lost were the following: total UIUC use- $7.7 \%$, a favorable ratio of 6.3 to 1 ( $48.4 \%$ to $7.7 \%$ ); and estimated annual UIUC use- $8.1 \%$, a favorable ratio of 6.0 to 1 . Moreover, the mean cost-per-use measures of the subset canceled by the accounting method- $\$ 594.67$ by title, $\$ 246.42$ by document-were higher than the respective measures in all three of the cancellation or nonpurchase subsets created with the sociometric methods.

As before, the commercial publishers bore the brunt of the cancellation or nonpurchase recommendations. Of the 44 titles recommended for such treatment, $28(63.6 \%)$ were those of foreign commercial publishers, $14(31.8 \%)$ belonged to U.S. commercial publishers, 1 was a foreign association title, and 1 -unsurprisingly, the Russian translation journal-was a U.S. association title. One-half of the titles in the subset recommended for cancellation or nonpurchase by the accounting method also belonged to the subset recommended for such treatment by the sociometric method based on total UIUC use. The accounting method recommended for cancellation or nonpurchase $18(75.0 \%)$ of the 24 titles 
common to all three subsets created by the sociometric measures. However, before one waxes enthusiastic over the accounting method, it should be pointed out that the UIUC Chemistry Library use database was of extraordinarily high quality-even covering unbound issues-and it required no fewer than 23,412 counts to be made over a three-month period for its construction. One has to question whether many libraries-especially ones with broader subject scopes-have the organizational and labor potential to construct such databases.

\section{The Generalization of the Case of CHEMISTRY: STRUCTURE OF THE Desired Universe of Serials}

\section{Correlation of Faculty SCORE With}

NUMBER OF TITLES AND COST

With the sets defined and the measures of ST value constructed and validated, an investigation was undertaken to map out the structure of the library market for ST serials as this market was revealed by the needs stated by the LSU faculty in the SRP survey. For this purpose, the desired universe of serials was used, which consisted of all those serials listed by the faculty on the SRP questionnaires regardless of whether these serials were on subscription at LSU Libraries. A fundamental feature of this market is the phenomenon of concentration, which arises from the skewed distributions caused by the probabilistic mechanisms underlying this market. This concentration manifests itself both in the relationships among the curriculum cores and within the curriculum cores themselves.

Concerning the former, five curriculum cores-Biology, Chemistry, Mathematics, Physics, and Zoology \& Physiology - accounted for the bulk of the titles, cost, and faculty score of the serials listed by the LSU faculty in the SRP survey. Although these cores represented only $15.2 \%$ of all the cores, they contained $38.0 \%$ of the titles that accounted for $55.0 \%$ of the total costs and $40.1 \%$ of the aggregate faculty score. The five dominant cores were most intimately related to six LSU academic units-the Depart- ments of Chemistry, Mathematics, Microbiology, Physics \& Astronomy, Plant Biology, and Zoology \& Physiology-that had furnished $93(23.7 \%)$ of the 392 respondents to the SRP survey.

Under these conditions, the question naturally arose as to whether there were any imbalances between the resources requested and the faculty making these requests. For example, the Mathematics curriculum core had the greatest number of titles, with 220 (9.9\%) of the 2,226 listed titles, but only 22 (5.6\%) of the 392 respondents were from the Department of Mathematics; whereas the Physics curriculum core was the highest in total costs, accounting for $\$ 203,873(15.1 \%)$ of the $\$ 1,349,350$ cost of the desired universe, but there were only $25(6.4 \%)$ respondents from the Department of Physics \& Astronomy.

To test for the imbalance, the total faculty scores of the curriculum cores were correlated with their number of titles and total costs, and the answer was a resounding no-there were no major imbalances between the number and costs of the titles in the various curriculum cores on the one hand, and their value to the LSU faculty as a whole on the other. The correlation of total faculty score was 0.84 with number of titles and 0.79 with total cost. Only one outlier was found, and this concerned the core Food Science, which accounted for $1.5 \%$ of the titles but only $0.5 \%$ of the faculty score. When this outlier was excluded, the correlation of faculty score with number of titles rose to 0.86 .

Two factors account for this lack of imbalance of the number and costs of the serials in the various curriculum cores with their value to the faculty as whole, despite the discrepancy with the number of faculty officially related to the cores. First, there is Garfield's law of concentration on the interrelationship among disciplines. Second, there is the heavy dependence of applied technology on basic science. All five of the dominant curriculum cores were for the most part constructed from the LC Q schedules. Moreover, the six LSU academic units to which they were most closely related were in the Colleges of Arts and Sciences and Basic 
Sciences-which are oriented more toward pure science - and not in the Colleges of Agriculture and Engineering -which are oriented more toward applied technology. These correlation tests stand as further proof that the management of ST serials should be based within the library on library parameters and not allocated out to the faculty on departmental bases.

\section{CONCENTRATION AND SEPARATION OF \\ VALUE AND COST}

The phenomenon of concentration within the curriculum cores followed the same pattern as that between the curriculum cores. With respect to costs, the percentage of titles accounting for $75 \%$ of total costs ranged from a low of $19.2 \%$ in General Science to a high of $50.0 \%$ in both Biological and Agricultural Engineering and Electrical Engineering. For all 33 curriculum cores, the average percentage of titles accounting for $75 \%$ of costs was $34.4 \%$. Concerning ST value, the percentage of titles responsible for $75 \%$ of faculty score ran from $9.6 \%$ in General Science to $50.0 \%$ in Industrial and Manufacturing Systems Engineering. The average percentage of titles accounting for $75 \%$ of faculty score in all 33 curriculum cores was $33.7 \%$-very close to the average for $75 \%$ of total costs.

Given this concentration of costs and ST value, it was decided to investigate whether the library market for ST journals manifests in other subject areas two main features that had been found in chemistry by the analysis of the data from the 1993 SRP pilot project with the LSU Department of Chemistry, i.e.: (1) that ST value plays no role in the price of ST serials, and (2) that the market bifurcates, with costs tending to concentrate on the serials of the commercial, largely foreign publishers and ST value tending to concentrate on the journals of the U.S. associations. Other researchers had found these features with methods that used impact factor. For its proper utilization, impact factor should be employed with costs also controlled for size, and such methods have the disadvantage of masking the huge effects of the skewed distri- butions operative in the library market for ST serials. The most famous case concerned physics and the work done by Barschall (1988) and Barschall and Arrington (1988). Barschall, a University of Wisconsin-Madison physicist, divided cost measured in cents per 1,000 characters by impact factor and came to the following conclusion (Barschall 1988, 57):

All the publishers whose journals have low average costs per character or low ratios of cost to impact are scientific societies or associations, while the publishers whose journals have high costs per character or high ratios of cost to impact are commercial firms.

Barschall's findings were replicated by other researchers in other fields. Applying Barschall's method in chemistry, Christensen (1992) estimated that association journals were about 4 times more cost effective than commercial ones. Ribbe $(1988 ; 1990 ; 1991)$ tried a slightly different approach in the geosciences, dividing cost per citable source item by impact factor, which he found to be highly correlated with the proportion of papers supported by grants from the National Science Foundation, U.S. Department of Energy, and the National Aeronautics and Space Administration. However, his results were similar, and he found that by his index association journals rated on the average 5.0 times more favorably than commercial ones in Geosciences, 3.3 times more favorably in Geology, and 4.4 times more favorably in Paleontology. Ribbe's findings were corroborated by Turner (1994) in a study of 274 journals of interest to estuarine and coastal scientists. Using both total citations and impact factor, Turner concluded (p. 724) that "on the average, professional societies often (but not always) publish relatively high impact articles at one-third to one-tenth the price of commercial for-profit publishers." Moline (1991) used the Spearman rank-order correlation to test the relationship of impact factor to cost in cents per 1,000 characters for mathematics journals. She made this test with her data defined into three different sets: commercial publishers; "other" publishers such as 
associations, university presses, and university mathematics departments; and commercial and "other" publishers together. No significant results at the 0.01 level were found for the first two sets, and with the commercial and "other" publishers combined Moline actually found a negative correlation of -0.38 significant at the 0.01 level. In a study of 5,399 journals in 12 scientific disciplines, Van Hooydonk (1995) found upon grouping the journals by country of publication that U.S. titles had a cost per article considerably lower than average but impact factors 1.5 times the average, constituting one of the few bargains in the ST serials market.

A number of researchers have utilized impact factor without correcting costs for size. For example, Baldwin and Baldwin (1989) visually compared impact factors to price for 1,048 journals in 15 subject categories, and came to the conclusion that (p. 128):

\section{... it is apparent that high price does not correlate necessarily with high impact fac- tor. ... Instead, journal price correlates more closely with the type of publisher which produces the title. Titles from com- mercial publishers cost on the average more than twice as much as titles from associa- tion, university, or government publishers and yet they did not have correspondingly higher impact factors.}

More questionable are the results of studies by Nisonger (1993) and Petersen (1992), because these researchers employed standard statistical techniques without correcting price for size. Nisonger's results fit the standard pattern, as he found no statistically significant correlation at the 0.05 level between institutional subscription prices and impact factors of genetics journals for the years 1980, 1985, and 1990. However, Petersen's findings for economics journals represent an anomaly, because of all the researchers whose work was reviewed, Petersen was the only one to find a positive and significant relationship of a journal's "impact" with its price.

To conduct his analysis, Petersen utilized a regression model in which 1990 price was made the dependent variable and the independent or causal variables encompassed the following factors: size (number of issues per year and pages per issue), circulation, presence or absence of advertising, type of publisher (commercial or nonprofit such as an association), country (U.S. or Canadian, British, European, or other), and "impact." For "impact" Petersen used a ranking constructed by Leibowitz and Palmer (1984) in the following complicated manner: a set of economics journals was chosen; this set was then ranked by total citations to these journals in 1980 to issues published between 1975 and 1979 to control for age; these total citations were then adjusted by excluding citations from noneconomics issues and reducing the weight of citations coming from the lesser-cited economics journals to emphasize the importance of the journal to the economics profession; and, finally, the adjusted citations were controlled for size by dividing them by the total number of characters published by the journals in the 1975-79 period. Not surprisingly, major discrepancies were found between this ranking and the most influential contemporaneous one established by peer ratings of academic economists.

Except for the positive relationship of "impact" to price, Petersen's findings followed the usual pattern: bigger journals measured by number of issues per year cost more; high circulation journals cost less; commercial journals cost more than nonprofit ones; and European journals cost more than U.S. or Canadian ones. As for his finding on "impact," this is highly dubious for the following reasons: he used 1990 prices unadjusted for size against 1980 citations adjusted for size by 1975-79 size measures; he violated Garfield's law of concentration by using a measure that deliberately excluded citations from other disciplines; and the ranking he used did not conform to contemporary peer ratings.

It should be pointed out that in none of the above studies did researchers take into account the effect of the higher impact factors of review journals.

To investigate the structure of the library market for ST journals, Evaluator 
TABLE 6

Characteristics on a Global Basis of the Publishers of the

SERIALS ACCOUNTING FOR:

\begin{tabular}{|c|c|c|c|c|c|c|}
\hline \multirow[b]{2}{*}{ Publisher Type } & \multicolumn{2}{|c|}{$75 \%$ of Total Costs } & \multicolumn{2}{|c|}{$75 \%$ of Faculty Score } & \multicolumn{2}{|c|}{$\begin{array}{l}\text { Evaluator Recom- } \\
\text { mendations for } \\
\text { Cancellation or } \\
\text { Nonpurchase }\end{array}$} \\
\hline & No. & $\%$ & No. & $\%$ & No. & $\%$ \\
\hline \multicolumn{7}{|l|}{ United States } \\
\hline Commercial & 105 & 14.5 & 115 & 16.3 & 57 & 13.9 \\
\hline Association & 80 & 11.1 & 227 & 32.1 & 33 & 8.0 \\
\hline University Press & 8 & 1.1 & 9 & 1.3 & 4 & 1,0 \\
\hline Miscellaneous Nonprofit ${ }^{1}$ & 3 & 0.4 & 7 & 1.0 & 0 & 0.0 \\
\hline \multicolumn{7}{|l|}{ Foreign } \\
\hline Commercial & 480 & 66.4 & 276 & 39.0 & 290 & 70.6 \\
\hline Association & 25 & 3.5 & 49 & 6.9 & 15 & 3.6 \\
\hline University Press & 16 & 2.2 & 13 & 1.8 & 9 & 2.2 \\
\hline Miscellaneous Nonprofit ${ }^{1}$ & 6 & 0.8 & 11 & 1.6 & 3 & 0.7 \\
\hline TOTALS & 723 & 100.0 & 707 & 100.0 & 411 & 100.0 \\
\hline
\end{tabular}

lThe Miscellaneous Nonprofit category contains academic departments, institutes, museums, etc, acting as publishers.

runs were made for the purpose of measuring the trade-offs in costs versus ST value within the desired universe of serials-i.e., for every title named by the LSU faculty in the SRP survey-in all 33 curriculum cores. For this investigation, the Evaluator's second algorithm was once again chosen, and again the runs were made at the default settings of trying to reduce total costs by $75 \%$ while retaining $75 \%$ of total ST value. Of primary interest was the type of publisher involved in these trade-offs.

The lack of correlation between price and ST value became immediately apparent. The lowest trade-off in terms of loss of ST value for cost reduction was in Food Science, where a $24.3 \%$ reduction in costs could be achieved with the loss of $9.5 \%$ in total faculty score - a favorable ratio of 2.6 to 1 . The highest trade-off in terms of loss of ST value for cost reduction was in General Science, where costs could be reduced by $73.1 \%$ for only a loss of $4.4 \%$ in total faculty score - a favorable ratio of 16.6 to 1 . For all 33 curriculum cores the average cost reduction was $38.6 \%$ for an average loss in total faculty score of $7.7 \%$ - a favorable ratio of 5 to 1 .

\section{TyPes of Publishers InVolved in the} IMBALANCE BETWEEN ST VALUE AND COST An examination of the types of publishers involved in these trade-offs corroborated in general the findings of Bensman (1996). For purposes of this examination, publishers were first divided into U.S. and foreign. Then these two sets were each further divided into the following subsets: commercial, association, university press, and miscellaneous nonprofit (which contained academic departments, institutes, museums, etc., acting as publishers). It should be emphasized that serials published under association auspices but produced and marketed by commercial publishers were defined as commercial.

Table 6 presents the findings on the types of publishers involved in the trade-off in costs versus ST value on a global basis by aggregating the data from 
all the curriculum cores. In this table, the dominance of the U.S. association, U.S. commercial, and foreign commercial publishers at the upper ends of the cost and ST value distributions is visible. These three types of publishers produced $92.0 \%$ of the serials that accounted for $75.0 \%$ of total costs per curriculum core and $87.4 \%$ of the serials that accounted for $75.0 \%$ of total faculty score per core. However, their shares in these two sets were remarkably different.

On the one hand, of the titles that accounted for $75.0 \%$ of total costs in the different curriculum cores, the U.S. associations published only $11.1 \%$, whereas the U.S. commercial publishers and foreign commercial publishers respectively produced $14.5 \%$ and $66.4 \%$, which together totaled $80.9 \%$ of these titles. On the other hand, of the serials that accounted for $75.0 \%$ of total faculty score in the various curriculum cores, the U.S. association serials represented $32.1 \%$ of the titles, whereas the U.S. commercial publishers and foreign commercial publishers were respectively responsible for $16.3 \%$ and $39.0 \%$, which added up to $55.3 \%$ of these titles.

Thus, in a comparison of total cost to total faculty score, the share of the U.S. associations rose from $11.1 \%$ to $32.1 \%$, and the proportion of the commercial publishers dropped from $80.9 \%$ to $55.3 \%$, still a respectable amount that demonstrates the need to take the output of the commercial publishers seriously into consideration. It should be noted that in a small way, the performance of the U.S. associations is mirrored by the foreign associations, whose share rose from $3.5 \%$ of the titles accounting for $75 \%$ of total costs to $6.9 \%$ of the titles accounting for total faculty score.

The basic dichotomy in the library market for ST serials is emphasized by the Evaluator recommendations for cancellation or nonpurchase. Here the foreign commercial publishers alone produced $70.6 \%$ of the titles recommended for such treatment, dwarfing the shares of all other types of publishers. Together, the U.S. and foreign commercial publishers were responsible for $84.5 \%$ of the titles recom- mended by the Evaluator for cancellation or nonpurchase.

The same patterns emerge in table 7 , which summarizes the data by curriculum core. Once again the dominant role of the U.S. associations, U.S. commercial publishers, and foreign commercial publishers at the upper ends of the cost and ST value distributions is visible. The serials of these publishers not only were represented in a consistently higher percentage of curriculum cores but also accounted on the average for a much higher percentage of the serials responsible for $75 \%$ of the total cost and faculty score in the curriculum cores in which they were represented than those of the other publishers.

However, what is particularly striking in table 7 is the divergence of the serials of the U.S. associations and foreign commercial publishers in terms of costs and ST value. Thus, in terms of the serials accounting for $75 \%$ of the costs, U.S. association serials were represented in $69.7 \%$ of the curriculum cores, being on the average $17.5 \%$ of these titles in their respective cores, whereas foreign commercial publishers were present in $100.0 \%$ of the curriculum cores and produced on the average $64.9 \%$ of these titles in the cores. When the serials responsible for $75.0 \%$ of total faculty score were considered, U.S. associations were represented in $100.0 \%$ of the curriculum cores and accounted for on the average $36.9 \%$ of these serials in the cores, whereas foreign commercial publishers had serials in $97.0 \%$ of the curriculum cores and produced on the average $37.0 \%$ of these titles in the cores. As is evident, the average share of the U.S. associations rose dramatically in the transition from cost to faculty score, whereas precisely the opposite happened with respect to the foreign commercial publishers.

This dichotomy between cost and ST value was emphasized in the cancellation or nonpurchase recommendations of the Evaluator for each curriculum core. Whereas the titles of the U.S. associations averaged $18.0 \%$ of the cancellation or nonpurchase recommendations in $42.4 \%$ of the curriculum cores, those of the foreign commercial publishers averaged a stunning $71.3 \%$ of these recommendations 
212/ LRTS - 42(3) • Bensman and Wilder

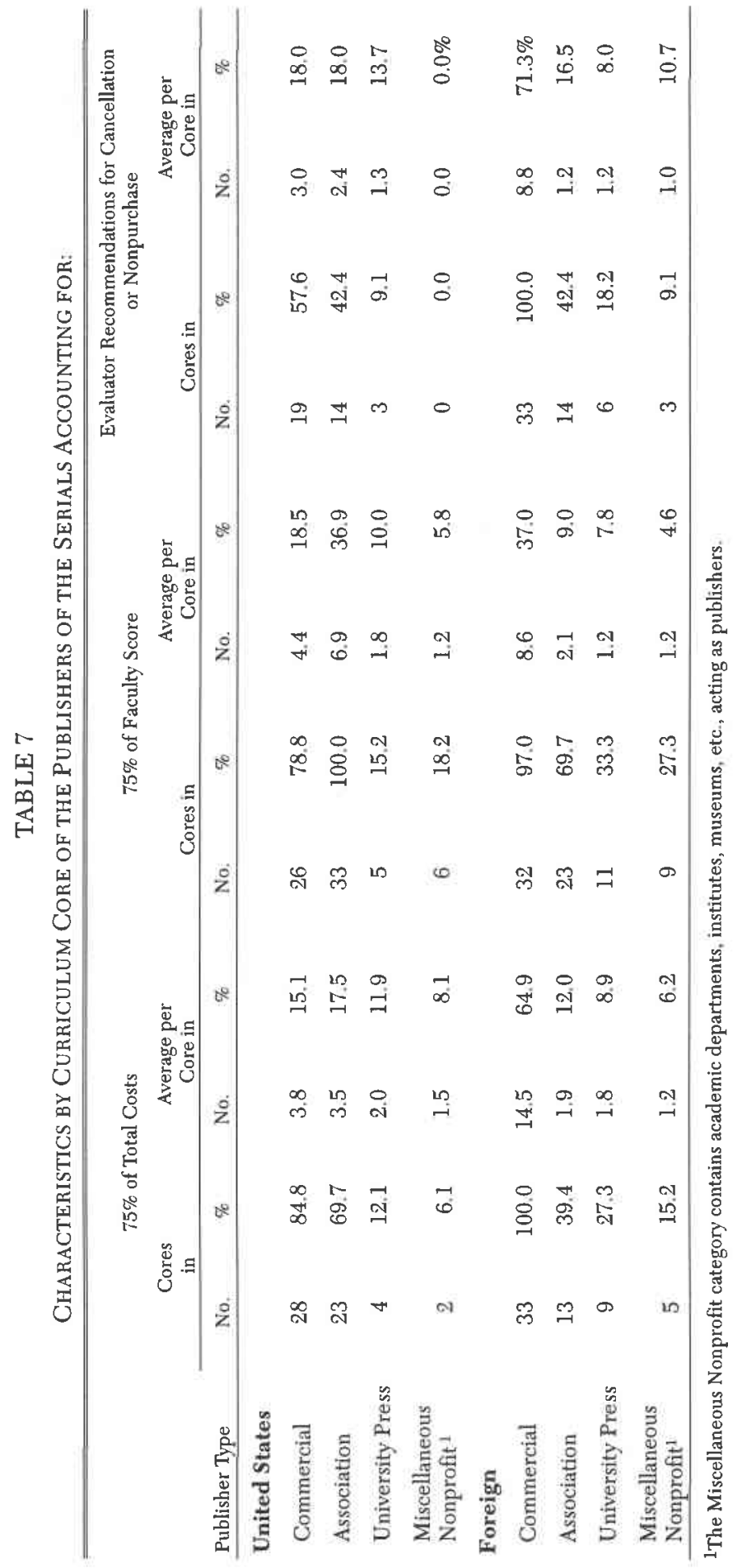


in $100.0 \%$ of the curriculum cores. However, it once again must be emphasized that the foreign commercial publishers produce enough serials of sufficient ST quality to merit serious consideration.

The basic divergence between cost and value in the library market for ST serials became even more pronounced when the anomaly presented by the Computer Science and Electrical Engineering curriculum cores was taken into account. In both of these cores, U.S. association titles predominated in the Evaluator recommendations for cancellation or nonpurchase, and this type of title accounted for $50.0 \%$ of such recommendations in the former and $46.2 \%$ in the latter. Altogether these two curriculum cores contained $16(48.5 \%)$ of the 33 U.S. association publications recommended by the Evaluator for cancellation or nonpurchase.

The two departments at the basis of these cores, Computer Science and Electrical and Computer Engineering, were closely linked in the SRP survey, and as a result of the high overlap in the serials selections on the part of the faculty of these two departments, it was decided to make the serials classed in the computer engineering part of the LC schedules (TK7885-7895) part of the Computer Science curriculum core to compensate for the low response rate of the Department of Computer Science to the SRP survey. A closer analysis of the Evaluator recommendations for cancellation or nonpurchase revealed that the anomaly was caused by the serials published by the Institute of Electrical and Electronics Engineers (IEEE).

The large and complicated bibliographic structure of the IEEE publications had a large role in the failure of perception that had led to the zero class in faculty score, and this structure had probably also led to the systematic underscoring of these serials. However, the ST value of the IEEE publications was demonstrated by the concentration of NOTIS use upon them. The importance of the IEEE serials manifested itself in the Evaluator cancellation or nonpurchase recommendations, because the diver- gence of cost and ST value was more pronounced for the titles of the commercial publishers than for these IEEE titles. Thus, in Computer Science the trade-offs in terms of budgetary reduction for ST value loss in terms of faculty score were 5.8 to 1 for U.S. commercial serials and 4.5 to 1 for foreign commercial ones, whereas for IEEE titles it was only 2.8 to 1. This phenomenon was repeated in Electrical Engineering. Here the trade-offs of budgetary reduction for ST value loss in terms of faculty score were 4.6 to 1 for U.S. commercial publications and 9.7 to 1 for foreign commercial titles, whereas for IEEE serials it was merely 1.9 to 1 .

With the exclusion of the Computer Science and Electrical Engineering cores, the share of U.S. association serials in the total number of Evaluator cancellation or nonpurchase recommendations drops from $33(8.0 \%)$ of 411 to 17 (4.3\%) of 395. As for the average number of titles per curriculum core in which such recommendations were made, it fell from 2.4 to 1.4 in contrast to the that of the foreign commercial publishers, which actually rose from 8.8 per core to 9.1 . With respect to the latter, cancellation or nonpurchase recommendations of U.S. association titles were once again made in less than half of the curriculums cores (12) than such recommendations were made for foreign commercial ones (31).

\section{The Trade-OfF}

StruCtuRE OF THE WORKING UNIVERSE OF Serials and Corrections to Faculty Score As stated above, the ultimate purpose of the exercise with the data collected by the SRP survey was to determine whether it would be possible to bring the serials holdings of LSU Libraries up to $75 \%$ of the ST value perceived by the faculty in the "desired universe" of the 33 curriculum cores with the resources remaining in the "working universe" of these cores even after the massive cancellations and the policy of adding no new subscriptions of the late 1980s and early 1990s.

Briefly recapitulated, the "desired universe" was all those serials listed by the 
LSU faculty on their SRP survey forms within the 45-title limit, whereas the "working universe" consisted of the following three categories: (1) all the serials within the desired universe on current subscription at LSU Libraries; (2) the faculty score zero class of serials on current subscription at LSU Libraries, i.e., those titles classed within the 33 curriculum cores either not listed by the faculty on the survey forms or listed beyond the 45-title limit; and (3) those highly rated titles that accounted for $75 \%$ of the faculty score within the desired universe of each curriculum core but that were not on current subscription at LSU Libraries. This working universe consisted of 1,687 titles with an aggregate faculty score of 48,161 and costing $\$ 1,081,989$. The mean faculty score per title was 28.5 , and the mean cost per title was $\$ 641.37$.

Evaluator runs were made on the working universe with the second algorithm set at the default values of trying to reduce the total costs by $75 \%$ while retaining $75 \%$ of total ST value. Given the purpose of the exercise, it was decided to place all the titles in the third category of the working universe above on subscription, even in those cases where they were no longer among the highly ranked titles accounting for $75 \%$ of faculty score due to a change in the total faculty score divisor caused by the differing serials composition of the desired and working universe cores. Moreover, the decision was made to cancel all titles in the faculty score zero class despite some of these titles not being among the highly priced ones that accounted for $75 \%$ of the total cost of their respective curriculum cores.

Due to the faults discovered in faculty ratings during their validation, it was deemed necessary to adjust both the subscription and cancellation decisions by applying citation and library use correctives to the faculty score measure. The adjustment to subscriptions necessitated a restructuring of the working universe, and it concerned the highly skewed character of informetric distributions. As has been seen above, on the average, when the serials were ranked in descending order by faculty score, more titles were required to raise the faculty score in each curriculum core another $25 \%$ from $51 \%$ to $75 \%$ than to reach the first $50 \%$. This phenomenon resulted from the rapidly decreasing interval distances between the ordinal ranks as one went down the list. The titles that accounted for the first $50 \%$ were not considered a problem, because the level of faculty consensus was so high. However, the faculty scores of the serials in the next $25 \%$ were much smaller, and at the bottom of the range approximated the scores of those at the top of the range of the lower majority of the titles accounting for only $25 \%$ of the faculty score. Therefore the decision was made to eliminate from the working universe those serials not on subscription at LSU Libraries and located in the range from $51 \%$ to $75 \%$ of faculty score of the desired universe of the curriculum cores if they did not also meet the criterion of having an impact factor above the median impact factor of the largest of their respective ISI subject groups. Before making this adjustment, it was considered necessary to place on subscription 186 titles with an aggregate faculty score of 6,888 and a total cost of $\$ 114,066$. The adjustment reduced the subscription list by 68 titles $(36.6 \%)$ to 118 , the added aggregate faculty score by $1,568(22.8 \%)$ to 5,320 , and the total cost of the new subscriptions by $\$ 32,184$ ( $28.2 \%$ ) to $\$ 81,882$. As expected, the mean faculty score of the serials recommended for subscription rose $21.9 \%$ from 37.0 to 45.1 , but their mean price also increased $13.2 \%$ from $\$ 613.26$ to $\$ 693.92$. The elimination of the low impact factor titles from the working universe reduced the number of titles in this universe by $4.0 \%$ to 1,619 , the aggregate faculty score by $3.3 \%$ to 46,593 , and the total cost by $3.0 \%$ to $\$ 1,049,805$. In return, the mean faculty score per title in the adjusted working universe rose by $1.1 \%$ to 28.8 , and the mean cost per title also rose by $1.1 \%$ to $\$ 648.43$.

The adjustments to cancellations were regarded as necessary not only to correct for errors that resulted from the small differences in interval distances at the borderline of the highly rated titles accounting for $75 \%$ of the faculty score with the 
lower rated tiles accounting for only $25 \%$ of the faculty score but also to offset the complete failure in faculty perception apparent in the high NOTIS use of faculty score zero class titles. Unlike the subscription adjustments, those to cancellations did not require a restructuring of the working universe. The cancellation adjustments were twofold: (1) no title could be canceled if it had an impact factor above the median impact factor of the largest of its ISI subject groups; and (2) none of the 80 titles accounting for $80.2 \%$ of the NOTIS use of the faculty score zero class titles could be canceled. Without these adjustments, 528 titles with an aggregate faculty score of 2,336 and a total cost of $\$ 404,674$ were subject to cancellation. The two adjustments reduced the number of canceled titles by 186 ( $35.2 \%)$ to 342 , the lost aggregate faculty score by $1,002(42.9 \%)$ to 1,334 , and the cost reduction by $\$ 182,265(45.0 \%)$ to $\$ 222,409$. Surprisingly, the mean faculty score of the canceled titles fell $11.4 \%$ from 4.4 to 3.9 as a result of the adjustments. This had been totally unexpected because it had been thought that the elimination of so many titles with zero scores would raise the mean faculty score of the canceled titles, and this phenomenon again testifies to the strong correlation of faculty ratings with citation counts. However, the mean cost of the canceled titles also fell $-15.1 \%$ from $\$ 766.43$ to $\$ 650.32$.

Tables 8 and 9 show the working universe with the new subscriptions and cancellations resulting from the Evaluator runs. As is usual with databases in library and information science, the working universe was characterized by highly skewed statistical distributions. Five (15.2\%) of the curriculum cores - Biology, Chemistry, Mathematics, Physics, and Zoology \& Physiology-dominated in number of $\mathrm{t}$ thes $(39.7 \%)$, faculty score $(41.0 \%)$, and costs $(59.3 \%)$. However, faculty score's high Spearman rank-order correlation coefficients of 0.86 with number of titles and 0.82 with costs demonstrated that the number of titles and costs of the curriculum cores were roughly in accord with their importance to LSU's ST faculty as a whole.
Interestingly enough, the five dominant curriculum cores were all derived from the $Q$ or basic science schedules of the LC classification system and were related to academic units in the Colleges of Basic Sciences and Arts and Science. Therefore, the correspondence of the cores in terms of titles and costs to their importance can be seen not only as the result of Garfield's law of concentration, but also of the reliance of technology represented by the Colleges of Agriculture and Engineering on basic science literature.

However, what is also noticeable is that the concentration of costs on these five dominant cores was higher than the concentration of titles and faculty score. This phenomenon was the result of the high average costs of the titles in Chemistry and Physics, which alone accounted for $33.8 \%$ of the total costs of the working universe. Physics titles had the highest mean cost of $\$ 1,902.66$, which was 3.8 times higher than the $\$ 504.57$ mean cost for all the cores and 2.2 times higher than third-highest mean cost of $\$ 849.54$ for Biochemistry. Chemistry's secondhighest mean cost of $\$ 1,557.60$ was 3.1 times more than the mean cost for all the cores and 1.8 times more than thirdhighest Biochemistry.

\section{Characteristics of Serials Evaluator}

RECOMMENDATIONS FOR SUBSCRIPTIONS The 118 titles recommended for subscription as a result of the above processs were located in 31 of the 33 curriculum cores. Two small cores-Biological and Agricultural Engineering and Fisheries, the former related to the College of Engineering, the latter to the College of Agriculture-required no new subscriptions. The new subscriptions were also characterized by highly skewed distributions. Of the curriculum cores requiring new subscriptions, five accounted for 41 $(34.7 \%)$ of the 118 new subscriptions, $1,917(36.0 \%)$ of the 5,320 faculty score points of the new subscriptions, and $\$ 38,840(47.4 \%)$ of the $\$ 81,882$ cost of the new subscriptions. However, unlike the measures for the total size of the cores, there was not a complete overlap of the five dominant curriculum cores in new 


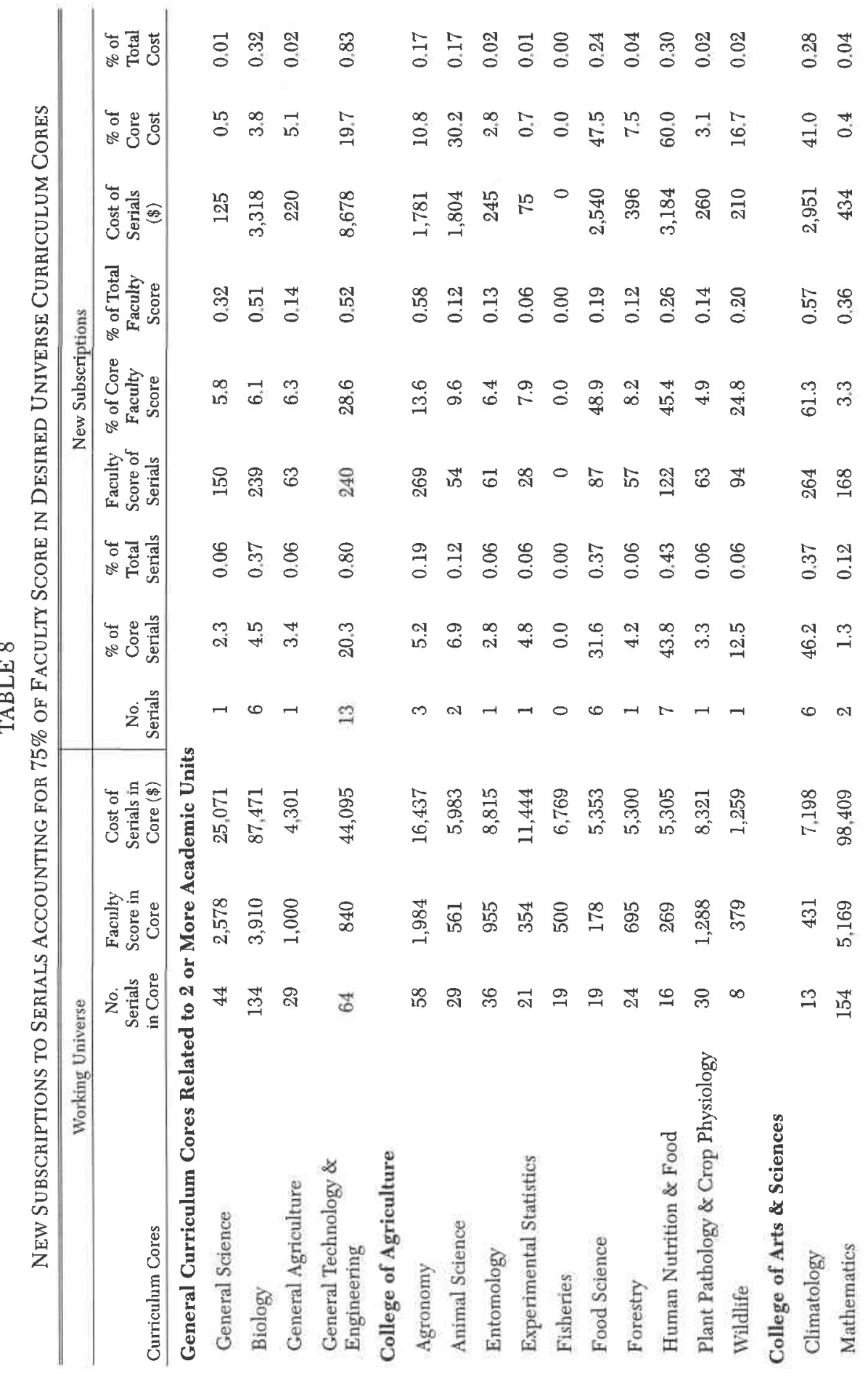




\section{LRTS • 42(3) - ST Serials Holdings Optimization /217}

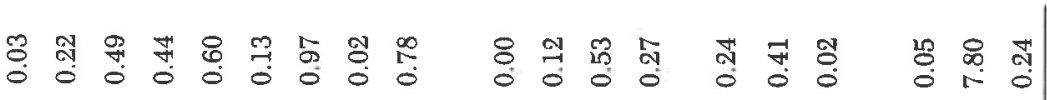

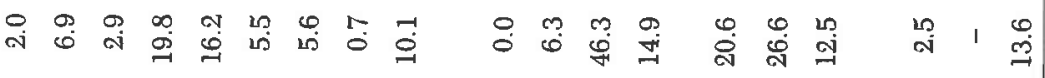

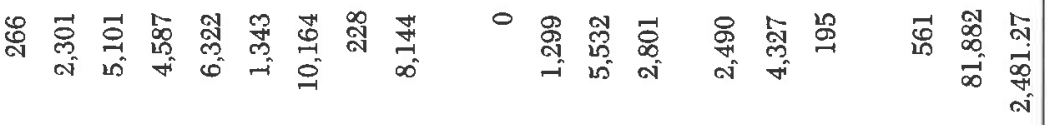

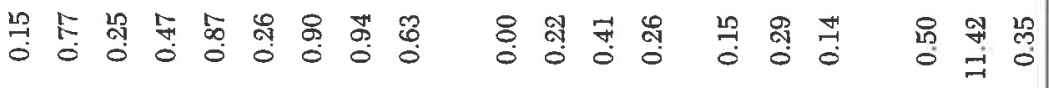

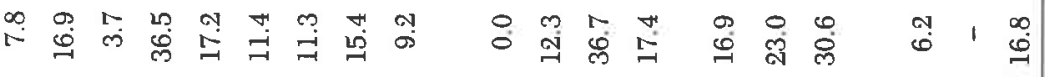

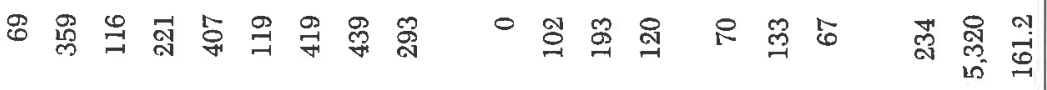

궝 궁 $\frac{9}{0}$ 동

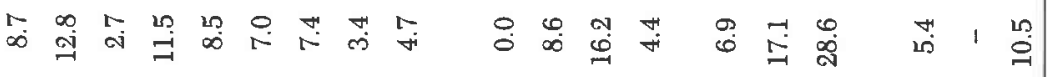

ब nू

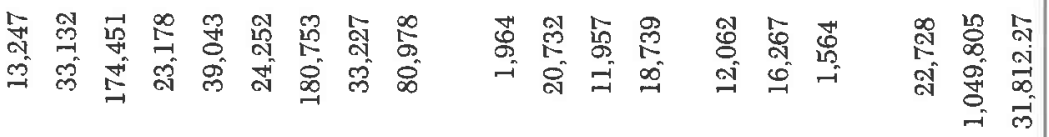

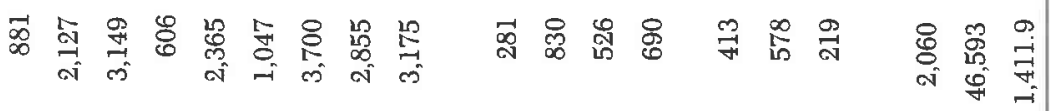

๙

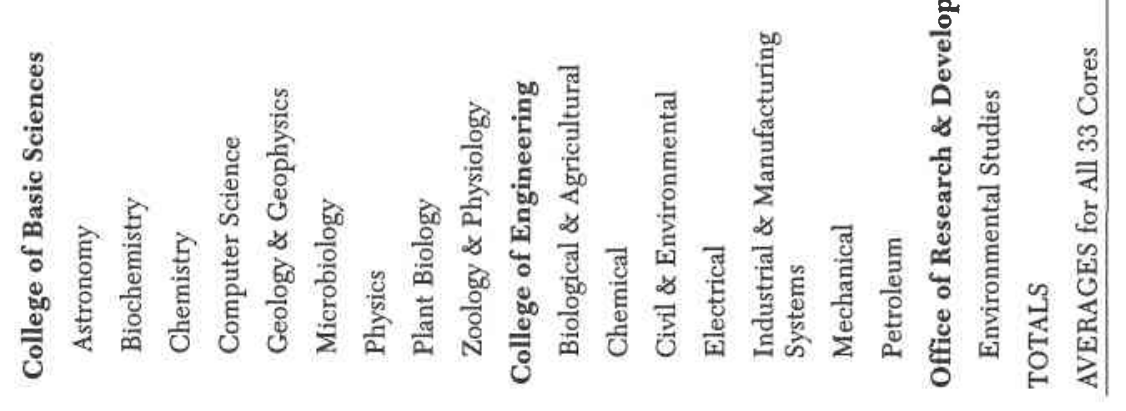




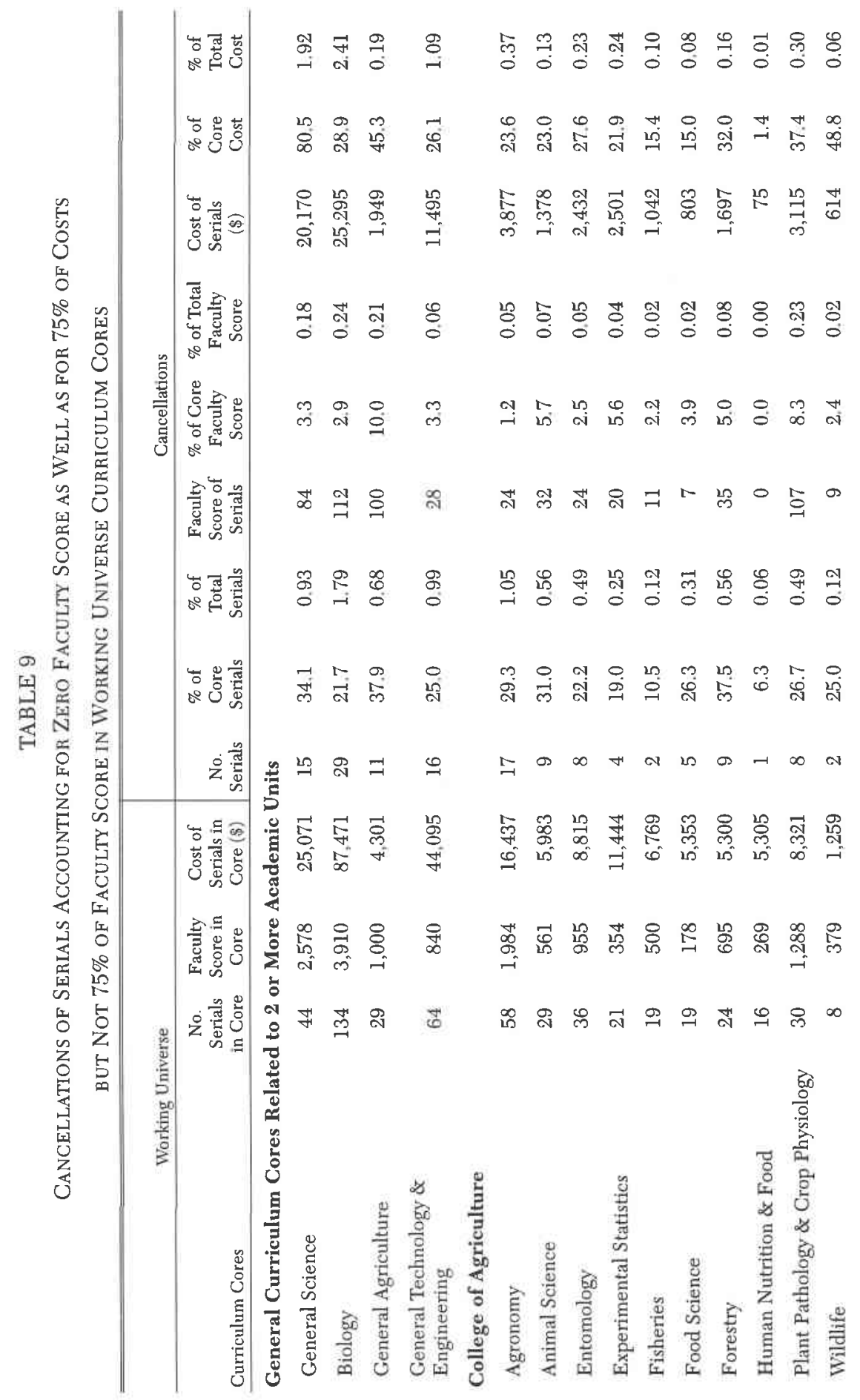


잉

每

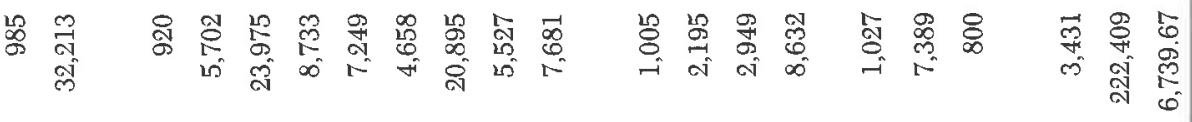

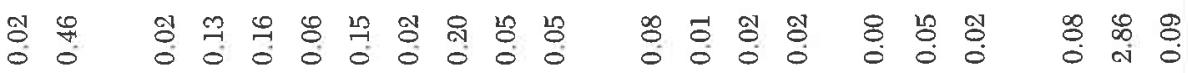

걱

の

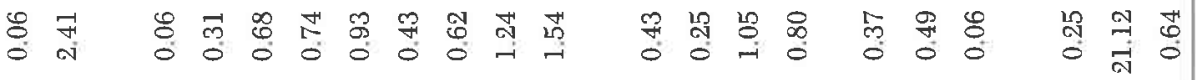

Г

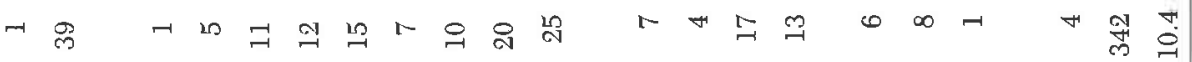

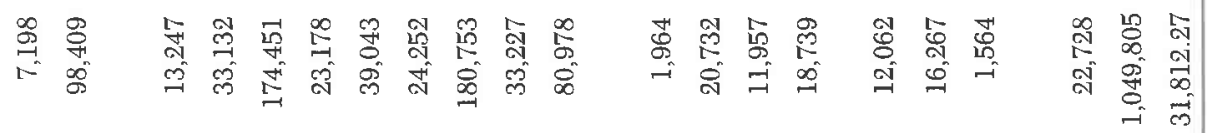

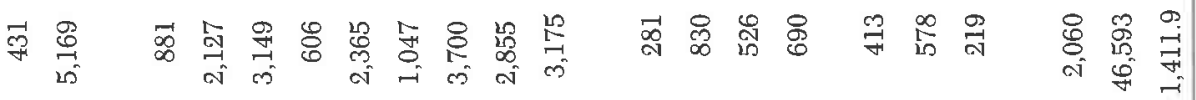

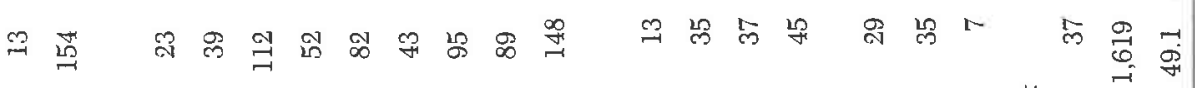

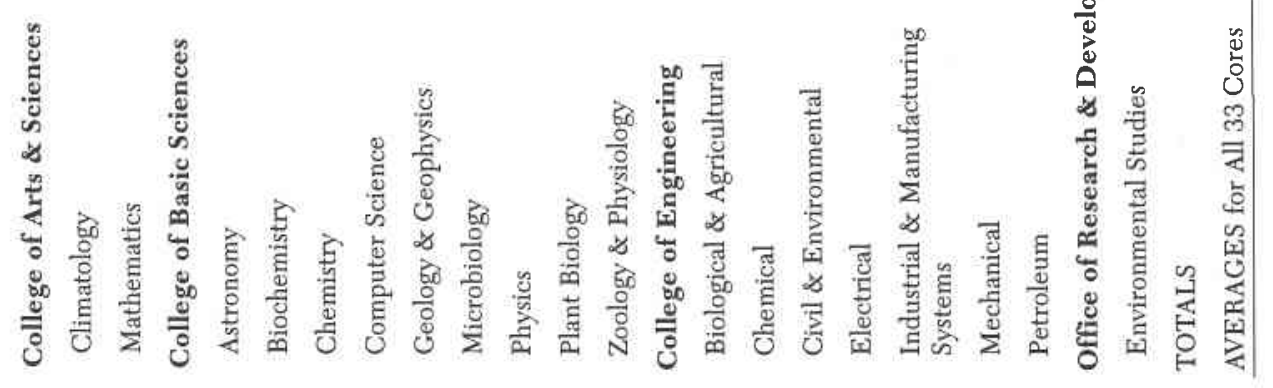


subscriptions. Only three cores-Geology \& Geophysics, Physics, and Zoology \& Physiology-appeared in the top five cores on all three aspects of new subscription size (i.e., number of titles), faculty score, and costs. Physics and Zoology \& Physiology had consistently appeared among the five dominant cores in total titles, faculty score, and costs, whereas Geology \& Geophysics had always appeared among the top eight cores on these measures.

In their distribution over the curriculum cores, all three new subscription measures of size were highly and positively intercorrelated. The Spearman rank-order correlation coefficients of new subscription titles, faculty score, and cost over the cores ran from 0.64 to 0.89 , with the correlation of new subscription cost with new subscription faculty score at the bottom of the range and with new subscription titles at the top of the range. However, a different picture emerged when it came to the correlations of the new subscription measures with the overall core size measures. Here only total number of core titles and total core cost correlated with all three measures of new subscription size with the Spearman rank-order coefficients ranging from 0.45 to 0.71 . The anomaly was total core faculty score, which had no significant correlation with either new subscription titles or cost, although it had a significant Spearman rank-order coefficient of 0.57 with new subscription faculty score.

The reason for the anomaly of the lack of significant correlations of total core faculty score with both new subscription titles and cost emerged during the analysis of the new subscription measures in terms of their percentage relationship to their equivalent size measures of their respective cores. Once again the distributions were highly and positively skewed. In terms of the percentage of new subscription titles to total core titles, the top five cores ranged from $20.3 \%$ to $46.2 \%$ with a mean of $34.1 \%$, compared to the overall mean $10.5 \%$ for all 33 cores. In terms of percentage of new subscription faculty score to total core faculty score, the top five cores ranged from $36.5 \%$ to
$61.3 \%$ with a mean of $45.8 \%$, compared to the overall mean of $16.8 \%$ for all 33 curriculum cores. And in terms of percentage of new subscription cost to total core cost, the top five cores ranged from $30.2 \%$ to $60.0 \%$ with a mean of $45.0 \%$, compared to the overall mean of $13.6 \%$ for all 33 cores. Three cores-Climatology, Food Science, and Human Nutrition and Food-consistently appeared among the five dominant cores in this respect, and, unlike the finding with the new subscription measures in actual numbers, these three cores were always among the smaller ten cores in terms of total titles, faculty score, and costs.

Spearman rank-order correlation tests were performed to analyze the new subscription measures as percentages of their respective core measures in the following three respects: (1) their relationship to each other, (2) their relationship to the new subscription measures in actual numbers, and (3) their relationship to total core size measures. Concerning the first, the new subscription measures as percentages of their respective core measures were highly intercorrelated on all aspects of title number, faculty score, and costs, with the coefficients ranging from 0.79 to 0.88 .

However, when it came to the relationship to new subscription measures as percentages of their respective core measures to these measures in actual numbers, the same discrepancy appeared as was found with the correlation of total core size measures with new subscription measures in actual numbers. The new subscription subscription measures as percentages of their respective core measures correlated well with these measures in actual numbers on the aspects of titles and cost with coefficients ranging from 0.47 to 0.63 . In contrast, the faculty score aspects of these new subscription measures had a significant correlation only with each other $(0.36)$ but no significant correlations with the measures on the aspects of title number and cost.

The meaning of this phenomenon became clear with the correlation tests of the new subscription measures as percentages of their respective core measure 
to the total core size measures. Here the only significant correlations were those of total core faculty score with new subscription measures as percentages of their respective core measures on all three aspects of title number, faculty score, and cost. These correlations were all negative, ranging from -0.44 to -0.47 , i.e., the lower the total faculty score of the core, the higher the new subscriptions as percentages of core titles, faculty score, and cost.

The implications of this finding are obvious: the ST serials holdings of LSU Libraries tended to be more damaged in those subject areas where faculty interest and political power were weaker. Such a conclusion is buttressed by the Spearman rank-order coefficient of 0.56 found above between the percentage faculty response of academic units to the SRP survey and the 1993 National Research Council peer ratings of these units' scholarly quality, where such comparisons could be made. The latter finding was cited as evidence that the faculty who were engaged in research that was recognized at the national level tended to have more concern for the state of LSU Libraries' serials holdings.

For purposes of deeper analysis, the new subscription titles were stratified into those located in the top $50 \%$ of the faculty score in the desired universe of their respective curriculum cores and those located in the midrange of the faculty score from $51 \%$ to $75 \%$. In the ensuing discussion, the first category will be described as the "high faculty score" set, and the second category will be called the "mid-faculty score" set. The high faculty score set contained 53 of the 118 new subscription titles, and the mid-faculty score set had 65 of these titles. Of the titles in the high faculty score set, I5 (28.3\%) were U.S. association serials.

The new subscriptions for both the high faculty score and the mid-faculty score sets were located in 25 curriculum cores, 6 fewer than the 31 cores that required "overall" new subscriptions, i.e., the combined new subscriptions from both sets. However, there was a major difference between the six curriculum cores that required no further high faculty score new subscriptions and the six needing no further mid-faculty score new subscriptions. The former tended to be concentrated either in the general cores related to two or more academic units or in the cores related to College of Basic Sciences. Five-Astronomy, Biology, Chemistry, General Agriculture, and General Science-were of this nature, whereas the sixth, Forestry, resembled the two cores that required no new subscriptions at all in that it was a smaller core related to a technological unit, in this case the College of Agriculture. From this perspective, the eight cores that required no new high faculty score subscriptions were evenly split between basic science and technology.

In contrast, the six cores that required no new mid-faculty score subscriptions resembled for the most part the two that required no new subscriptions at all in that they were generally small cores that related to academic units engaged in technology and not basic science. FourEntomology, Experimental Statistics, Plant Pathology \& Crop Physiology, and Wildlife-were related to the College of Agriculture, and one-Petroleum Engineering - was related to the College of Engineering. The sixth such core was Mathematics, which was connected with the College of Arts \& Sciences. Taken all together, the eight curriculum cores that needed no new mid-faculty score subscriptions broke down into seven related to technology and one to basic science.

The mean faculty score of the overall new subscription titles was 45.1. In comparison, the high faculty score set average on this measure was 51.8, and the mid-faculty score set average was 39.6. The same pattern held in terms of costs: whereas the mean cost of the overall new subscription titles was $\$ 693.92$, for high faculty score titles it was $\$ 753.74$, and for mid-faculty score titles, $\$ 645.14$. Nevertheless, the higher ST value of the high faculty score titles overcame their price disadvantage on a global basis. These titles accounted for $44.9 \%$ of the overall new subscription titles but $51.6 \%$ (2,747 of 5,320 ) of the faculty score points found in the overall new subscription set and $48.8 \%$ $(\$ 39,948$ of $\$ 81,882)$ of the cost of this set. 
The advantage of the high faculty score titles over the mid-faculty score titles in terms of global ST value and cost held true when averaged for all 33 curriculum cores. Of the mean of 3.6 overall new subscription titles per core, 1.6 was attributable to the high faculty score set, and 2.0 to the mid-faculty score set. The reverse held true for the means of the overall new subscription titles for the 33 cores in terms of faculty score and cost. Concerning the former, the mean of 161.2 overall new subscription faculty score points per core broke into 83.2 for the high faculty score titles and $\mathbf{7 8 . 0}$ for the mid-faculty score titles, whereas the mean overall new subscription cost of $\$ 2,481.27$ per core divided into $\$ 1,210.54$ for the high faculty score set and $\$ 1,270.73$ for the mid-faculty score set.

In the manner characteristic of library and information science, both the high and the mid-faculty score distributions were highly and positively skewed, manifesting a tendency to concentrate in a few curriculum cores. Concerning the high faculty score distributions, five cores accounted for $22(41.5 \%)$ of the 53 of the high faculty score titles, 978 (35.6\%) of the 2,747 faculty score points attributable to these titles, and $\$ 22,266$ ( $55.7 \%$ ) of the $\$ 39,948$ cost of these titles. Interestingly, there was no overlap among the five dominant cores on these high faculty score measures, and no Spearman rank-order correlation coefficients of these measures with core size measures were significant except for the ones of high faculty score points with total number of core titles (0.38) and total core costs (0.39).

As with the high faculty score distributions, those for the mid-faculty score new subscription measures followed the pattern of concentrating on a few cores. Here five dominant cores accounted for 31 $(47.7 \%)$ of the 65 mid-faculty score titles, $1,204(46.8 \%)$ of the 2,573 faculty score points attributable to these titles, and $\$ 23,036(54.9 \%)$ of the total $\$ 41,934$ cost of these titles. However, unlike the high faculty score titles, there was an overlap of the mid-faculty score measures on two cores, Biology and Physics, which were among the five cores dominant on all measures of core size. Furthermore, every mid-faculty score measure had significant positive Spearman rank-order coefficients ranging from 0.42 to 0.65 with all measures of total core size except in one case that involved the relationship of mid-faculty score new subscription cost to total core faculty score.

From this finding it is evident that mid-faculty score new subscriptions were related to core size, while high faculty score new subscriptions were not. Moreover, whereas both the high faculty score and mid-faculty score new subscription measures tended to be highly correlated among themselves and with overall new subscription measures, they showed little relationship between each other, and for the most part the Spearman rank-order coefficients between the high faculty score and mid-faculty score new subscription measures were not significant.

An extremely interesting picture emerged from the analysis of the high faculty score and mid-faculty score new subscription measures as percentages of their respective core measures. Here, once again, the phenomenon of concentration manifested itself. Concerning the high faculty score measures, in terms of percentage of total core titles, the highest 5 cores ranged from $14.3 \%$ to $30.8 \%$ with a mean of $25.0 \%$, compared to the overall new subscription mean of $10.5 \%$ for the 33 cores. In terms of percentage of total core faculty score, the highest 5 cores ranged from $24.8 \%$ to $49.7 \%$ with a mean of $36.7 \%$, compared to the overall new subscription mean of $16.8 \%$ for the 33 cores. And in terms of percentage of total core cost, the highest 5 cores ranged from $19.1 \%$ to $39.2 \%$ with a mean of $28.5 \%$, compared to the overall new subscription mean of $13.6 \%$ for the 33 cores.

As for the mid-faculty score measures, in terms of percentage of total core titles, the highest 5 cores ranged from $8.7 \%$ to $18.8 \%$ with a mean of $13.8 \%$, compared to the high faculty score mean of $25.0 \%$ and the overall mean of $10.5 \%$. In terms of percentage of total core faculty score, the highest 5 cores ranged from $11.6 \%$ to $21.6 \%$ with a mean of $14.7 \%$, compared to the high faculty score mean of $36.7 \%$ and 
the overall mean of $16.8 \%$. And in terms of percentage of total core cost, the highest 5 cores ranged from $16.1 \%$ to $30.3 \%$ with a mean of $22.1 \%$, compared to the high faculty score mean of $28.5 \%$ and the overall mean of $13.6 \%$.

The most significant revelation of these comparisons of mean core percentages is that the high faculty score new subscriptions tended to have a much greater impact than the mid-faculty score ones. This impression was reinforced by the finding that the mean percentages of the overall new subscription measures as percentages of their respective curriculum core measures broke down in the following manner: of the mean $10.5 \%$ of overall new subscription titles per core, $6.2 \%$ were high faculty score titles and $4.3 \%$ were mid-faculty score titles; of the mean $16.8 \%$ of overall new subscription faculty score, roughly $11.3 \%$ came from high faculty scores and $5.5 \%$ from mid-faculty scores; and of the mean $13.6 \%$ of overall new subscription costs, $7.7 \%$ were high faculty score costs and $5.9 \%$ were mid-faculty score costs.

The fundamental reasons for the greater impact of the high faculty score new subscriptions over that of the mid-faculty score ones lay not only in the higher average ST value of the former over the latter but also in the dichotomy in the way these two sets were distributed over the curriculum cores. This dichotomy had manifested itself in the finding that in terms of actual numbers the mid faculty score new subscription measures were related to the measures of core size, while the high faculty score ones were not.

Concerning distribution over cores, unlike high faculty score new subscription measures in terms of actual numbers, these measures as percentages of core titles, faculty score, and cost, overlapped in their 5 respective dominant cores on 3 of them-Climatology, Food Science, and Human Nutrition. These were precisely the same three cores where this overlap had occurred in the case of the overall new subscription measures as percentages of their respective core measures. The three cores were among the smallest on all aspects of core size, but only total core fac- ulty score had consistently significant Spearman rank-order correlations with the high faculty score new subscription measures as percentages of their respective core measures. Once again, as with overall new subscriptions, these coefficients were all negative, ranging from -0.47 to -0.60 , indicating that the damage to the ST serials holdings of LSU Libraries in terms of high faculty score titles had occurred where faculty interest and political power were weaker.

A different picture emerged from the analysis of mid-faculty score new subscription measures as percentages of their respective core measures in relation to their distribution over the curriculum cores. Overlap of all the mid-faculty score new subscription measures in these terms occurred among their own five dominant cores only on one of them, General Technology \& Engineering, which ranked among the highest eight cores in number of titles and costs but only at the median in terms of faculty score. Moreover, there were no significant correlations of core size measures with mid-faculty score new subscription measures as percentages of their respective core measures. Everything taken together indicated that, unlike the high faculty score titles (where damage was inversely related to the amount of faculty interest and political pressure), the damage to the mid-faculty score titles was more random and influenced by core size.

The importance of high faculty score new subscriptions in overall new subscriptions is revealed in the concept of "leverage." Leverage was defined as the ratio of the percentage of faculty score to the percentage of cost. In this way, for example, if the percentage of faculty score were equal to the percentage of cost, the ratio of faculty score to cost would be 1 to 1 , and the leverage would be zero. If the percentage of faculty score were 1.5 times greater than the percentage of cost, the ratio of faculty score to cost would be 1.5 to 1 , and the leverage would be positive. Finally, if the percentage of faculty score were half of the percentage of cost, the ratio of faculty score to cost would be 0.5 to 1 , and the leverage would be negative. 
Leverage was calculated in the three following ways: (1) total leverage-the percentage of the total working universe faculty score to the percentage of the total working universe cost; (2) average leverage-the average of the percentages of faculty score of core faculty score for the 33 cores to the average of the percentages of cost of core cost for the 33 cores; and (3) core-by-core leverage-the percentage of faculty score of core faculty score to the percentage of new subscription cost of core cost for each individual core. In the core-by-core method, no leverage was calculated for those cores where none had taken place, i.e., for those cores not having new subscriptions at the level at which the leverage was being calculated.

For overall new subscriptions, total leverage was 1.46 to 1 ; for high faculty score new subscriptions, it was 1.55 to 1 ; and for mid-faculty score ones, it was 1.38 to 1 . Here it can be seen that much of the total leverage of the overall new subscriptions came from the high faculty score new subscriptions. Concerning average leverage, for overall new subscriptions, it was 1.2 to 1 ; for high faculty score subscriptions, it was 1.5 to 1 ; and for mid-faculty score new subscriptions, it was already negative at 0.9 to 1 . As with total leverage, high faculty score new subscriptions were crucial in average leverage. On a coreby-core basis, the range of overall subscription leverage ran from 0.3 to 1 in Animal Science to 22.4 to 1 in Plant Biology, with a mean of 3.1 to 1 . The range of high faculty score new subscriptions ran from 0.5 to 1 in Animal Science to 29.8 to 1 in Environmental Studies with a mean of 5.4 to 1 . The range of mid-faculty score new subscriptions ran from 0.2 to 1 in Industrial and Manufacturing Systems Engineering to 20.8 to 1 in Plant Biology with a mean of 2.8 to 1 .

The fundamental dichotomy between high faculty score and mid-faculty score new subscriptions also showed itself in the matter of leverage. This was demonstrated with correlation analyses involving leverage calculated on a core-by-core basis. Whereas both high faculty score and mid-faculty score new subscription leverage were highly correlated with overall new subscription leverage-the former having a Spearman coefficient of 0.70 and the latter having one of 0.85 - the correlation between them was insignificant. Moreover, mid-faculty score new subscription leverage correlated well with all three measures of core size (number of titles, faculty score, and cost), the Spearman coefficients ranging from 0.41 to 0.64 . However, there was only one significant correlation of the six possible ones of the core size measures with overall and high faculty score new subscription leverage - the relatively low and barely significant Spearman coefficient of 0.36 between total core faculty score and overall leverage. Once, again, it was revealed that mid-faculty score new subscriptions were basically dependent on core size, whereas, for the most part, overall and high score new subscriptions were not.

\section{Characteristics of Serials Evaluator}

RECOMMENDATIONS FOR CANCELLATION

In contrast to new subscriptions, cancellation recommendations occurred in all 33 curriculum cores. For purposes of simplicity, comparisons will be made of cancellations only to overall new subscriptions, and not to either high faculty score or mid-faculty score new subscriptions. The cancellation measures followed the usual highly skewed pattern. In terms of actual numbers, the top five cores in cancellation titles accounted for $130(38.0 \%)$ of the 342 titles recommended for such treatment; the top five cores in cancellation faculty score accounted for 628 $(47.1 \%)$ of the 1,334 faculty score points attributable to the cancellation titles; and the top five cores in cancellation costs accounted for $\$ 122,548(55.1 \%)$ of the $\$ 222,409$ in budgetary savings that would result from the cancellations.

Two cores-Biology and Mathematics-appeared among the five dominant cores on all three cancellation measures, and these cores were also among the five dominant cores on all three measures of total core size. This phenomenon was similar to the one that had occurred with the five dominant cores in overall new subscription measures, where the overlap 
had also taken place on three of the larger cores. Therefore it was not surprising to find that the cancellation measures in actual numbers correlated significantly with all three total core size measures, with Spearman rank-order coefficients that ranged from 0.40 to 0.92 . However, this result was different from that of the analysis of the relationship of the overall new subscription measures in actual numbers to core size measures, where total core faculty score did not correlate significantly with overall new subscription titles and costs.

There were major similarities and one telling difference between cancellation and overall new subscription measures as percentages of their respective core measures. The similarities were the highly skewed distributions and the overlap at the low end of core size measures. Concerning the percentage of cancellation titles of core titles, the top five cores ranged from $34.1 \%$ to $53.8 \%$ with a mean of $41.8 \%$, compared to a mean of $22.1 \%$ for all 33 cores. As for percentage of faculty score of core faculty score, the top five cores ranged from $5.6 \%$ to $12.5 \%$ with a mean of $8.4 \%$, compared to a mean of $3.3 \%$ for all 33 cores. With respect to percentage of cancellation cost to core cost, the top five cores ranged from $46.1 \%$ to $80.5 \%$ with a mean $55.6 \%$, compared to a mean of $26.6 \%$ for all 33 cores. Here the overlap occurred only on Biological and Agricultural Engineering, which was among the smallest cores on all three core size measures. This overlap resembled the one among the five dominant cores on overall new subscription measures as percentages of their respective core measures. The latter overlap had also taken place at the lower end of core size measures, although on three small cores instead of one.

Of great importance was the telling difference between overall new subscription and cancellation measures as percentages of their respective core measures in their relationship to core size measures. All three overall new subscription measures in these terms had significant negative correlations with total core faculty score only, demonstrating that the
ST serials holdings of LSU Libraries tended to be damaged where faculty interest and political power were weak. However, there were no significant correlations of the cancellation measures in these terms with any core size measures, making it appear that the cancellations were independent in this respect.

The crucial difference between the cancellations and the overall new subscriptions recommended as a result of the exercise revealed itself in the matter of leverage, i.e., the ratio of percentage of ST value to the percentage of cost. Thus, the overall new subscriptions total leverage of a positive 1.46 to 1 was 11.2 times greater than the total cancellation leverage of a negative 0.13 to 1 . The story was the same with average leverage. In this case, the overall new subscription average leverage of a positive 1.2 to 1 was 10.0 times more than the cancellation average leverage of a negative 0.12 to 1 . On a core-by-core basis, cancellation leverage ranged from 0.0 to 1 in Human Nutrition and Food as well as Industrial and Manufacturing Systems Engineering, where only zero-class faculty score titles were recommended for cancellation, to 0.26 to 1 in Food Science. The mean core-by-core cancellation leverage was a negative 0.12 to 1 , and the overall new subscription mean core-by-core leverage of 3.1 to 1 was 25.8 times higher than this.

\section{The Trade-Off in Terms of Number of}

Titles, FaCUlty SCORE, and COST

The mean price of the 118 serials recommended for subscription was $\$ 693.92$, and their mean faculty score was 45.1 . In contrast, the mean price of the 342 serials recommended for cancellation- $\$ 650.32$ was almost the same, but their mean faculty score of 3.9 was far lower. Given this lack of relationship of cost to ST value, the outcome of the exercise was predictable. To summarize, the purpose of the exercise was to determine whether the ST serials holdings of LSU Libraries could be brought up to $75 \%$ of the ST value perceived by the LSU faculty in the desired universe of serials with the resources available in the working universe of serials, i.e., all those serials on subscription at LSU 
Libraries in the 33 curriculum cores with the addition of those highly ranked serials that were not on subscription but that accounted for $75 \%$ of value perceived by the LSU faculty within the desired universe of these cores. Due to the faults inherent in such expert ratings, the perceptions of the LSU faculty had to be corrected by citation and use measures. For the purpose of the exercise, a measure called "trade-off" was constructed. This was done by simply subtracting the cancellation measures in terms of titles, faculty score, and costs from their equivalent overall new subscription measures to gauge the results of eliminating the cancellations from the working universe while retaining the new subscriptions in it. The percentage relationships of the trade-offs were calculated with respect to the working universe both as a totality and on an average core-by-core basis.

Concerning titles, 118 were recommended for new subscription, whereas 342 were recommended for cancellation. The net title trade-off was therefore a reduction of the working universe by $224 \mathrm{ti}$ tles. With respect to the 1,619 titles comprising the working universe, the net reduction was $13.83 \%$. As a percentage of their respective core titles, the trade-off titles ranged from $-53.8 \%$ in Biological and Agricultural Engineering to $+38.5 \%$ in Climatology with a mean of $-11.6 \%$ for all 33 curriculum cores.

As for faculty score, the 118 new subscriptions had an aggregate faculty score of 5,320 , whereas the 342 cancellations had an aggregate faculty score of 1,334 . The net faculty score trade-off, therefore, was an increase of the working universe faculty score by 3,986 . With respect to the total working universe faculty score of 46,593 , this represented a net gain of $8.56 \%$. As percentages of the faculty score of their respective cores, the faculty score trade-offs ranged from $-12.5 \%$ in Biological and Agricultural Engineering to $+59.2 \%$ in Climatology with a mean of $+13.5 \%$ for the 33 curriculum cores.

And, finally, with regard to costs, the 118 new subscriptions cost $\$ 81,882$, whereas the cancellations had a cost of $\$ 222,409$. The net cost trade-off was therefore a reduction of the cost of the working universe by $\$ 140,527$. With respect to the total cost of the working universe of $\$ 1,049,805$, this represents a net reduction of $13.39 \%$. As percentages of the costs of their respective core, the cost trade-offs ranged from $-80.0 \%$ in General Science to $+58.6 \%$ in Human Nutrition \& Food with a mean of $-13.0 \%$ for all 33 curriculum cores.

All in all, the inference that must be drawn from the results of this exercise is obvious. Despite the cancellation of 2,207 titles and the institution of the policy of adding no new subscriptions during the period 1986-94 in the face of an exponentially growing serials population, the ST serials holdings of LSU Libraries emerged relatively unscathed from the debacle. Instead of the hundreds of new subscriptions one might expect would be needed to bring these holdings up to $75 \%$ of the ST value perceived by the LSU faculty in the universe of serials desired by them in the 33 curriculum cores, only 118 were required, and much of the benefit of these 118 new subscriptions came from the 53 high faculty score serials. The 65 mid-faculty score serials were already approaching marginality in terms of leverage. Moreover, not only were relatively few new subscriptions required to bring the ST serials holdings in the 33 cores up to the optimal level of the value perceived by the LSU faculty, there still remained hundreds of serials in these cores that cost hundreds of thousands of dollars and could be canceled at minimal loss in perceived ST value.

These results can be attributed not only to the careful management of the cancellations during the crisis but also to the highly skewed and stable nature of the ST journal system. In essence, the commanding heights of the ST serials holding of LSU Libraries were for the most part still intact, and the results of the exercise would have been even more favorable in terms of trade-offs had these commanding heights suffered major damage.

To verify this, the leverage in terms of LSU faculty score was calculated for a sample of 25 of the 50 most-often cited journals in 1989 and 1994, as identified by Garfield (1996). This sample was constructed by moving down the list in 
descending rank order of total 1994 citations and selecting those journals that were in the serials set under investigation until the desired number had been reached The titles were located in nine curriculum cores, and they included numerous prestigious journals, such as American Jourmal of Physiology, Astrophysical Journal, Cell, Journal of Geophysical Research, Journal of the American Chemical Society, Physical Review, and Science. With rare exception all were still on subscription at LSU Libraries. The mean leverage of these titles was 5.55 to 1 , which was 3.6 times more than the 1.55-to-1 total leverage of the high faculty score new subscriptions, 3.8 times more than the 1.46-to-1 total leverage of the overall new subscriptions, 4.0 times more the 1.38-to-1 total leverage of the mid-faculty score new subscriptions, and 42.7 times more than the 0.13 -to- 1 total leverage of the cancellations.

\section{Conclusion: Economic Consequences and Options}

The InEFFICIENT MARKET:

CONTRADICTION BETWEEN SOCIAL AND ECONOMIC LOGIC

Human knowledge appears to function on the same probability structure as the rest of living nature and society. It is a structure dominated by highly skewed, exponential distributions that arise from the operation of two basic multiplicative, often interactive stochastic processes: inhomogeneity and contagion. Because all probabilities must add to one, the result is essentially a zero sum game in which the success of the few necessitates the failure of the many. The library market for ST journals is characterized by an imbalance between two such distributions, one for ST value and the other for cost.

Two principles dominate the library market for ST journals. The first is societal and is exemplified by the U.S. scientific and technical associations. Associations have long played an important role in American society, and their importance was noted by none other than Alexis de Tocqueville (1969, 189-95, 513-25), who in his famous book Democracy In America called particular attention to the significance of American intellectual and moral associations. The importance of U.S. scientific and technical associations in the library market for ST serials is that they are the primary social organizations of those involved in science and technology, and it is largely through the medium of their publications that the ST elite communicate the results of their work.

In a landmark article Cole and Cole (1972) analyzed the comparative contributions of the various social strata of scientists to scientific progress, using the work of Jose Ortega y Gasset to set the null hypothesis that science was advanced by the work of many average scientists making minor contributions. Cole and Cole rejected this hypothesis. To the contrary, they found that scientific progress is mainly the work of a small elite concentrated at a relatively few institutions and that even the minor discoveries come primarily from the top strata of the scientific community.

Using Price's modification of Lotka's law, Cole and Cole estimated that roughly $50 \%$ of all scientific papers are produced by approximately $10 \%$ of the scientists, and they analyzed the extent to which the $10 \%$ of the scientists who produce $50 \%$ of the research depend on the other $90 \%$ of the scientists responsible for the remaining 50\%. To do this, Cole and Cole examined the references made by 84 university physicists in their most highly cited papers in the $1965 S C I$ to a random sample of 385 physicists drawn from those referenced in these 84 papers. Of the 385 cited physicists, $72 \%$ were affiliated with universities, and $60 \%$ of these were located at the nine physics departments given the highest rating of "Distinguished" in the Cartter 1964 assessment of quality in U.S. graduate education. The nine top departments represented $10.5 \%$ of the 86 physics programs rated that year, and at the risk of redundancy their names in descending rank order were California at Berkeley, Cal Tech, Harvard, Princeton, Stanford, MIT, Columbia, Illinois at Urbana-Champaign, and Cornell.

In general, Cole and cole found among those highly cited many who were 
members of the National Academy of Sciences and winners of the Nobel prize as well as other awards, and there was a tendency for the elite to cite the elite and to be cited by those lower down the science stratification system. It is this elite that lies at the basis of ST value, which they transfer to U.S. association serials by publishing their most important work in them. Because of the nature of the probability structure governing science and technology, it is the elite's success that reduces the success of others, causing zero classes in citations and library use.

The other principle dominating the library market for ST serials is commercial, and this principle is epitomized by the commercial publishers, both domestic and foreign. It would be easy to end this paper by praising the societal principle and denouncing the profit motive, but unfortunately the picture appears to be much more complex. The separation of ST value from cost may be mainly the result of the interaction of the science and technology social stratification system with the economics of journal publishing rather than the profit motive.

The conceptual model proposed by Noll and Steinmueller (1992) for the analysis of scientific journal prices is extremely interesting from this perspective. According to these authors, scholarly journals have essentially the same cost structure as any other media product in that this cost structure consists of two parts: (1) "first copy cost," which includes all activity associated with producing the basic information that the product contains; and (2) the costs of actually printing and distributing the publication, which for scholarly journals are a relatively small part of the total costs. Given this cost structure, Noll and Steinmueller point out that circulation is a key variable and that prices must be higher for journals with low circulation because the fixed first copy cost must be recovered from a smaller number of subscribers. They further posit that a fundamental factor in determining the demand for academic journals is the need of the faculty to publish for promotion and salary purposes.

In the view of Noll and Steinmueller, scholarly journals exist within social hierarchies, and as more faculty seek publication outlets, it becomes increasingly difficult to be published in the "best" journals. The result is that a smaller and smaller proportion of scholars succeed in publishing at the top of the hierarchy. In their model, both publishers and scholars respond to this situation by seeking to create new publishing outlets that form new hierarchies by narrowing the scope of journals, because it is better to be at the top of a small, new hierarchy than at the bottom of an established, large one. Noll and Steinmueller state that the type of market that develops in this regime is one of "monopolistic competition," where each producer supplies a somewhat different product from all others, attempting to serve a relatively small subset of the overall market. However, they point out that as more and more such journals are launched, the subscription base of all the competing serials is reduced, forcing price rises to cover the high fixed (first copy) costs of serials. Noll and Steinmueller then state (p. 34):

The only journals that are likely to be able to persist in earning excess profits in this type of market are those that are immune to loss of subscriptions from the entry of a more specialized publication. These are likely to be the most prestigious general purpose academic journals in a discipline-the outlets that all scholars, regardless of specialty, rank at the top of the hierarchy across a broad spectrum of specialties. Usually the journals of the major professional societies fall into this category, since they reach a very large audience and so draw a very large number of submissions.

In their opinion, the performance of the journals market under such conditions is "socially undesirable and economically inefficient" (p. 35) for the following reasons: (1) secondary journals tend to publish many articles that are not particularly important and that could not sustain sufficient circulation to keep a journal viable; and (2) as average circulation declines and prices go up to cover first copy costs, a wider spread develops between the marginal cost of a journal and its 
price. The situation is loaded with social dynamite with possible catastrophic consequences, for in a model developed by Quandt (1996), if in the presence of myopic behavior publishers try to maintain their revenue by raising prices to compensate for falling subscriptions, and libraries cancel journals on the basis of cost and importance, there could be a dramatic implosion in subscriptions, ranging from $13 \%$ to $96 \%$.

Credence was given to Noll and Steinmueller's model by Bensman's (1996) analysis of the library market for chemistry journals, using the database compiled as a result of the SRP pilot project in 1993. Regression tests with this database had shown that for every type of publisher-association and commercial, domestic and foreign-serials prices tended to go down in line with the increase in the number of libraries holding them. Taking all types of publishers together, prices decreased in terms of standardized regression coefficients either 0.40 or 0.47 standard deviations for every one standard deviation increase in holding libraries, depending on which measure of scientific value was utilized. U.S. publishers' prices were much more sensitive to this variable than foreign ones, but this could have been an artifact of the holding libraries being predominantly located in the U.S. For the present analysis, the database was supplemented with the use data contemporaneously gathered at the University of Illinois at Urbana-Champaign (UIUC) Chemistry Library.

The analysis was done in two stages. First, the reasons why libraries purchase and hold serials were investigated by regressing the OCLC library holdings of the chemistry journals on their price and scientific value measured sequentially in terms of LSU faculty ratings, total ISI citations, and total UIUC Chemistry Library use. Preliminary analyses for setting up the regression equations uncovered outliers of three basic types (besides the consistent appearance of one title as such for unexplainable reasons).

One type of outlier was subject-related and could have been the result of the set of journals under analysis being defined by a survey of the Department of Chemistry without taking into account the Department of Biochemistry. This type occurred when LSU faculty ratings and total ISI citations were utilized as the measures of scientific value, and it required the exclusion of the Annual Review of Biochemistry, Free Radical Research Communications, and the Journal of Biological Chemistry as outliers.

The second type of outlier related to all three measures being research oriented. Use in the UIUC Chemistry Library was so, because this library supports a large research-doctorate program that has been consistently ranked at the top of such programs in chemistry from 1910 through 1993. This characteristic led to the considerable underprediction of the number of libraries holding Chemical and Engineering News, the main informational publication of the American Chemical Society, and the Journal of Chemical Education, whose purpose is primarily instructional.

The final type of outlier included one title, and it was the most interesting, because it was due to an extreme imbalance between price and scientific value. This title was the Journal of the American Chemical Society, which had to be excluded as an outlier from the model that used LSU faculty score as the measure of scientific value as well as from the model that used total UIUC use in this role. The reason for this was that the Jourmal of the American Chemical Society was such a bargain in terms of price and scientific value that, instead of the 1,381 libraries actually holding it, the model with LSU faculty score predicted that it should be held by 4,429 libraries, and the one with total UIUC use, by 5,688 -in both cases, probably more libraries that needed it than exist in reality.

All three models showed that scientific value plays a much more important role than price in determining why libraries purchase and hold serials. With respect to LSU faculty score, the standardized regression coefficients showed that for each move of one standard deviation upwards in scientific value, library holdings went up 0.64 standard deviations; for 
each move of one standard deviation upwards in price, library holdings went down 0.15 standard deviations. The model accounted for $39.7 \%$ of the variance in library holdings, and by itself LSU faculty score accounted for $39.5 \%$ of the variance beyond that caused by price, whereas by itself price caused only $2.3 \%$ of the variance beyond that caused by LSU faculty score.

The same picture was obtained when total ISI citations were used as the measure of scientific value. Here the standardized regression coefficients showed that for each move of one standard deviation upwards in scientific value, library holdings increased 0.61 standard deviations, whereas for each move upwards of one standard deviation in price, library holdings decreased 0.24 standard deviations. This model accounted for $33.2 \%$ of the variance in library holdings, and by itself total ISI citations accounted for $33.0 \%$ of the variance beyond that caused by price, whereas by itself price accounted for only $5.2 \%$ of the variance beyond that caused by total ISI citations.

These findings were corroborated by the model using total UIUC Chemistry Library use as the measure of scientific value. With this model, the standardized regression coefficients revealed that for each move of one standard deviation upwards in scientific value, library holdings rose 0.61 standard deviations, whereas for each move upwards of one standard deviation in price, library holdings fell 0.23 standard deviations. This model accounted for $33.9 \%$ of the variance in library holdings, and by itself total UIUC use accounted for $33.6 \%$ of the variance beyond that caused by price, whereas by itself price accounted for merely $4.7 \%$ of the variance beyond that caused by total UIUC use.

The next stage of the analysis was devoted to investigating the dichotomy between the serials of the U.S. associations on the one hand and those of the commercial publishers, both domestic and foreign, on the other. It was done in two steps. First, the means of these types of publishers were compared on the independent variables of the above models-price,
LSU faculty ratings, total ISI citations, and total UIUC Chemistry Library use. In all cases, the serials of the U.S. associations represented far better purchases for libraries than those of the commercial publishers. In terms of price, the mean was $\$ 575.76$ for the serials of the U.S. associations, $\$ 878.67$ for titles of U.S. commercial publishers, and $\$ 1,565.24$ for those of the foreign commercial ones. In terms of LSU faculty score, the mean was 189.7 for the titles of the U.S. associations, 53.6 for the serials of U.S. commercial publishers, and 72.5 for those of the foreign commercial publishers. In terms of total ISI citations, the mean was $30,073.8$ for the serials of the U.S. associations, $6,541.8$ for those of the U.S. commercial publishers, and 8,975.6 for the foreign commercial titles. In terms of total UIUC Chemistry Library use, the mean was $1,440.2$ for the U.S. association serials, 175.0 for the U.S. commercial ones, and 391.2 for the foreign commercial titles. ISI impact factor was also tested as part of the investigation of the independent variables, and only in terms of mean ISI impact factor did the commercial serials do well against the U.S. association titles. However, interestingly enough, it was only the differences between the impact factor means that were not statistically significant, once again calling into question the validity of this measure.

In the second step, the dependent variable-library holdings-was examined, and not unexpectedly, the serials of the U.S. associations fared much better here than those of the commercial publishers. The mean library holdings were 743.0 for a U.S. association serial, 387.5 for a U.S. commercial one, and 316.7 for a foreign commercial title. The differences between these means were also statistically significant. Evidence exists of a positive relationship between library holdings and the scholarly value of serials in other subjects besides chemistry; for example, Wallace and Boyce (1989) found significant correlations ranging from 0.49 to 0.74 between OCLC holdings and total citations in business, clinical psychology, ecology, genetics and heredity, and international relations. 
On the basis of the Noll and Steinmueller model, it is now possible to say that the logic of the social stratification system of science and technology works contrary to the economic logic of the ST journal market, enabling better ST information to be delivered at a cheaper price and forcing worse ST information to be delivered at a higher price. Even if the U.S. associations were operating on the principle of profit maximization, they would still be able to underprice the commercial publishers. However, for whatever the reason, the propensity of commercial publishers to charge more for their products is causing zero classes of unknown magnitude not only in library monographic purchases but perhaps even in the launching of good ST serials.

One of the major bases of modern investment theory is the "efficient market hypothesis" (EMH). According to this hypothesis, a stock market is efficient when share prices reflect all the information relevant to the companies underlying them (Bodie, Kane, and Marcus 1996, 338-41). From this perspective, the library market for ST journals is extremely inefficient. Libraries pay the highest prices for serials with the lowest ST value and the lowest probability of being used. The inefficiency of the library market for ST serials is demonstrated by the three regression models above, where from $60.3 \%$ to $66.8 \%$ of the variance in library holdings is left unexplained by the two variables-price and scientific valuewhich should be dominant in their determination.

A number of basic factors might play an important role in causing this inefficiency besides academic politics. First, academic libraries tend to compare themselves on the basis of the ARL Library Index. However, this index is a measure of the relative size of libraries, and it does not attempt to measure the quality of collections or success in meeting the needs of the users (Kyrillidou and Blixrud, 20 March 1997). The ARL Library Index is constructed from five data elementsnumber of volumes held, number of volumes added, number of current serials received, total operating expenditures, and number of staff-and, insofar as the number and cost of ST serials are factored into this index, it may be a measure of not which is the better library but of which is the greater fool.

Second, there persists a belief among librarians that publishers charge according to the quality of their serials, and this belief found expression in the following statement quoted by Dougherty and Barr $(1988,8)$ :

Every study we've done or seen indicates that high cost and high use are linked; and this limits our power to drop expensive journals, even where cooperation is assured. The publishers know what they are doing when they price their core journals.

On the contrary, Bensman (1996) used regression analyses of chemistry serials to demonstrate that the primary determinant in pricing by all types of publishers-association and commercial, domestic and foreign-is size and not quality, which plays virtually no role.

Third, many librarians think that the commercial publishers possess monopoly power (Stoller, Christopherson, and Miranda 1996), but this does not appear to be the case if so many of their serials can be canceled with extremely small losses in ST value. On the contrary, careful consideration of the evidence presented here might lead to the conclusion that many of the publishers-who do possess monopoly power due to the quality of their products-actually charge less for these products.

A fourth factor possibly causing inefficiency in the library market for ST serials is more subtle, and it is that librarians appear to feel a professional obligation to preserve all human knowledge, no matter its importance. In studies of serials cancellations by five ARL libraries in the Midwest Chrzastowski and Schmidt (1993; 1996) noted that libraries tended to cancel English-language science titles that had a higher-than-average subscription price and that they alone held. The authors attributed this phenomenon to the operation of the Matthew Effect, which was leading to the development of similar core collections of high-use and frequently 
cited serials titles. Chrzastowski and Schmidt regretted this loss of "diversity," calling for cooperative collection development to address the issue of cancellations. However, the progress of science and technology requires high levels of consensus with agreed- upon paradigms and established channels of communication. By their very uniqueness, the canceled titles demonstrated their unimportance, and the relatively high cost of these titles more than likely resulted from this lack of importance.

In a discussion of the EMH, Frankfurter and McGoun (1996, 60-61) specify three versions of market efficiency. In all three versions the library market for ST serials can be considered inefficient. The first is "informational efficiency." This has been defined above, and we have shown that the prices of ST journals certainly do not reflect the information that is available or easily obtained as to their underlying ST value. The second version is "allocational efficiency," and Frankfurter and McGoun state that "markets are allocationally efficient, if investment projects are financed at the marginal productivity of capital." However, due to the highly skewed distributions of ST value, the marginal utility of journals diminishes at a rapid rate, while at the same time the prices of these same journals are forced up by the need to recover first copy costs from the fewer number of subscriptions dictated by their lower ST value. If one considers the serials holdings of a library as part of its capital, then libraries are investing money at a point where the cost of journals far exceeds their productivity in terms of usable human knowledge, making the library market for ST serials allocationally inefficient. The third version is "operational efficiency." According to Frankfurter and McGoun, operational efficiency is "concerned with the ease and speed by which capital markets make the meeting of buyers and sellers possible," and this in turn depends upon the level of market liquidity. From this perspective, the library market for ST serials can be seen as operationally inefficient, because libraries have a large part of their resources tied up in fixed costs for serials of questionable ST value, reducing their liquidity and flexibility in meeting new informational needs.

\section{Options for Resolving THE CRISiS}

The crisis predicted by Price a generation ago is now here. New serials are being established at a rapid rate. For example, the 35th edition of Ulrich's for 1997 ( vol. 1, vii-viii) reports adding nearly 6,000 titles; the 36 th edition for 1998 ( vol. 1, vii- viii) increased its coverage by about 7,000 titles, of which more than 3,571 were known to have begun publication since January 1, 1995.

Moreover, the U.S. Periodicals Price Index (USPPI) for 1998 (Alexander and Dingley 1998) shows that inflation continues unabated. Excluding Russian translations, the average price of a U.S. periodical rose $34.3 \%$ from $\$ 149.46$ in 1995 to $\$ 200.74$ in 1998 . In addition, the 1998 USPPI reveals that the subject category Chemistry \& Physics remains at the heart of the problem. The average price of the serials in this category increased $38.4 \%$ from $\$ 767.96$ in 1995 to $\$ 1,062.49$ in 1998. Once again, with the exclusion of Russian translations, the average price of Chemistry \& Physics serials was the highest, being 5.3 times higher than the average price of all 1998 USPPI serials of $\$ 200.74$ and twice as high as the second-most expensive subject category, Medicine, which averaged $\$ 524.65$. With the elimination of Russian translations, the Chemistry \& Physics subject category accounted for only $4.6 \%$ of the 3,729 titles in the 1998 USPPI sample but $24.1 \%$ of the $\$ 748,559.46$ that this sample cost.

Three basic factors appear to be driving the inflationary spiral in the prices of ST serials. First, there is the normal exponential growth of science and technology, which manifests itself in the increasing number and size of ST serials. As Price pointed out, this growth outstrips that of the socioeconomic institutions supporting science and technology. It alone could cause the prices of ST serials to rise faster than other prices in society.

Second, as the Noll and Steinmueller model indicates, the problem of normal 
ST growth is probably compounded by the dysfunctions introduced by the university promotion and tenure system. Publishers are serving the need of the faculty to publish by providing ever-more specialized outlets, and the constant shrinkage of the markets for such outlets makes it ever-more difficult to cover first copy costs. The result is the production of much ST literature whose cost of production cannot be justified by its potential use. These features have been well documented in two studies done under the sponsorship of the ARL by Economics Consulting Services, Inc. (1989) and Okerson (1989), who located the roots of the crisis of the serials system in, among others, the growth in the volume of published research, the promotion and tenure system, the effect of first copy costs, the "twigging" of journals into subspecialties, and the role of the commercial publishers.

Finally, the inflating mass of ST literature appears to be fast approaching its socioeconomic limits as is witnessed by the growing inability of library budgets to finance it. Libraries are being forced to make the transition from ownership to access, and the resulting cancellations are stressing the entire system by making it ever more difficult to cover first copy costs. Even a relatively few cancellations can have an enormous impact on the system, because the market for many ST serials is small. Of the 154 serials in the database compiled as a result of the 1993 SRP pilot project with the LSU Department of Chemistry, $75 \%$ had library holdings of 528 or fewer, and the median library holding of the sample was only 318.5 .

Unfortunately, there does not seem to be either an easy or a rational solution to the crisis of the ST serials system in its present form. Technology does not provide an answer and may even exacerbate the situation because it places additional stress on the system without altering the economic fundamentals of ST publishing.

This consequence of technology is apparent in the factors which the American Chemical Society (ACS) takes into account when it prices the newly established online versions of its 26 journals. Over the last 5 years, the ACS has spent millions of dollars on electronic publishing. During a recent interview (Wilkinson 1998, 18), Bovenschulte, ACS Publications Division director, stated that it was costing the ACS approximately $\$ 2$ million per year to support Web publishing through investments in new staff, training in computers and networks, additional servers, and backup systems. Bovenschulte estimated that such expenses were likely to increase, and he noted that the ACS still had all the costs associated with print.

In a recent talk, Garson (1997a), chief technology officer of the ACS Publications Division, analyzed the economics of ST publishing. He particularly emphasized the impact of the new technology. Garson located the primary cause of the rapid escalation of ST journal prices in the explosive increase in the amount of material being published. According to him, despite substantial improvements in productivity, publishing costs are directly proportional to the amount of material published. Noting that scientific publishers are under tremendous pressure to publish, Garson then gave the following statistics on the growth of ACS publishing for the period from 1980 to 1996: the number of articles rose from around 8,000 per year to over 18,000 ; the average number of pages per article increased from around 5 to about 7.25; and the number of pages published by the ACS increased from approximately 40,000 to about 135,000 . He also pointed out that much-even most-of the material rejected for publication under the ACS system of strict peer review eventually was published elsewhere.

Garson then divided ACS journal publishing expenses into two categories, giving their percentages for 1996 as follows: (1) first copy costs (peer review and external editors, technical editing, database building and composition, marketing and sales, research and development)-84.3\%; and (2) paper, printing, and distribution costs or expenses directly associated with distribution of the information- $15.7 \%$. Of the first copy costs, database building and composition was by far the largest, comprising $43.4 \%$ of total production costs, and this 
fact is important because, as he indicated, database creation is necessary to produce both print and electronic products in a cost-effective manner. The second-highest first copy cost-peer review and external editors, comprising $19.3 \%$ of total costs--is also of interest, because it reflects the emphasis of the ACS on the quality of the science it publishes.

Garson held out no hope for a technological solution to the ST serials crisis through electronic journals. By his estimate, even with electronic journals, first copy costs would still be $80 \%$ or more, while the format threatened a reduction in the number of copies that could be sold to cover these costs. In a response to questions about his talk, Garson (1997b) noted that ACS first copy costs of $80 \%$ or more might be much higher than others due to the association's heavier investment in front-end database creation and rigorous peer review. As evidence of this, for example, Cox (1997), managing director of Carfax Publishing, estimated average first copy costs of scholarly journals at between $60 \%$ and $70 \%$.

From the viewpoint of the ACS, electronic journals pose a threat to publishers, because the costs of producing them are the same or even greater than print versions, while they reduce the number of needed subscriptions due to their accessibility from remote points. In his interview (Wilkinson 1998, 13), Bovenschulte noted that the ACS had already experienced an erosion in print subscription numbers over the past five to seven years due to individual subseriptions being replaced by sitewide institutional subscriptions as well as readers and libraries wanting the bells and whistles that electronic journals provide. In his opinion, "electronic journals are going to take over in the long run, no sooner than five years, but no longer than 10," and he declared that, as a result, "scientific publishers-and maybe journal publishers in general-are going to give up counting print subscriptions as a measure of journal success."

The points made by Bovenschulte and Garson were driven home by Durniak (1997) in a written justification of why the
ACS had to charge more for its electronic products than its print ones. His rationale basically boiled down to two points: (1) the ACS had to invest more into the first copy cost of database creation to provide such enhancements as powerful search software, hypertext links, interactive molecular models and animations, etc.; and (2) the number of subscriptions would decline as ACS members canceled their personal print subscriptions with the availability of electronic versions from their libraries, and as large organizations eliminated the now redundant duplicate subscriptions to ACS journals. The hostile response to the ACS policy of pricing electronic journals prompted Durniak to declare ruefully (Wilkinson 1998, 16), "Pioneers are the ones that always have the arrows in their chests."

Moreover, similiar to technology, neither cooperative collection development nor consortia offer solutions to the crisis embracing the ST serials system in its present form. The simple fact of the matter is that important ST information is largely restricted to a relatively few serials, and research has consistently shown that these serials not only dominate internal library use but also interlibrary loan. Evidence of this phenomenon appeared in the analysis of the documents supplied by UnCover to LSU from July 1, 1994, to June 30,1996 , from titles classed in the 33 curriculum cores, where a crucial role was played by serials either highly rated by the university's faculty or having high impact factors.

Because of this, all university libraries must have basically the same set of journals-a condition dictated by their being a part of the same social stratification system-something that was demonstrated here by the high intercorrelations among LSU chemistry faculty ratings, ISI citations, and UIUC Chemistry Library use. Moreover, the required set of journals-as the ACS publication data show-has a tendency to grow exponentially. Therefore, in the long run, no library will agree to waste scarce resources on titles that have a low probability of being either used internally or borrowed by other libraries, particularly because such 
titles are most likely to be subject to inflationary pressures due to a shrinking subscription base from cancellations by other libraries.

Consortia offer no solution to the crisis due to first copy costs. As libraries reduce the number of subscriptions by banding together to buy expensive titles, they force publishers to raise prices to recover these costs. This holds particularly true for electronic journals that are more easily shared, and it is behind the ACS policy of imposing a $25 \%$ premium over collective print expenditures on consortia for Web access to those of its journals to which any member library subscribes. When this offer was made to Sanville (29 April 1998) of OhioLINK, it provoked him to describe the premium as "huge" and the acceptance of anything remotely resembling the ACS proposal as "a disastrous message to the community - both publishers and libraries."

Because technology, cooperative collection development, and consortia offer no solutions to the crisis of the ST serials system in its present form, the only option that may be open to librarians is to alter the market structure of the system. ARL has come to this realization, and through its Scholarly Publishing and Academic Resources Coalition (SPARC) project it is seeking "to create a more competitive marketplace for research information by providing opportunities for new publishing ventures, endorsing new publications and information products, and recruiting authors, editors, and advisory board members" (Case 1998, 1). Cognizant of one of the major causes for the dysfunction in the ST information market, the ARL is also working for "the decoupling of the academic credentialing process from formal publication" (p. 5).

Altering the market structure of the ST information system would entail a continuation of the transfer from ownership to access by taking advantage of the ability of the new technology to provide information speedily. In today's parlance, the electronic journal and the fax machine offer libraries the opportunity-through rapid document delivery-to buy "justin-time" instead of "just-in-case." Under the constant pressure of a dysfunctional ST serials system, librarians will be compelled to rationalize the cost structures of their institutions by carefully placing high cost, low ST value serials on document delivery, essentially removing them from the subscription system to a free market. However, such a transfer raises the crucial question of who should assume the financial risk of the zero and other low use classes-libraries or publishers. This question was raised by ACS director of publications Marks, who in an interview dealt with the issue of single-article ordering in the following manner (Borman 1995, 49):

... a journal publishes everything submitted that is deemed top-quality science, whether or not anyone ever even reads it. In effect, an archive of peer-reviewed research is created. Subscribers to the printed journal pay for everything that's there, and the cost is fairly reasonable because it's distributed among a large number of subscribers. If you have everything available electronically and people only pay for what they print out, we won't be able to support this system.

Nevertheless, the real cost of a journal is not its subscription price but its cost-per-use. This was demonstrated here by the cost accounting method applied to the price and use data of the serials held by the UIUC Chemistry Library. For example, whereas the subscription price of the Journal of the American Chemical Society was $\$ 1,055.00$, its cost-per-use was calculated to be $\$ 2.45$. In contrast, another title had a subscription price of $\$ 2,331.01$ but a cost-per-use of $\$ 4,079.27$. The true costs of the secondary ST literature that have been for the most part hidden under the present subscription system will have to manifest themselves in the free market of document delivery.

One must keep firmly in mind that what is described here is not a solution to the crisis but its violent denouement and the transition of the ST serials system to a different economic basis. Such a transition can result in the dramatic implosion modeled by Quandt (1996), because it threatens the very revenue base of many publishers. This menace is evident from 
the data presented by Garson (1997) on the journal revenues of the ACS in 1996. Of these revenues, $81.3 \%$ were derived from subscriptions, and only $15.8 \%$ came from reprints, page charges, microfilm, back issues, or copyright royalties. Ninety percent of the subscription revenues came from institutions, and $10 \%$ from ACS members.

Given these facts and the probability structure of human knowledge, it is highly doubtful whether many publishers can recover their lost subscription subsidies from library budgets through the sale of documents. The transition will not be a pleasant one, because there are powerful forces with vested interests in the existing ST serials system. At LSU, in the famous words of Pogo Possum (Kelly 1982, 224) "We have met the enemy and he is us." After being shown an Evaluator run that brought his pet journal up for cancellation-a foreign commercial title with an extremely narrow subject focus-one LSU professor shouted, "When it comes to my journal, your damn statistics mean nothing!" He then threatened to run to the Provost's Office. The journal in question had a faculty score of 10 , suggesting perhaps that 1 faculty member had selected it and assigned it top priority. In his outburst the LSU professor initially directed his anger against his own colleagues for not supporting this journal, and he declared that not only should the journal be kept on subscription but that the university should pour more money into the subspecialty covered by the journal as a natural path to national preeminence. The LSU professor later admitted that he had his own personal subscription to the journal, which indicates that more issues are involved than simple access to information.

It is a terrible thing to be caught in an inefficient market that suddenly becomes efficient. No less a personage than Sir Isaac Newton found this out. When reportedly asked to comment on the South Sea Bubble in whose collapse he subsequently lost his shirt (Carswell 1960, 131, 199), Newton is said to have replied that he could calculate the motions of the heavenly bodies but not the madness of people.

\section{Works Cited}

Alexander, Adrian W., and Brenda Dingley. 1998. U.S. periodical prices-1998. American libraries 29, no. 5: 82-90.

Allison, Paul D. 1980. Inequality and scientific productivity. Social studies of science 10: 163-79.

Association of Research Libraries. ARL statistics. Washington, DC: ARL. Published annually.

Bagust, A. 1983. A circulation model for busy public libraries. Journal of documentation 39: 24-37.

Baldwin, Jane, and W.M. Baldwin, III. 1989. Let the buyer beware: High price does not necessarily mean high quality. Advances in serials management 3: 111-29.

Barnett, Vic, and Toby Lewis. 1984. Outliers in statistical data. 2nd ed. Chichester [Eng.]: J. Wiley.

Barschall, Henry H. 1988. The costeffectiveness of physics journals. Physics today 41, no. 7: 56-59.

Barschall, Henry H., and J.R. Arrington. 1988. Cost of physics journals: A survey. Bulletin of the American Physical Society, Ser. 2, 33: $1437-47$

Beckman, R.J., and R.D. Cook. 1983. Outlier........ Technometrics 25: 119-49.

Begley, Sharon. 1991. Gridlock in the labs: Does the country really need all those scientists? Newsweek 117, no. 2: 44.

Bensman, Stephen J. 1982. Bibliometric laws and library usage as social phenomena. $\mathrm{Li}$ brary research 4: 279-312.

_-1985a. An assessment of doctoral programs at Louisiana State University: A report to the LSU Graduate Council. Photocopied. Baton Rouge, LA: Louisiana State University.

- $1985 \mathrm{~b}$. Journal collection management as a cumulative advantage process. College \& research libraries 46: 13-29.

- 1996. The structure of the library market for scientific journals: The case of chemistry. Library resources \& technical services 40: 145-70.

Blaivas, Alex et al. 1982. Consensuality of peer nominations among scientists. Knowledge: Creation, diffusion, utilization 4: 252-70.

Bliss, C. I. 1953. Fitting the negative binomial distribution to biological data. Biometrics 9: 176-96.

BLLD/SINFDOK serials study 1975. 1975. BLL review 3: 107-8.

Bodie, Zvi, Alex Kane, and Alan J. Marcus. 1996. Investments. 3rd ed. Chicago: Irwin.

Bookstein, Abraham. 1990a. Informetric distributions, part I: Unified overview. Jour- 
nal of the American Society for Information Science 41: 368-75.

1990b. Informetric distributions, part II: Resilience to ambiguity. Journal of the American Society for Information Science 41: 376-86.

1995. Ambiguity in measurement of social science phenomena. In Fifth International Conference of the International Society for Scientometrics and Informetrics: Proceedings, 1995, ed. Michael E.D. Koenig and Abraham Bookstein, 73-82. Medford, NJ: Learned Information.

. 1997. Informetric distributions, part III: Ambiguity and randomness. Journal of the American Society for Information Science 48: 2-10.

Borman, Stu. 1995. Electronic publishing increasingly offered as alternative to print medium. Chemical and engineering news 73, no. 13: 42-49.

Boswell, M.T., and G.P. Patil. 1970. Chance mechanisms generating the negative binomial distributions. In Random counts in models and structures, vol. 1 of Random counts in scientific work: Expanded from the proceedings of the Biometric Society Symposium, Dallas, Texas, December 1968, ed. G.P. Patil, 3-22. University Park: Pennsylvania State University Press.

Bott, David M., and Lowell L. Hargens. 1991. Are sociologists' publications uncited?: Citation rates of journal articles, chapters, and books. American sociologist 22: 147-58.

Bower, C.A. 1976. Patterns of use of the serial literature at the BLLD. BLL review 4: 31-36.

Bradford, Samuel C. 1953. Documentation. London: Crosby Lockwood.

Brass, W. 1958. Simplified methods of fitting the truncated negative binomial distribution. Biometrika 45: 59-68.

Broad, William, and Nicholas Wade. 1982. Betrayers of the truth. New York: Simon and Schuster.

Brookes, Bertram C. 1980a. The foundations of information science, part I: Philosophical aspects. Journal of information science 2: 125-33.

- $1980 \mathrm{~b}$. The foundations of information science, part II: Quantitative aspects: Classes of things and the challenge of human individuality. Journal of information science 2: 209-21.

- 1980c. The foundations of information science, part III: Quantitative aspects: Objective maps and subjective landscapes. Journal of information science 2: 269-75.
1981. The foundations of information science, part IV: Information science: The changing paradigm. Journal of information science 3: 3-12.

Broude, Jeffrey. 1978. Journal deselection in an academic environment: A comparison of faculty and librarian choices. Serials $l i$ brarian 3: 147-66.

Brownsey, K.W. R., and Quentin L. Burrell. 1986. Library circulation distributions: Some observations on the PLR sample. Journal of documentation 42: 22-45.

Burrell, Quentin L. 1980. A simple stochastic model for library loans. Journal of documentation 36: 115-32.

- 1982. Alternative models for library circulation data. Joumal of documentation 38: 1-13.

-1. 1984. Library circulation models. Journal of documentation 40: 68-71.

- 1985. A note on ageing in a library circulation model. Journal of documentation 41: 100-15.

1986. A second note on ageing in a library circulation model: The correlation structure. Journal of documentation 42 : 114-18.

-1987. A third note on ageing in a library circulation model: Applications to future use and relegation. Journal of documentation 43: 24-45.

- 1988. A simple empirical method for predicting library circulations. Joumal of documentation 44: 302-314.

- 1990. Using the gamma-Poisson model to predict library circulations. Journal of the American Society for Information Science 41: 164-70.

Burrell, Quentin L., and Violet R. Cane. 1982. The analysis of library data. Journal of the Royal Statistical Society, Series A (General) 145, Part A: 439-71.

Burrell, Quentin L., and Michael R. Fenton. 1994. A model for library book circulations incorporating loan periods. Journal of the American Society for Information Science 45: 101-16.

Bustion, Marifan, and Jane Treadwell. 1990. Reported relative value of journals versus use: A comparison. College \& research libraries 51: 142-51.

Carpenter, Kathryn Hammell, and Adrian W. Alexander. 1996. U.S. periodical price index for 1996. American libraries 27, no. 5: 97-105.

Carswell, John. 1960. The South Sea bubble. Stanford, CA: Stanford University Press.

Cartter, Allan M. 1966. An assessment of quality in graduate education. Washington, 
DC: American Council on Education.

Case, Mary M. 1998. ARL promotes competition through SPARC: The Scholarly Publishing \& Academic Resources Coalition. ARL 196: 1-5.

Cattell, James McKeen. 1906. A statistical study of American men of science. Science 24: 658-65; 699-707; 732-42.

- 1910. A further statistical study of American men of science. Science 633-48; 672-88.

Chan, Lois Mai. 1990. Immroth's guide to the Library of Congress Classification. 4 th $\mathrm{ed}$. Englewood, CO: Libraries Unlimited.

Christensen, John O. 1992. Cost of chemistry journals to one academic library, 1980-1990. Serials review 18, no. 3: 19-34.

Chrzastowski, Tina E. 1991. Journal collection cost-effectiveness in an academic chemistry library: Results of a cost/use survey at the University of Illinois at Urbana-Champaign. Collection management 14: 85-98.

Chrzastowski, Tina E., and Mary A. Anthes. 1995. Seeking the $99 \%$ chemistry library: Extending the serial collection through the use of decentralized document delivery. Library acquisitions: Practice \& theory 19: 141-52.

Chrzastowski, Tina E., and Brian M. Olesko. 1997. Chemistry journal use and cost: Results of a longitudinal study. Library resources \& technical services 41: 101-11.

Chrzastowski, Tina E, and Karen A. Schmidt. 1993. Surveying the damage: Academic library serial cancellations 1987-88 through 1989-90. College \& research libraries 54: 93-102.

-1996. Collections at risk: revisiting serial cancellations in academic libraries. College \& research libraries 57: 351-64.

Clarke, Ann. 1981. The use of serials at the British Library Lending Division in 1980. Interlending review 9: 111-17.

Cohen, Joel E. 1971. Casual groups of monkeys and men: Stochastic models of elemental social systems. Cambridge, MA: Harvard University Press.

- 1980. Publication rate as a function of laboratory size in a biomedical research institution. Scientometrics 2: 35-52.

1981. Publication rate as a function of laboratory size in three biomedical research institutions. Scientometrics 3: 467-87.

Cole, Jonathan R., and Stephen Cole. 1972. The Ortega hypothesis. Science 178: 368-75.

Coleman, James S. 1964. Introduction to mathematical sociology. New York: Free Press of Glencoe.

Cooper, R.A., and A.J. Weekes. 1983. Data, models and statistical analysis. Totowa, NJ: Barnes \& Noble.

Cox, John. 1997. The changing economic model of scholarly publishing: Uncertainty, complexity, and multi-media serials. Paper presented at 17 th annual Charleston Conference, Charleston, South Carolina, November 1997.

Dougherty, Richard M., and Nancy E. Barr. 1988. Paying the piper: ARL libraries respond to skyrocketing journal subscription prices. Journal of academic librarianship 14: 4-9.

Durniak, Anthony. 1997. Rationale for American Chemical Society web journal prices. Newsletter on serials pricing issues 193: 1.

Economic Consulting Services, Inc. 1989. A study of trends in average prices and costs of certain serials over time. In Report of the ARL Serials Prices Project. Washington, DC: ARL.

Ehrenberg, A.S.C. 1959. The pattern of consumer purchases. Applied statistics 8:26-41.

Elliott, J.M. 1977. Some methods for the statistical analysis of samples of benthic invertebrates. 2d. ed. Freshwater Biological Association scientific publication, no. 25. Ambleside, Eng.: Freshwater Biological Association.

Feller, William. 1943. On a general class of "contagious" distributions. Annals of mathematical statistics 14: 389-400.

Ferguson, Anthony W., and Kathleen Kehoe. 1993. Access vs. ownership: What is most cost effective in the sciences. Journal of library administration 19: 89-99.

Flynn, Roger R. 1979. The University of Pittsburgh study of journal use: A summary report. Serials librarian 4: 25-33.

Frankfurter, George M., and Elton G. McGoun 1996. Toward finance with meaning: The methodology of finance, What it is and what it can be. Contemporary studies in economic and financial analysis, v. 80. Greenwich, Conn.: JAI Press.

Fussler, Herman H. 1949. Characteristics of the research literature used by chemists and physicists in the United States. $\mathrm{Li}$ brary quarterly 19: 19-35, 119-43.

Garfield, Eugene. 1976. Significant journals of science Nature 264: 607-15.

1979. Citation indexing-its theory and application in science, technology, and humanities. Philadelphia: ISI Press.

1980. Is information retrieval in the arts and humanities inherently different from that in science?: The effect that ISI's citation index for the arts and humanities is expected to have on future scholarship. 
Library quarterly 50: 40-57.

1991. To be an uncited scientist is no cause for shame. Scientist 5, no. 6: 12 .

. 1996. The significant scientific literature appears in a small core of journals. Scientist 10, no. 17: 13-16.

__ 1997. Dispelling a few common myths about journal citation impacts. Scientist 11 , no. 3: 11 .

Garson, Lorrin R. 1997a. Economics of scientific publishing. Paper presented at the $\mathrm{Di}$ vision of Chemical Education Symposium "Confronting the library funding crisis of the ' $90 \mathrm{~s}$ at undergraduate institutions," 214th American Chemical Society national meeting, Las Vegas, Nevada, September 1997.

1997b. Letter to Stephen J. Bensman. 20 September,

Geary, R, C. 1947. Testing for normality. Biometrika 34: 209-42.

Gelman, E., and H.S. Sichel. 1987. Library book circulation and the beta-binomial distribution. Journal of the American Society for Information Science 38: 4-12.

Ghosh, Jata S. 1974. Uncitedness of articles in the Journal of the American Chemical Society. Information storage and retrieval 10: 365-69.

- 1975. Uncitedness of articles in $\mathrm{Na}$ ture, a multidisciplinary scientific journal. Information processing \& management 11 : 165-69.

Gibbons, Jean Dickinson. 1993. Nonparametric measures of association. Quantitative applications in the social sciences, v. 91. Newberry Park, CA: Sage Publications.

Goehner, Donna. 1984a. Periodical coverage in academic collections: A comparison of faculty choices of core titles and holdings of medium-sized libraries. Technical services quarterly 1 , no. 4; 1-16.

- 1984b. Core lists of periodicals selected by faculty reviewers. Technical services quarterly 1, no. 4: 17-38.

Goldberger, Marvin L., Brendan A. Maher, and Pamela Ebert Flattau, eds. 1995. Research-doctorate programs in the United States: Continuity and change. Washington, D. C.: National Academy Press.

Gossen, Eleanor A., and Suzanne Irving. 1995. Ownership versus access and low-use periodical titles, Library resources d technical services 39: 43-53.

Graham, Hugh Davis, and Nancy Diamond. 1997. The rise of American research universities: Elites and challengers in the postwarera. Baltimore: Johns Hopkins University Press.
Greig-Smith, P. 1983. Quantitative plant ecology. 3rd ed. Studies in ecology, vol. 9. Berkeley, CA: University of California Press.

Haight, Frank A. 1978. Distributions, statistical: Special discrete distributions. In International encyclopedia of statistics, vol. 1 , ed. William H. Kruskal and Judith $\mathbf{M}$. Tanur, 155-61. New York: Free Press.

Hamaker, Charles A. 1994. Re-designing serials collections. Journal of library administration 20 , no. 1: 37-47.

1996. Redesigning research libraries: First step toward the 21 st century. Journal oflibrary administration 22, no. 4: 33-48.

Hamilton, David P. 1990. Publishing by-and for?-the numbers. Science 250: 1331-32.

1991. Research papers: Who's uncited now? Science 251: 25.

Hatcher, Larry, and Edward J. Stepanski. 1994. A step-by-step approach to using the SAS system for univariate and multivariate statistics. Cary, NC: SAS Institute.

Hays, William L. 1994. Statistics. 5th ed. Fort Worth: Harcourt Brace College Publishers.

Huber, John C. 1998. Cumulative advantage and success-breeds-success: The value of time pattern analysis. Journal of the American Society for Information Science 49: 471-76.

Hughes, Raymond M. 1925. A study of the graduate schools of America. Oxford, Ohio: Miami University.

1934 Report of the Committee on Graduate Instruction. Educational record 15: 192-234.

Hurd, Julie M. 1992. Interdisciplinary research in the sciences: Implications for library organization. College \& research libraries 53: 283-97.

Johnson, Norman L., and Samuel Kotz. 1969. Discrete distributions. Distributions in statistics. New York: Houghton Mifflin.

Jones, Lyle V., Gardner Lindzey, and Porter E. Coggeshall, eds. 1982, An assessment of research-doctorate programs in the United States. 5 vols. Washington, DC: National Academy Press.

Kelley, Grace O. 1937. The classification of books: An inquiry into its usefulness to the reader. New York: H.W. Wilson.

Kelly, Walt. 1982. The best of Pogo: Collected from The Okefenokee Star. Edited by Mrs. Walt Kelly and Bill Crouch, Jr. New York: Simon and Schuster.

Keniston, Hayward. 1959. Graduate study and research in the arts and sciences at the University of Pennsylvania, Philadelphia: University of Pennsylvania Press. 
Kent, Allen et al. 1978. A cost-benefit model of some critical library operations in terms of the use of materials. Washington, DC: U.S. Dept. of Commerce, National Technical Information Service.

- 1979. Use of library materials: The University of Pittsburgh study. Books in library and information science, v. 26. New York: M. Dekker.

Kingma, Bruce R., with Suzanne Irving. 1996. The economics of access versus ownership: The costs and benefits of access to scholarly articles via interlibrary loan and journal subscriptions. New York: Haworth Press.

Kinnucan, Mark T., and Dietmar Wolfram. 1990. Direct comparison of bibliometric models. Information processing \& management 26: 777-90.

Kleiner, Jane P., and Charles A. Hamaker. 1997. Libraries 2000: Transforming libraries using document delivery, needs assessment, and networked resources. College \& research libraries 58: 355-74.

Kochen, M., R. Crickman, and A. Blaivas. 1982. Distribution of scientific experts as recognized by peer consensus. Scientometrics 4: 45-56.

Kuhn, Thomas S. 1970. The structure of scientific revolutions. 2nd ed., enl. International encyclopedia of unified science, v.2, no.2. Chicago: University of Chicago Press.

Kurth, William H. 1962. Survey of the interlibrary loan operation of the National Library of Medicine. Washington, DC: U.S. Dept. of Health, Education, and Welfare, Public Health Service.

Kyrillidou, Martha, and Julia Blixrud. 1997. Letter to directors of ARL libraries re the 1995-96 ARL membership criteria index. 20 March.

Leemans, Marie-Jeanne et al. 1992. The negative binomial distribution as a trend distribution for circulation data in Flemish public libraries. Scientometrics 25: 47-57.

Liebowitz, S.J., and J.P. Palmer. 1984. Assessing the relative impacts of economics journals. Journal of economic literature 22 : 77-88.

Line, Maurice B. 1984. Changes in rank lists of serials over time: Interlending vs citation data. Interlending and document supply 12: 145-47.

Line, Maurice B., and Stephen Roberts. 1976. The size, growth and composition of social science literature. International social science journal 28: 122-59.

Line, Maurice B., and D.N. Wood. 1975. The effect of a large-scale photocopying service on journal sales. Journal of documen- tation 31: 234-35.

McGrath, William E., and Norma Durand. 1969. Classifying courses in the university catalog. College of research libraries 30: 533-39.

McGrath, William E., Donald J. Simon, and Evelyn Bullard. 1979. Ethnocentricity and cross-disciplinary circulation. College $\&$ research libraries 40: 511-18.

Merry, Karen, and Trevor Palmer. 1984. Use of serials at the British Library Lending Division in 1983. Interlending and document supply 12: 56-60.

Merton, Robert K. 1968. The Matthew Effect in science. Science 159: 56-63.

Metz, Paul. 1983. Landscape of literatures: Use of subject collections in a university library. ACRL publications in librarianship, no. 43. Chicago: ALA.

Metz, Paul, and Charles A. Litchfield. 1988. Measuring collections use at Virginia Tech. College dresearch libraries 49: 501-13.

Moline, Sandra R. 1991. Mathematics journals: Impact factors and cents per thousand characters. Serials librarian 20 , no. 4 : 65-71.

Narin, Francis, Gabriel Pinski, and Helen Hofer Gee. 1976. Structure of biomedical literature. Journal of the American Society for Information Science 27: 25-45.

Nisonger, Thomas E. 1993. The relationship between price and citation data for journals in two subject areas. Proceedings of the ASIS annual meeting 30: 151-59.

Noll, Roger, and W. Edward Steinmueller. 1992. An economic analysis of scientific journal prices. Serials review 18 , nos. 1-2: 32-37.

Okerson, Ann. 1989. Of making many books there is no end: Report on serial prices for the Association of Research Libraries. In Report of the ARL Serials Prices Project. Washington, DC: ARL.

Oluić-Vuković, Vesna. 1997. Bradford's distribution: From the classical bibliometric "law" to the more general stochastic models. Journal of the American Society for Information Science 48: 833-42.

Pendlebury, David A. 1991. Letter. Science 251: 1410-11.

Petersen, H. Craig. 1992. The economics of economics journals: A statistical analysis of pricing practices by publishers. College \& research libraries 53: 176-81.

Pilling, Dennis. 1986. Use of serials in document delivery systems in Europe and the U.S. Interlending and document supply 14: 80-82.

Plank, Tom M., and Douglas L. Blensly. 1989. 
Accounting desk book: The Accountant's everyday instant answer book. 9th ed. Englewood Cliffs, NJ: Prentice Hall.

Price, Anna L., and Kjestine R. Carey. 1993. Serials use study raises questions about cooperative ventures. Serials review 19: $79-84$.

Price, Derek J. de Solla. 1975. Science since Babylon. Enl. ed. New Haven : Yale University Press.

- 1976. A general theory of bibliometric and other cumulative advantage processes. Journal of the American Society for Information Science 27: 292-306.

—_ 1986. Little science, big science ... and beyond. New York: Columbia University Press.

Quandt, Richard E. 1996. Simulation model for journal subseription by libraries. Journal of the American Society for Information Science 47: 610-17.

Rapoport, Anatol, and William J. Horvath. 1961. A study of a large sociogram. Behavioral science 6: 279-91.

Ravichandra Rao, I.K. 1980. The distribution of scientific productivity and social change. Journal of the American Society for Information Science 31: 111-22.

- 1982. Document and user distributions. Library science with a slant to documentation 19: 69-96.

1988. Probability distributions and inequality measures for analyses of circulation data. In Informetrics 87/88, ed. Leo Egghe and Ronald Rousseau, 231-48. Amsterdam: Elsevier Science.

1990. Journal productivity in economics. In Informetrics 89/90: Selection of papers submitted for the second International Conference on Bibliometrics, Scientometrics and Informetrics, London, Ont., Canada, 5-7 July 1989, ed. Leo Egghe and Ronald Rousseau, 251-80. Amsterdam: Elsevier Science.

Ribbe, Paul H. 1988. Assessment of prestige and price of professional publications. American mineralogist 73: 449-69.

-1990. A scientist's assessment of a microcosm of the serials universe. Serials $l i$ brarian 17, nos. 3/4: 121-42.

. 1991. The value of serials: Relevance to producers and consumers of scientific journals. In Geological societies and information transfer in the electronic age, ed. Marie Dvorzak. Proceedings of the 25th meeting of the Geoscience Information Society, Oct. 29-Nov. 1, 1990, Dallas, TX, vol. 21, 41-53. Alexandria, VA: Geoscience Information Society.
Roche, Marilyn M. 1993. ARL/RLG interlibrary loan cost study: A joint effort by the Association of Research Libraries and the Research Libraries Group. Washington, DC: ARL.

Roose, Kenneth D., and Charles J. Andersen. 1970. A rating of graduate programs. Washington, DC: American Council on Education.

Sanville, Tom. 29 April 1998. American Chemical Society. Online posting to Consortium List. consort@ohiolink.edu.

Sapp, Gregg, and Peter G. Watson. 1989. Librarian-faculty relations during a period of journals cancellations. Journal of academic librarianship 15: 285-89.

Schlotzhauer, Sandra D., and Ramon C. Littell. 1987. SAS system for elementary statistical analysis. Cary, NC: SAS Institute.

Seglen, Per O. The skewness of science. Journal of the American Society of Information Science 43: 628-38.

Snedecor, George W., and William G. Cochran. 1989. Statistical methods. 8th ed. Ames, IA: Iowa State University Press.

Stern, Richard E. 1990. Uncitedness in the biomedical literature. Journal of the American Society for Information Science 41: 193-96.

Stokes, Maura E., Charles S. Davis, and Gary G. Koch. 1995. Categorical data analysis using the SAS system. Cary, NC: SAS Institute.

Stoller, Michael A., Robert Christopherson, and Michael Miranda. 1996. The economics of professional journal pricing. College \& research libraries 57: 9-21.

Tague, Jean. 1981. The success-breedssuccess phenomenon and bibliometric processes. Journal of the American Society for Information Science 32: 280-86.

Tague, Jean, and Isola Ajiferuke. 1987. The Markov and mixed-Poisson models of library circulation. Journal of documentation 43: 212-31.

Tague, Jean, and Jason Farradane. 1978. Estimation and reliability of retrieval effectiveness measures. Information processing \& management 1978: 1-16.

Tocqueville, Alexis de. 1969. Democracy in America. Edited by J.P. Mayer. A new translation by George Lawrence. 2 vols. Garden City, NY: Doubleday.

Trueswell, Richard L. 1969. Some behavioral patterns of library users: The $80 / 20$ rule. Wilson library bulletin 43: 458-61.

Turner, R. Eugene. 1994. Comparisons of estuarine and coastal journal quality. Estuaries 17: 721-25.

Ulrich, Carolyn F. 1932. Periodicals directory: 
A classified guide to a selected list of current periodicals foreign and domestic. New York: R.R. Bowker.

Ulrich's international periodicals directory. New Providence, NJ: R.R. Bowker. Published annually.

Urquhart, John A. 1982. Has Poisson been kicked to death?-A rebuttal of the British Library Lending Division's views on the inconsistency of rank lists of serials. Interlending review 10: 97-100.

Van Hooydonk, G, 1995. Cost and citation data for 5399 scientific journals in connection with journal price-setting, copyright laws and the use of bibliometric data for project review. Serials librarian 27, no. 1: 45-56.

Wallace, Danny P., and Bert R. Boyce. 1989. Holdings as a measure of journal value. Library \& information science research 11: 59-71.

Webster, David S., and Tad Skinner. 1996.
Rating PhD programs: What the NRC report says ... and doesn't say. Change 28 , no. 3: 22-44.

Wenger, Charles B., and Judith Childress. 1977. Journal evaluation in a large research library. Journal of the American Society for Information Science 28: 293-99.

Wilkinson, Sophie L. Electronic publishing takes journals into a new realm. Chemical and engineering news 76, no. 20: 10-18.

Williams, C.B. 1964. Patterns in the balance of nature and related problems in quantitative ecology. London: Academic Press.

Wood, James L. 1969. A review of the availability of primary scientific and technical documents within the United States. Washington, DC: U.S. Dept. Of Health, Education, and Welfare, Office of Education, Bureau of Research.

Zuckerman, Harriet. 1977. Scientific elite: Nobel Laureates in the United States. New York: Free Press.

\section{Elegant Solutions for Preservation}

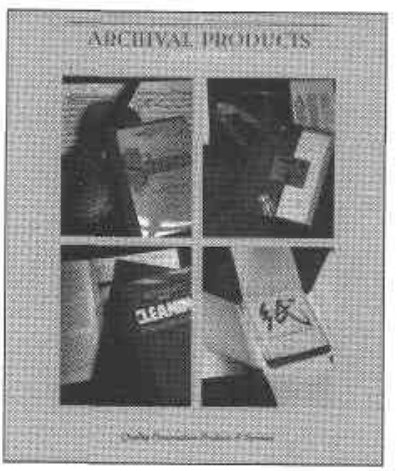

Call for a complete catalog

\begin{tabular}{|lllllllll}
\hline A & R & C & H & I & V & A & L \\
\hline P & R & O & D & U & C & T & S \\
\hline
\end{tabular}

\section{Protective Enclosures}

Pamphlet Binders

Music Binders

Bound Four Flap Enclosures

Tan Archival Board

Grey/White Archival Board

Drop Spine Archival Boxes

Academy Folder

Manuscript Folder

3" Ring Binder Album

P.O. Box 1413, Des Moines, Iowa 50305-1413

PH. 800-526-5640

FAX 800-262-409I

E-MAIL archival@ix.netcom.com

WEB SITE http://www.archival.com 